\title{
V. Die Gleichzeitigkeit des semantisch Ungleichzeitigen: Konturen und Transformationen des Begriffsfeldes bis 1835
}

\author{
1. Frankreich
}

a) Die Julirevolution als Sieg des système libéral und die bannières du Libéralisme:

Sécurité, Tolérance und Tranquillité

Die 1831 erschienene Histoire de la Restauration warf die Frage nach den Gründen für den Fall der Bourbonenherrschaft auf und kam dabei zu dem Ergebnis, daß der Handlungsspielraum der Monarchie zwischen den „ultra-royalistes“ der Minsterien Villèle und Polignac und der „opposition libérale“ am Ende der 1820er Jahre immer enger geworden sei. Die ideologische Polarisierung der Lager spiegelte sich dabei in der unüberbrückbaren Differenz der Begriffe: Im Kampf „avec le parti de la cour et de l'émigration, avec les fautes et les exigences du libéralisme "sei die Bourbonenmonarchie schließlich gescheitert. ${ }^{1}$ Die zunehmenden innenpolitischen Spannungen hatten die Behörden schon im Februar 1830 auf die dominierende „opinion libérale, constitutionnelle“ zurückgeführt, ${ }^{2}$ die aber im Selbstverständnis der libéraux selbst keinesfalls mit einer republikanischen Ordnung gleichgesetzt wurde. So betonte der National im April 1830:

si la chose changeait par les mots et devenait une république, nous n'en voudrions pas, parce que nous sommes libéraux, très-libéraux, et non républicains... Quand donc nous voulons l'unité, l'hérédité, l'inviolabilité dans le dépositaire de l'autorité exécutive, quand nous voulons réunir dans cette même autorité l'initiative, le droit de paix et de guerre, l'administration, la sanction, la dissolution, nous ne sommes point des républicains. ${ }^{3}$

1 [CAPEFIGUE] Histoire de la restauration et des causes qui ont amené la chute de la branche aînée des Bourbons. Par un homme d'état, Bd. 1, Paris 1831, S. 10 f.; vgl. dagegen Polignacs nachträglichen Versuch, die Ordonnanzen vom Juli 1830 noch mit den „intensions larges, libérales" der Krone in Verbindung zu bringen, DE Polignac, Considérations politiques sur l'époque actuelle, adressées à l'auteur anonyme de l'ouvrage intitulée Histoire de la Restauration, par un homme d'état, Paris 1832, S. $87 \mathrm{f}$.

2 Rapport de gendarmerie im Februar 1830, zitiert nach VIDALENC, S. 262.

3 Nouvelle réponse à un grand argument, in: Le NaTional, 21. April 1830, zitiert nach Lettre à Monsieur le Directeur du National ou examen des doctrines politiques du National, du Globe, de la Gazette de France et du Journal des Débats, Paris 1830, S. 23-31, hier S. 27 und $30 \mathrm{f}$. 
Die Julirevolution erschien diesen Anhängern des parti libéral als Erfüllung ihrer politisch-konstitutionellen Vorstellungen. ${ }^{4}$ Enthusiastisch bezog Adolphe Thiers den politischen Aufbruch ganz Europas auf den erneut von Frankreich ausgehenden Siegeszug des système libéral, dessen semantische Integrationskraft sich gleichsam auf einer gesamteuropäischen Ebene zu entfalten schien:

Comparons l'Europe de 1829 à celle de 1831. A la première époque, le système de la sainte alliance dominait partout; La France y était soumise par la dynastie du droit divin et par l'émigration; L'Angleterre par l'administration du général de la sainte alliance, qui refusait la réforme; Le Piemont, le royaume de Naples, l'Espagne et le Portugal l'avaient subi par suite de l'occupation autrichienne en 1821, de l'invasion française en 1823, de l'usurpation de Don Miguel en 1827; La confédération germanique y était entrée par le congrès de Carlsbad et la commission extraordinaire de Mayence... Aujourd'bui le système libéral est établi dans une partie de l'Europe; et il reste, du grand mouvement de juillet: Le gouvernement de la France ... Le ministère whig, en Angleterre, et l'entreprise de la réforme... L'introduction ou l'extension du régime représentatif dans la plupart des états de l'Allemagne. ${ }^{5}$

Für die Bestimmung der politischen Kräfte in Frankreich stellte sich nach der Julirevolution das Problem der Aussonderung überholter Begriffe. Die während der Bourbonenherrschaft dominierende Polarisierung zwischen libéraux und royalistes oder ultra bedurfte einer Revision. Für Thiers stellten die Bezeichnungen bonapartistes und carlistes nur noch Reminiszenzen ohne aktuelle politische Relevanz dar. Der „parti bonapartiste“ bestand danach nur noch aus „quelques vieilles fermmes, quelques jeunes gens aimant les chimères, et aussi quelques vieux personnages mécontens d'un régime sévère, fondé sur l'économie, la publicité, une discussion perpétuelle des actes des fonctionnaires publics." Auch die carlistes als Anhänger des letzten Bourbonenherrschers seien nur noch "un certain nombre d'individus qui avait surtout cherché dans la légitimité les faveurs qu'elle répandait sur eux. "Demgegenüber identifizierte Thiers die Julimonarchie mit dem parti libéral: Die Prinzipien der Charte, die für den parti libéral den programmatischen Mittelpunkt während der Bourbonenherrschaft dargestellt hatten, schienen durch das orleanistische Bürgerkönigtum garantiert. Zugleich grenzte Thiers den parti libéral von der permanenten opposition und den anarchistes ab. Gegenüber der Konnotation als Oppositionsbegriff bis 1830 wandelte sich parti libéral nach der Julirevolution schon bald zum Leitbegriff eines politischen Systems, das sich von neuen Oppositionskräften herausgefordert sah. Dabei überwog 1832 Thiers' Vertrauen in die gesellschaftliche Integrationskraft der Julimonarchie und ihrer Regierung:

4 In die lexikalischen Bestimmungen gingen die durch die Zäsur von 1830 entstandenen neuen Bedeutungselemente zunächst noch nicht ein, vgl. Dictionnaire de l'Académie françoise. Supplément, Paris 1831, S. 3; Dictionnaire de l'Académie française, Bd. 2, 6. Aufl. Paris 1835, 112f.; Dictionnaire de l'Académie française, Bd. 2, 6. Aufl. Brüssel 1835 sowie Désiré Chésurolles, Nouveau Dictionnaire classique et complet de la langue française, d'après la dernière édition de l'Académie, et les ouvrages des lexicographes les plus estimés, Bd. 2, Paris 1841, S. 177.

5 A. Thiers, La Monarchie de 1830, Berlin 1832, S. 77. 
Quant au parti libéral enfin, le gouvernement actuel, qui est ce parti même, arrivé au pouvoir, l'a rallié tout entier et vit par lui et sur lui. Il n'est resté en dehors que des hommes pour qui l'habitude de l'opposition est une habitude de la vie à laquelle on ne renonce pas à leur âge; des jeunes gens impatiens, inexpérimentés ... enfin, au dehors, au delà de ces jeunes gens, la classe des anarchistes qui est de tous les temps... classe redoutable, que le calme dissout, mais que l'agitation grossit et réveille ... Le gouvernement a donc rallié la masse sensée et nombreuse de chaque parti, pour laisser en dehors la portion extrême, c'est-à-dire la moins considérable; il a rallié les majorités et laissé en dehors les minorités. ${ }^{6}$

Diese mit dem parti libéral verbundene Integrationserwartung zog sich wie ein roter Faden durch die Publizistik nach 1830. In einem Überblick zur Entwicklung der politischen Parteien in Frankreich seit 1814 unterschied A. Randouin von den royalistes, absolutistes und bonapartistes, die ihm nun als historisch überholte Etiketten erschienen, vor allem den „parti républicain“ und die „constitutionnels ou libéraux. “ Jener bestünde aus den „hommes qui rêvaient la république en haine du despotisme. "Diese seien aber keine "théoriciens entêtés", sondern diejenigen,

qui, dédaigneux des principes et de leur application, s'attachent à un nom comme à une chimère; là où ces hommes consciencieux et sans arrière-pensée rencontreront les garanties de la liberté civile et religieuse, de fortes barrières édifiées contre les envahissemens du pouvoir, quel qu'il soit, l'absurde doctrine du droit divin solennellement répudiée, le dogme sacré de la souveraineté du peuple solennellement reconnu, ils trouveront leur utopie réalisée. Ce parti est personnifié dans le général Lafayette. ${ }^{7}$

Die einzig zukunftsweisende politische Bewegung verkörperte für den Autor aber die „immense aggrégation des constitutionnels ou libéraux qu'bier encore on appelait une faction et qui, du jour où les bateleurs ont disparu, où le fantôme à fait place à la réalité, se sont trouvés être la nation tout entière. "Die Oppositionsbezeichnung libéral verwandelte sich hier in einen nationalen Identifikationsbegriff, mit dem man den Sieg vom Juli 1830 assoziierte und von dem man die Integration aller gesellschaftlichen Kräfte erwartete:

C'est ce parti auquel s'étaient réunis tous les autres, moins les jésuites, qui a opéré le prodige de trois grandes journées; c'est lui qui a prodigué son sang en holocauste à la liberté, c'est lui qui a opposé aux bayonettes suisses le meilleur des boucliers, une poitrine découverte, lui, qui sous la puissante égide des Gérard, des Laffitte, des Constant, des Schonen et des Périer, a renversé le roi très-chrétien et très-parjure, et porté Philippe sur le pavois. ${ }^{8}$

Das Examen politique des quatre partis qui divisent la France, das Achille François ebenfalls unter dem Eindruck der Julirevolution 1830 verfaßte, unterschied neben dem carlisme drei oppositionell konnotierte Bewegungsbegriffe. Neben bonapartisme und républicanisme stand libéralisme für eine "puissance

6 Ebd., S. 94-6.

7 A. RANDOUin, De l'état des partis en France, et de la marche à suivre par le gouvernement, Paris 1830, S. 4, 6 und 8.

8 Ebd. S. 9; vgl. zur Kennzeichnung der Regierung Louis Philippes ferner [P. L. RoEDERER] Adresse d'un constitutionnel aux constitutionnels, Paris 1835, S. 37: „Lonis-Philippe a pour tâche de donner de la stabilité à la monarchie constitutionnelle; sa marche est tracée par les circonstances sur une ligne étroite entre le carlisme et la démocratie." 
nouvelle " innerhalb der Entwicklung der Zivilisation. Dabei betonte der Autor einerseits das Erbe der Aufklärung, andererseits das Ziel politisch-gesellschaftlicher Stabilität, die den Gehalt des „libéralisme pur [et] ... sage“ im Gegensatz zum „libéralisme turbulent, inquiet, ardent à détruire" auszeichneten. Im Gegensatz zu 1789 konnten sich nun auch Adel und Kirche, so die Meinung des Autors, auf die Ausrichtung des libéralisme an den sozialen Versöhnungsattributen sécurité, tolérance sowie tranquillité, ordre und paix verlassen:

Né de la civilisation, le Libéralisme vient de briser le sceptre du despotisme, et d'élever un trône où il a placé un citoyen. L'Europe a tremblé, parce que l'Europe croyait déjà voir sortir de nos foyers des légions de héros; mais le Libéralisme portait sur ses étendards: Paix an monde. L'Aristocratie n'a plus songé à Coblentz, parce qu'elle avait lu sur les bannières $d u$ Libéralisme: Sécurité. La religion ne s'est point couverte de deuil, elle n'a point fermé ses temples, parce qu'elle a entendu le Libéralisme prononcer le mot sacré de Tolérance. Les provinces ne se sont point vu arracher leurs enfans, parce que le Libéralisme a crié: Tranquillité. Tels sont les prestiges, tels sont les enchantemens à l'aide desquels règne le Libéralisme, né d'un jour. Ami de l'ordre et de la paix, il guérira nos plaies, cicatrisera nos blessures, fera taire les orages, calmera les tempêtes: apôtre de la tolérance, il prouvera que religion est autre chose que fanatisme; père des idées généreuses, il agrandira nos esprits, élevera nos intelligences, ennoblira nos destins. ${ }^{9}$

Die Parallele zwischen der Bestimmung der idées libérales nach 1815 und der von libéralisme nach 1830 ist nicht zu übersehen: In beiden postrevolutionären Situationen ging es um die Projektion politischer Stabilität und gesellschaftlicher Versöhnung vor dem Hintergrund einer tiefgreifenden Zäsur. Signifikant für diese Bedeutungsrichtung war, so paradox es anmutet, gerade die Distanzierung von der revolutionären Tradition, denn nur wenn diese überparteiliche Ausrichtung von libéralisme gelang, ließ sich ein gesamtgesellschaftlicher Anspruch untermauern. Schon vor dem Juli 1830 hatten zahlreiche Publizisten libéraux und libéralisme gegenüber dem Vorwurf der anarchisch oder republikanisch intendierten Revolution in der Tradition von 1789 in Schutz genommen. ${ }^{10}$

\section{b) Zwischen utopistes, doctrinaires und légitimistes:}

\section{Die Genese des antirevolutionären Ordnungsbegriffes libéralisme nach 1830}

Die Julirevolution fügte dem durch die politischen Zäsuren Frankreichs seit 1789 bereits besonders differenzierten Vokabular politischer Gruppenbezeichnungen und Bewegungsbegriffe neue Elemente hinzu. Das Spektrum umfaßte zunächst neben den dynastisch konnotierten Bezeichnungen carlistes und légitimistes auch das allgemeiner bestimmte Etikett royalistes. Darüber hinaus unterschied man die bonapartistes als alte Anhänger Napoleons und die répu-

9 AChille François, Examen politique des quatre partis qui divisent la France, ou le carlisme, le bonapartisme, le républicanisme et le libéralisme, Soissons 1830, S. $12 \mathrm{f}$.

10 Vgl. D’Ollé de Mantet, Dialogue historique entre un royaliste et un libéral, Paris 1830, S. 6 f. und 9f. sowie im Kontext der Wahlen von 1830 N. Rosset, Aux Royalistes, sur les calomnies qu'ils se permettent à l'égard des libéraux, in: Vte DE CALVIMONT SAINT-MARTIAL, Le Libéralisme en présence des élections, S. 197-204, hier S. $198 \mathrm{ff}$. 
blicains oder patriotes, die im Juli 1830 die Basis des revolutionären Umsturzes gebildet hatten und danach zur dominierenden Oppositionskraft gegenüber der neuen Ordnung geworden waren. Die Anhänger der Julimonarchie selbst wurden als actualistes, constitutionnels oder juste-milieu identifiziert. ${ }^{11} \mathrm{Im}$ letzten Begriff trat neben die tradierten politischen Gruppenbezeichnungen die sozioökonomisch bestimmte Kategorie des Besitzbürgertums, die den semantischen Differenzierungsgrad politischer Begriffe insgesamt veränderte.

J. N. Poubelle unterschied als wichtigste Gruppierungen des Juli 1830 patriotes, libéraux und doctrinaires. Seine Begriffsbestimmung ordnete die libéraux als überzeugte Anhänger der konstitutionellen Monarchie zwischen den revolutionär gesinnten patriotes und den nur von eigenen Machtinteressen geleiteten doctrinaires ein. Als Opposition gegen die Bourbonen hätten die libéraux auf eine evolutionäre Reformierung der Monarchie ohne revolutionären Umsturz gehofft. Nun repräsentierten sie ein eher defensives Bekenntnis zur Freiheit, das immer mehr von der Furcht vor den Massen überschattet schien:

Ils faisaient de l'opposition contre les ministres, en s'inclinant devant la majesté royale; ils croyaient à la possibilité d'améliorer, de modifier le gouvernement des Bourbons, et non à la nécessité de le renverser; ils n'auraient éprouvé aucune répugnance à devenir les ministres de la légitimité... Les libéraux ne manquaient jamais de présenter dans leurs discours le roi avec la Charte, et la Charte avec le roi, comme bases indestructibles du bonbeur de la France ... En résumé les libéraux dépensaient toutes leurs ressources en discours de tribune, dans lesquels ils n'invoquaient la liberté qu'avec une timide circonspection. N'osant adresser directement leurs hommages à cette fière déesse, ils la transformèrent en petites divinités, qu'ils appelaient les libertés, et qui convenaient à la faiblesse de leur caractère; mais ce culte bâtard et sans dignité était plutôt fait pour amortir que pour exciter l'énergie des masses populaires ... Les doctrinaires faisaient ... l'opposition par calcul et non par conviction: leur but était d'arriver au pouvoir, et non de conquérir la liberté qu'ils n'ont jamais aimée. Quand les ordonnances de juillet paruent, ces trois factions obéirent à leurs antécédens. Les patriotes coururent aux armes, les libéraux hésitèrent, et les doctrinaires se mirent à trembler de tous leurs membres. ${ }^{12}$

Die Bezeichnung libéraux nahm somit eine Mittelstellung zwischen revolutionär-republikanischen Kräften und den doctrinaires ein. Die Differenzen zwischen den verschiedenen Kräften, die im Juli 1830 primär von der gemeinsamen Wendung gegen die verhaßte Bourbonenmonarchie geeint worden waren, tra-

11 Vgl. Coup d'œil sur les opinions politiques en France; par Al. C., Paris 1831, S. 5; [DELORME] Opinion de M. Delorme, sur les divers partis qui se disputent le pouvoir, Bourges [1831], S. 1 und 3; FRÉDÉRIC MALET, Liberté, ordre public. La nation, la loi, le roi. Vivre libre ou mourir. Chants libéraux, dédiés aux soutiens de la patrie [Nancy 1831], S. 2; [JACQUES FrançOIS DE SADE] Royalistes. Ultras. Parti des Ultras (Extraits du Lexicon politique, ouvrage inédit du chevalier de Sade), Paris [1831], S. 1 f.; ÉmILE DosqueT, Le juste-milieu dévoilé, ou la France en 1832, Metz 1832, S. 18 und 29; De la foi politique et des partis en 1832, Paris [1832], S. 17, 23, 31 und 33; Il y a des libéraux, dit le Globe, qui sont surpris de l'assurance des légitimistes, Paris [1832]; ALPHONSE PePIN, De l'opposition en 1831, Paris 1832, S. 71 sowie [GAILLARD] Quelques mots sur le tiers-parti, Bordeaux 1835.

12 J. N. Poubelle, Des patriotes, des libéraux et des doctrinaires. Pour servir à l'Histoire de la Révolution de Juillet, Paris 1832, S. $11 \mathrm{f}$. und $18 \mathrm{f}$. 
ten jetzt offen hervor. Die libéraux als Synonym für die siegreiche Oppositionsbewegung von 1830 spalteten sich nach der Julirevolution in mindestens zwei neue Richtungen auf: Neben einer Ordnungspartei, die die revolutionäre Entwicklung keinesfalls weitertreiben wollte und die sich den doctrinaires zuordnen ließ, erkannte der Autor vor allem einen republikanisch orientierten „parti ultra-libéral“:

Le parti ultra-libéral qui, s'attribuant follement le monopole du patriotisme et les intérêts soi-disant populaires, s'était intitulé le parti du mouvement, du progrès; le parti patriote, puisqu'il faut l'appeler par son nom, trouva ses adhérens dans un grand nombre de journalistes trop préoccupés des anciens souvenirs de la révolution, pour sentir que le libéralisme doit avoir un point d'arrêt qu'indique assez la nature de ses principes. ${ }^{13}$

Die Differenzierung der Gruppenbegriffe, die 1789 eingesetzt hatte, schien sich vor dem Hintergrund der neuerlichen Zäsur von 1830 und der aus ihr resultierenden Spaltung der „opinions constitutionnelles “ in realpolitisch-pragmatische doctrinaires und utopistes, gleichsam einem historischen Grundgesetz entsprechend, fortzusetzen:

Nous avons vu, depuis le 29 juillet, les opinions constitutionnelles se modifier et former plusieurs nuances qui, avec le temps, se sont de plus en plus prononcées. Cet effet naturel $d u$ choc des partis a toujours lieu après la victoire. Sans aller chercher des exemples hors de nos dissensions politiques, nous pouvons nous rappeler que dans la première révolution des démocrates se sont divisés en girondins, en montagnards, en jacobins; sous la restauration, les royalistes deviennent ultra-montains, monarchistes ou olygarques. Ainsi, suivant toujours la loi de la nature, de nos modernes constitutionnels, les uns sont impatients, les autres sont stationnaires; ceux-ci sont des utopistes, ceux-là sont des doctrinaires; quelques-uns veulent une république absolue, quelques autres un dictateur. ${ }^{14}$

Damit geriet die Fragmentierung der Lagerbezeichnungen zum beherrschenden Kennzeichen der französischen Begriffsgeschichte, und zuweilen mündete diese Ausdifferenzierung in eine regelrechte Kakophonie:

Nous la divisons [i.e. la société française], en indifférents, anarchistes, républicains purs, républicains-américains, républicains avec un roi-président, progressifs-imaginatifs, dynastiques, légitimistes à droit divin, politiques-doctrinaires, enfin, constitutionnels voulant le gouvernement des trois pouvoirs démocratique, aristocratique, royal, avec la plénitude des attributions qui appartiennent à chacun de ces pouvoirs. ${ }^{15}$

Unübersehbar schälte sich aus diesem komplexen Nebeneinander aber mit doctrinaire ein Deutungsmuster heraus, das, um 1817 entstanden, seit den 1820er Jahren als Bezeichnung der Fraktion um François Guizot nachweisbar gewesen war, aber nach 1830 ein erheblich größeres Gewicht in der politischen Publizistik gewann. ${ }^{16}$ In der Konnotation von doctrinaire spiegelte sich die Differenzierung der Oppositionsbewegungen vom Juli 1830 wider. Dabei erschienen

13 H. Cavel, Épitaphe des partis; celui dit du juste-milieu, son avenir, Paris 1833, S. 2 sowie A. FreY, Les ultra-libéraux factieux, Paris 1831, S. 5 f.

14 De l'influence des partis sur les affaires publiques, depuis la révolution de juillet. Par un ami de la liberté, Paris 1831, S. 10 f.

15 Pepin, S. 4.

16 Vgl. Kapitel III.1.b). 
die doctrinaires weniger als überzeugte Freiheitskämpfer denn als eine machtorientierte Ordnungspartei, die auch vor dem Bündnis mit den légitimistes nicht zurückschreckte und die Charte nur als „médiation entre le pouvoir et la liberté “ betrachtete. ${ }^{17}$ Die Nichterfüllung aller mit der Revolution verbundenen Hoffnungen ließ sich vor diesem Hintergrund der „conspiration de l'oligarchie doctrinaire et libérale contre les justes conséquences de la révolution de juillet" anlasten. ${ }^{18}$

Aus legitimistischer Sicht formulierte man nach der Erfahrung der Julirevolution die Hoffnung auf eine Allianz mit den libéraux, was ein betont antirevolutionäres Verständnis von libéraux voraussetzte. Es ist signifikant für die Semantik nach 1830, daß dieser antirevolutionäre Charakter von libéraux und libéralisme immer pointierter hervorgehoben wurde. So definierte Auguste Séguin die libéraux als, ,bommes du mouvement... On entend ici par Libéraux, ceux qui, voulant des institutions libérales, repoussent néanmoins un système de terreur. "Dies stellte gegenüber dem nach 1815 noch eindeutig dominierenden Revolutionsvorwurf eine wichtige Richtungsänderung dar. Sie setzte sich in der Projektion eines Zusammenwirkens von libéraux und royalistes fort, die auf der Ablehnung der negativen Folgen der Julirevolution beruhen sollte. Darin spiegelte sich zugleich die Unzufriedenheit mit den doctrinaires und den dahinterstehenden Interessen des juste-milieu wider. Eine echte Stabilisierung bot aus dieser Perspektive nur die konsequente Absage an republikanische Ziele und die erneute Restauration der legitimen Dynastie. Nach 1830 war eine solche legitimistische Deutung aber nur noch in einer Anlehnung der Monarchie an das "large système de liberté “ zu vermitteln, was eine einseitige Rückkehr zum anachronistischen Gottesgnadentum der Bourbonenherrschaft unter Karl X. ausschloß:

Les libéraux ont avoué qu'ils ont été la dupe des doctrinaires et du juste-milieu, et que la souveraineté du peuple, tant vantée, a été escamotée. Les libéraux ont convenu que la révolution de juillet, semblable à une épidémie, tend visiblement à un relâchement total, et que la masse du peuple, inhabile de longue durée, s'est détachée la première de cette révolution... Les libéraux ont reconnu que la révolution de juillet est en état d'bostilité et de conjuration permanente contre l'Europe entière; et par conséquent, en guerre avec elle sous ce double rapport. Ils sont convenus qu'ils ont eu tort de rêver la république, incompatible avec le caractère français. Ils ont reconnue franchement que du rétablissement de la roy-

17 [F. Malebouche] Du système des doctrinaires, Paris 1831, S. 13 und 54; vgl. in kritischer Bestimmung der doctrinaires auch Michel PAlmieri DE MicCiché, À chacun selon sa capacité, à chaque capacité selon ses œuvres, ou le faux-doctrinaire et le libéral, Paris 1831; MerCIER-DesPonTEILles, M. Guizot en présence de l'opposition constitutionnelle, ou réponse au manifeste du parti doctrinaire contre les libertés françaises, Paris 1834, S. 3; LERMINIER, Lettres philosophiques adressées à un Berlinois. IV: De l'école apelée doctrinaire. - M. Guizot, in: Revue Des Deux Mondes 2 (1832), S. 183-99 sowie Lettres sur les hommes d'état de la France. Lettre deuxième, in: ebd. 1 (1833), S. 225-63, hier S. 262.

18 [COLNET] Variétés. Conspirations de l'oligarchie doctrinaire, libérale et féodale, contre les justes conséquences de la révolution de juillet. Par M., du département de la Manche, [Bordeaux] 1831, S. 3 und 7. 
auté légitime en France, dépendent la paix du monde, la stabilité des empires, la sûreté des individus, et le maintien de toutes les propriétés... Les libéraux ont donc reconnu que l'ordre de succession établi en France depuis quatorze siècles, est le seul qui puisse faire le bonbeur des français; mais ils ont déclaré que la loi qui règle la succession à la monarchie n'est nullement une loi de droit divin, mais une loi politique établie pour l'intérêt de ceux qui sont gouvernés, et non pour ceux qui les gouvernent. En conséquence, ils accepteront la royauté légitime fondée sur un large système de liberté. ${ }^{19}$

Diese Projektion einer möglichen Allianz zwischen libéraux und royalistes dokumentierte auch die zunehmende semantische Desintegration von libéraux und libéralisme: Die noch 1830 und 1831 dominierende Identifikation des Deutungsmusters mit der Julirevolution trat zurück. Symptomatisch für diese Entwicklung waren die nach 1830 ganz unterschiedlichen Möglichkeiten, sich auf die Begriffe zu berufen. Dahinter stand nunmehr keine integrative Oppositionshaltung mehr wie noch vor 1830, sondern ein weites Spektrum verschiedener, auch widersprechender Motive, die eine auch nur annähernd verbindliche Definitionsrichtung ausschlossen. Mit der Aufhebung des durch die Julirevolution aufgehobenen Antagonismus zwischen libéraux und royalistes oder ultra nahm die semantische Integrationskraft von libéralisme ab. Einerseits ließ sich zwar noch der Gegensatz zwischen den ideologischen Lagern von 1830, die "incompatibilité du principe libéral et du principe légitimiste ", hervorheben. ${ }^{20}$ Andererseits konnte man auf eine Allianz zwischen royalistes und libéraux gegen die Ergebnisse der Julirevolution hoffen. Diesem Konzept diente die Abschwächung des nach 1815 dominierenden Revolutionsvorwurfs und des Oppositionsgehalts von libéralisme nach 1830. Gerade von den neuen révolutionnaires, die man in den républicains als Gegner der orleanistischen Julimonarchie erkannte, mußten sich die libéraux nach dem Umsturz von 1830 distanzierten. A. de Marguerye konstatierte 1832 entsprechend:

Je fais ici une différence entre les libéraux et les révolutionnaires. Les libéraux sont des hommes à théorie qui aspirent au pouvoir et à réaliser leurs voux par des moyens législatifs; les révolutionnaires n'ont qu'un but, la destruction de tout ce qui existe par la force brutale, et la spoliation de la propriété d'autrui à leur profit. Les libéraux ont été forcés, pour réussir à renverser la vieille monarchie, de s'allier avec les révolutionnaires; mais cette alliance ne peut durer, car de tels associés sont trop dangereux pour qu'on ne les congédie pas le plus tôt possible. ${ }^{21}$

Daneben blieben auch die vor 1830 entwickelten negativen Bestimmungsmuster gegenüber libéralisme virulent, so etwa die polemische Verbindung von libéralisme und protestantisme aus katholischer Sicht, auch wenn dies nicht

19 [Auguste SÉGuin] Traité de paix et d'alliance entre les libéraux et les royalistes, Montpellier 1832, S. 6 und 13-15.

20 M. A. DE BRIQUEVILle, Lettre à Monsieur de Châteaubriand en réponse à sa brochure intitulé De la nouvelle proposition relative au bannissement de Charles X et de sa famille, etc., Paris 1831, S. 8.

21 A. DE MARguerye, Essai sur la Monarchie héréditaire et fédérative, Paris 1832, S. 40, Anmerkung; vgl. Ders., Fais ce que dois, advienne que pourra. Le royaliste et le libéral. Dialogue sur la souveraineté, Paris 1832. 
mehr die gleiche Intensität wie nach 1820 erreichte. ${ }^{22}$ Differenziert wurde dies nach 1830 durch die stärker sozioökonomische Identifizierung des libéralisme als Interessenbegriff des bürgerlichen juste-milieu. ${ }^{23}$ Wo nach den Gewinnern und Verlierern der Julirevolution gefragt wurde, trat zunehmend die Kritik an den libéraux als negatives Synonym für die durch die Revolution nicht erfüllten Hoffnungen der kleinbürgerlichen Schichten hervor:

Que sont devenues toutes ces espérances, ces promesses, ces nouvelles organisations, ces vastes projets tant prônés par les soi-disant libéraux?... Comment veut-on que le peuple soit tranquille? depuis la révolution de juillet l'ouvrier ne fait rien, et la plupart des chefs des ateliers ont fait des pertes irréparables. ${ }^{24}$

Ein weiteres Bestimmungsmuster knüpfte an die Überlegungen Lamennais' von einer Verbindung zwischen catholicisme und libéralisme an, die zwar weiterhin erbitterte Kritik hervorrufen konnte, aber das Bild eines unabänderlichen Antagonismus zwischen beiden Deutungsmustern doch relativierte. ${ }^{25}$

22 Vgl. Honoré De BAlZac, Le curé de village (1845), in: Ders., Scènes de la vie militaire et scènes de la vie de campagne. La Comédie Humaine, Bd. 13, Paris 1845, S. 510-728, hier S. 568; vgl. F. R. DE CHATEAUBRiand, De la restauration et de la monarchie élective; ou réponse à l'interpellation de quelques journaux sur mon refus de servir le nouveau gouvernement, Paris 1831, S. 13; Portrait de Napoléon et des libéraux par M. de Châteaubriand. Mot d'un militaire et de deux hommes du peuple, sur la brochure De la monarchie élective du même écrivain. Publié par la Contemporaine, Paris 1831, S. 27; Cel. EsPanet, Appel du catholicisme à toutes les opinions politiques, ou entretiens d'un catholique avec un royaliste et un libéral. Première partie, Paris 1831; LEBRUN DE CHARMETTE, Épîtres politiques sur nos extravagances, Paris 1831; Ders., Épître au comte Edmond de V. sur le libéralisme, in: ebd., S. 3-47, hier S. 33 sowie DERS., Épître aux libéraux, in: ebd., S. 50-82.

$23 \mathrm{Vgl} . \mathrm{V}^{\text {te }}$ DE CALvimont SAINT-MARTial, Le royalisme en présence des élections, Paris 1834, S. 43 sowie Qu'est-ce qu'un homme du juste milieu?, Rouen [1831], S. 2: „Un bomme du juste milien est celui qui croit que la révolution de 1830 s'étant faite aux cris de vive la Charte, il y a eu folie ou manvaise foi de la part des hommes qui, après la victoire, ont voulu autre chose que la Charte. "; vgl. ferner Le juste milieu en toutes choses et surtout en politiques, Paris [1832], S. $3 \mathrm{ff}$.

24 J.-A. DumAs, Le trône renversé, ou la dernière semaine de juillet 1830; poème burlesco-historico-tragique, en sept journées, mis à la portée des vainqueurs du Louvre et des Tuileries, avec des notes sur les discours et les actions des soi-disant libéraux, Paris 1831, S. 62.

25 Vgl. aus belgischer Perspektive Théodule Normand, Du Catholicisme et du Libéralisme, Eghien 1841, S. 84 f.: „Nous avons prouvé ... que le Libéralisme est une grande négation, une chimère, une utopie fatale, une théorie d'incessantes révolutions politiques, une vraie recrudescence du protestantisme, une hâche qui démolit la philosophie comme la religion... Beaucoup de libéraux... diront que tel n'est pas leur système, et que telles ne sont pas les conclusions de leur doctrine: - qu'ils veulent simplement la liberté garantie par la constitution. C'est possible pour les libéraux qui n'ont pas l'esprit assez philosophique pour étudier la nature intime du Libéralisme, ou qui veulent s'arrêter au milieu du chemin tracé par les doctrines libérales; c'est possible aussi pour ceux que se nomment libéraux au lieu de s'appeller Constitutionnels; mais en attendant ces messieurs grossissent le nombre des libéraux dogmatiques, de ceux qui agissent avec connaissance des principes et des résultats, de ceux qui veulent tout ce que nous avons déduit de la définition du Libéralisme." 
Gerade die Julirevolution bot dafür ein wichtiges Argument, indem sich gezeigt habe, daß weder der tradierte royalisme in seiner einseitigen Orientierung an der Vergangenheit noch der republikanisch ausgerichtete libéralisme in der Lage seien, eine langfristige Stabilisierung der Gesellschaft zu erreichen:

les écrivains catholiques comprirent que ni le royalisme, ni le libéralisme ne sauraient réaliser aucun ordre social stable: le premier, parce que soumettant les peuples à la volonté arbitraire d'un homme qu'il déclarait affranchi de toute loi spirituelle extérieurement obligatoire, il consacrait et la tyrannie et la servitude; le second, parce que niant qu'un pouvoir bumain pût être investi d'un droit dérivé de Dieu même, et forcé de ne reconnaître d'autre souveraineté que la souveraineté individuelle, il créait autant de souverainetés qu'il y a d'individus, et par cela même consacrait l'anarchie.

Aus dieser Perspektive schien es geradezu zwangsläufig, daß libéralisme sich zu einem konservativen Ordnungsbegriff - „qu'il renferme de sociable et de compatible avec l'ordre“ - wandeln müsse, um alle revolutionär-anarchischen Konnotationen abzustreifen. Dies wiederum prädestinierte eine Annäherung von libéralisme und catholicisme: „Chaque jour plus épuré, le libéralisme en proclamant la vraie liberté, gravite par cela même vers l'ordre, c'est-à-dire, vers le catholicisme, d'où tout ordre dérive naturellement. "Hinter dem programmatischen Motto „Dieu et Liberté“ stand das Urteil über die zeitgemäße Relevanz konkurrierender Bewegungsbegriffe: „Il s'ensuit que le libéralisme est, dans ce moment-ci, bien plus que le royalisme, en rapport avec le grand besoin de la société, qui est la liberté“.26

\section{c) La source de cette confusion d'idées:}

Die semantische Desintegration von libéralisme

Die Abfolge der zahlreichen politischen Gruppenbezeichnungen und ihre komplexen Bedeutungsgehalte führten in der Publizistik nach $1830 \mathrm{zu}$ einer verbreiteten Klage über den „abus des mots ... la fausse application des mots, la difficulté de nous entendre sur leur sens ... la source de cette confusion d'idées“.27 Die Fragmentierung der Nomenklaturen ließ eine Verständigung über die ihnen zugrundeliegenden Bedeutungen immer schwieriger erscheinen. Der Vielfalt politischer Kräfte und sozialer Interessen entsprach eine wachsende Begriffsverwirrung. Vor diesem Hintergrund zeichnete sich bereits um 1835 eine zunehmende semantische Desintegration des Deutungsmusters ab. Sie ging zunächst von der Erfüllung der wesentlichen konstitutionellen Postu-

26 De la position des partis telle que l'a faite la révolution de 1830, Nantes 1831, S. $11 \mathrm{f}$., $26 \mathrm{f}$. und 36.

27 Pierre-Victor, À la Chambre des Députés. De l'égarement de l'opinion publique en France sur la révolution de la Belgique, et de la nécessité d'une alliance entre la France et la Hollande, pour résoudre la question belge, Paris 1831, S. 3; vgl. HONORÉ DE BALZAC, Les Rivalités. Deuxième histoire: Le Cabinet des antiques (1837), in: Ders., Scènes de la vie de province. La Comédie Humaine, Bd. 7, Paris 1844, S. 120-244, hier S. 128 und 132. 
late in der Julirevolution aus. Die Überwindung des Antagonismus libéraux ultra durch den vermeintlichen Sieg des système libéral reduzierte die Integrationswirkung des Wortfeldes. Dazu korrespondierte eine inhaltliche Transformation, die man als Historisierung von libéral und libéralisme bezeichnen kann. In einem Rückblick auf Ursprünge und Entwicklungen des parti libéral unterstrich der Autor der Histoire de la Restauration 1835, daß der Bewegungsbegriff libéralisme gerade keiner homogenen politischen Partei im engeren Sinne, sondern einer allgemeinen Haltung entsprochen habe, die sich auf die Charte als Bedingung für eine konstitutionelle Monarchie gegründet habe. Die Ursprünge lagen demnach in denjenigen gesellschaftlichen Gruppen, deren Erfahrungshintergrund durch die Revolutionsepoche und die napoleonische Herrschaft geprägt worden sei. Entscheidend blieb die Herausbildung des oppositionellen Charakters von libéral unter der Bourbonenmonarchie. Nach 1818 schienen die Integrationswirkung des Begriffes und seine gesamtgesellschaftliche Resonanz am größten gewesen zu sein:

Le Parti libéral ... qui sous la Restauration prit le nom de libéral, n'avait aucune homogénité. Sa dénomination en effet était vague; le libéralisme est un sentiment; il ne peut être la cohésion d'un parti... L'origine du parti libéral était bourbonienne; c'étaient quelques débris de l'ancien parti constitutionnel des assemblées, quelques unes des victimes du 18 fructidor, des mécontents de l'Empire ... ils avaient présidé à la charte de 1814; ils voulaient en suivre les développemens. A mesure que ce parti s'avançait et que la Restauration ne suivait pas les voies d'une large constitutionnalité, quelques uns des noms qui à l'origine avaient servi à la consolider, se jetèrent dans l'opposition. Elle fut alors calme et sage, cette opposition, et toutes les bouderies se rangèrent autour d'elle ... de vieux républicains se postèrent monarchistes libéraux; des impérialistes se transformèrent également, et ce camp à nuances si diverses vécut de doctrines constitutionnelles, et se recruta successivement de toutes les inquiétudes publiques... Aussi le parti libéral grandit-il démesurément depuis 1818 jusqu'au ministère de M. de Martignac, où il fit invasion dans le gouvernement même. Alors il n'y avait plus moyen de l'arrêter, car il s'infiltrait partout; il était dans les mours, dans les institutions; la puissance lui appartenait, parce qu'il était la majorité dans le pays.

Nicht die Revolution sei der prägende Erwartungshorizont des parti libéral gewesen, sondern die evolutionäre Entfaltung der politischen Freiheitsrechte im Rahmen der Charte. Das nicht erkannt zu haben, sei ein fundamentales Versagen der Bourbonen gewesen:

Il y eut des libéraux qui voulurent sincèrement le progrès; il y en eut d'autres antipathiques aux Bourbons, qui visèrent au renversement; quelque concession qu'on pht faire, ces derniers ne cessaient d'être mécontens, car ils voulaient un autre résultat que le paisible développement des libertés du pays. La faute du gouvernement d'alors fut de ne pas les séparer les uns des autres; il était si facile de détacher de la révolte les libéraux sincères! ... mais la masse du parti libéral avait accepté les Bourbons; une révolution lui faisait peur. ${ }^{28}$

Für den Autor bestand die historische Leistung des parti libéral in der Durchsetzung einer konstitutionellen Monarchie, die nach 1815 einen Entwicklungspunkt markierte, der eine einseitige Restauration des Ancien régime endgültig

28 [CAPEFIGUE] Le gouvernement de juillet, les partis et les hommes politiques. 1830 à 1835. Par l'auteur de L'Histoire de la restauration, Bd. 1, Paris 1835, S. 36-9. 
ausschloß. Hinsichtlich seiner sozialen Verankerung blieb die Kopplung des parti libéral an die bourgeoisie bestimmend. Der libéralisme rationnel verkörperte danach die erfolgreiche Strategie der classe moyenne, die eigenen Interessen nach der Julirevolution durchzusetzen und dieses Ergebnis gegen die Volksmassen abzusichern. Der sozialexklusive Charakter des parti libéral trat nach dem Sieg im Juli 1830 immer deutlicher hervor:

depuis 1815 il habitua le peuple à l'étude du gouvernement représentatif; il rendit la société plus paisible, en rattachant tous les intérêts à une représentation rationnelle, en appelant des réformes légales. Son opposition ne fut pas toujours éclairée, il eut souvent même un peu de niaisierie dans sa polémique, mais il agit admirablement pour se rattacher la classe moyenne; il domina l'intelligence du paysan, de cette bourgeoisie, jalouse des classes supérieures, inquiètes $d u$ bas peuple. Tout cela produisit ses fruits après Juillet; le libéralisme rationnel a voulu arracher la victoire des mains de la portion active et armée de la révolution.

Entscheidend für das Verständnis des parti libéral blieb sein zwischen 1815 und 1830 dominierender Oppositionscharakter. Hier konnte der Begriff seine maximale Integrationskraft entfalten. Mit der Durchsetzung der orleanistischen Lösung verschwand auch die Kohäsionswirkung, die von royaliste, monarchiste und ultra ausgegangen war. Die Aufhebung dieses semantischen Antagonismus und der ihn flankierenden Polemik der Schlagworte bedingte eine Richtungsänderung von libéral vom Oppositionsetikett zum konservativen Regierungsattribut. Die Erwartung politischer Stabilität und gesellschaftlicher Versöhnung - Grundthema der politischen Publizistik seit dem Ausgang der Französischen Revolution und Ursprung der Bestimmung der idées libérales schien der Begriff auch nach 1830 nicht erfüllen zu können: „Le parti libéral était plutôt une opposition qu'un gouvernement; admirable pour détruire, son œuvre la plus difficile ềt été de reconstituer les formes de l'administration régulière; quand il l'a entrepris, il n'a pu produire qu'un mobile échafaudage, bouleversé chaque vingt-quatre heures" ${ }^{29}$ Ein solcher Wandel ließ sich als Übergang von einer offensiven zu einer defensiven Konnotation deuten. Dem gab ein Artikel in der Revue des deux Mondes von 1835 besonders pointierten Ausdruck: Das verbindende Element zwischen bourgeoisie, industrie und démocratie als gesellschaftliche und ideologische Kräfte bildete danach die „opinion libérale. “ Die offensive und integrative Wirkung von libéral und libéralisme zwischen 1815 und 1830 wich im Verlauf der 1830er Jahre immer deutlicher einer nur noch fragilen „opinion libérale“, einer heterogen zusammengesetzten, defensiven Interessenkoalition, die ihre Position gegenüber den Massen abzusichern suchte:

Ce qu'il y avait, dans cet ordre de conceptions, d'antipatbique au génie de la civilisation moderne, groupait alors l'opinion libérale, et lui imprimait un ensemble qui ... tenait moins à la cohésion de ses élémens qu'à une résistance commune. La bourgoisie, qui comprenait l'impossibilité de s'asseoir au gouvernement de la société, tant que le droit historique y conserverait la prépondérance; l'industrie, dont l'importance et les développemens ne pouvaient se concilier avec l'ascendant de la propriété immobilière; la démocratie, qui, 
dans ses sympathies patriotiques et ses tendances rationalistes, était sans cesse blessée par des idées et des affections qu'elle ne comprenait pas; toutes ces forces, aujourd'bui séparées, marchaient alors de front contre un pouvoir que son origine enchainait fatalement aux destinées d'une école dont il avait plutôt la volonté que la puissance de se séparer. Si le parti libéral ne formait pas une école dans le sens propre de ce mot, c'était moins une irrésistible coalition; s'il n'était pas uni dans ses principes, il l'était dans sa résistance. ${ }^{30}$

\section{Deutschland}

a) Eine politische und bürgerliche Religion:

Der konstitutionelle und nationale Horizont von Liberalismus um 1830/32

Die politische Aufbruchstimmung der Jahre 1830/1832 ergab sich in den deutschen Staaten aus den aufgestauten Erwartungen einer Öffentlichkeit, die durch den externen Impuls der französischen Julirevolution von 1830 und die von ihr ausgehende Welle konstitutioneller Offensiven und sozialer Protestbewegungen wenigstens temporär zu größeren Handlungsspielräumen führte. Diese Erfahrung katalysierte und dynamisierte eine Fundamentalpolitisierung und konfrontierte die oppositionellen Kräfte zugleich mit der Frage nach der weiteren programmatischen und strategischen Orientierung. Neben die bestehenden oder neu eingerichteten einzelstaatlichen Parlamente traten mit dem politischen Vereinswesen und dem von ihm organisierten Massenprotest, wie er insbesondere im Hambacher Fest von 1832 deutlich wurde, dezidiert außerparlamentarische Aktionsräume und Aktionsformen. ${ }^{31}$ Obgleich der Impuls der französischen Julirevolution 1830 und die Welle politischer und sozialer Unruhen in den deutschen Staaten, die einen zweiten Konstitutionalisierungsschub auslösten, für die parlamentarische und außerparlamentarische Opposition die strukturelle Reformblockade längerfristig nicht aufzuheben vermochten, erwies sich die Erfahrung von 1830/32 schon bald als tiefgreifende Zäsur: Die beginnenden 1830 er Jahre konfrontierten den Gehalt von liberal und Liberalismus mit neuen politischen Erfahrungen und Bedingungen. Die weitreichenden, aber heterogenen Erwartungen hinter dem Deutungsmuster antizipierten zugleich das semantische Spannungsfeld bis zur Jahrhundertmitte. Zunächst überwog jedoch das Bewußtsein der Zeitgenossen für den politisch-gesellschaftlichen Scharniereffekt der Ereignisse. Ihnen war die mit den Umbrüchen von 1830 verbundene Epochenwirkung gegenwärtig, und für den neuen „Geist der Zeit" bediente man sich erwartungsfroh des oppositionellen Zauberworts Liberalismus:

30 Louis de Carné, Des partis et des écoles depuis 1830, in: Revue des Deux Mondes 3 (1835), S. 203-28, hier S. 211.

31 Vgl. W. SCHIEDER, Der rheinpfälzische Liberalismus, S. 169 ff. und FoERSTER, Sozialstruktur, S. $147 \mathrm{ff}$. 
Jabrbunderte haben in den politischen Verbältnissen Europa's nicht die Veränderung hervorgebracht, die das einzige Jahr 1830 bewirkt hat. Der Geist der Zeit ist, gleich einem wilden Strome, aus seinen Ufern gebrochen ... Liberalismus und Royalismus sind die zwei Zauberwörter, welche die europäische Menschbeit in zwei Heerhaufen theilte ... Und diese Spaltung theilt nicht bloss den Staat, sie theilt auch das bürgerliche Leben, die Gesellschaft, Literatur und Wissenschaft. ${ }^{32}$

Vor dem Hintergrund der antagonistischen Deutungsmuster Liberalismus und Royalismus schien der euphorisch begrüßte Aufbruch die Fortschrittserwartung der 1820er Jahre, die universalhistorische und zivilisatorische Sendung des Liberalismus, zu bestätigen. Im Bekenntnis zu dem Begriff ließ sich der eigene historische Standort bestimmen: $\mathrm{Ob}$ man noch der Vergangenheit angehörte oder die Zukunft auf seiner Seite wußte, symbolisierten die Zeitbegriffe in ihrer Wirkung als Zauberwörter - im Rückgriff auf diese Ismen vollzog sich mithin eine ideologische Temporalisierung. ${ }^{33}$

Entsprechend bestimmten die meisten der zahlreichen Monographien, die zu Beginn der 1830er Jahre publiziert wurden, das Wortfeld als Synonym für Fortschrittlichkeit und Vernunft. Liberalismus erschien als gleichsam zivilisatorische Notwendigkeit. Ernst Ludwig Brauns identifizierte das „liberale System“ mit der „höchsten Entfaltung" des freien Bürgertums, das, von der Schweiz und Holland ausgegangen, über England nach Amerika gelangt sei. Dabei unterstrich er insbesondere den antifeudalen Gehalt des Begriffes. ${ }^{34}$ Joseph Gambihler erkannte im Liberalismus eine natürliche geistige Anlage des Menschen, eine Gesinnung, und ein philosophisches System, dem sich Ideale der Aufklärung wie Wahrheit, Humanität, vernünftiger Staat und politische Freiheit zuordnen ließen:

Liberalismus ist in unsern Tagen der Mittelpunkt der Gedanken aller Menschen geworden, die an den Ereignissen unsrer Zeit, vor allem aber der jüngsten, im Geiste oder in Thaten Antheil genommen haben; von den Guten wird er gehegt und geliebt, von den Bösen verstoßen ... Liberalismus haftet im Geiste; er hat seinen Sitz im Mittelpunkte des Heiligthumes der unsrer Erfabrung zugänglichen Vortrefflichkeit erwählt ... Wenn aber Liberalismus einmal in seiner Art der Verkünder der Energie des menschlichen Geistes ist, so muß

32 ERnst Freymund [i.e. August Friedrich GFrörer], Die Geschichte unserer Tage oder getreue Erzählung aller merkwürdigen Ereignisse der neuesten Zeit, 8 Bde., 2 Supplement-Hefte und 2 außerordentliche Hefte, Stuttgart 1831-1833, hier Einleitung, in: Bd. 1, Stuttgart 1831, S. 5-7.

33 Dieses politisch-semantische Kennzeichen korrespondiert mit der in der jüngeren Forschung hervorgehobenen allgemeinen Zäsur des Jahres 1830, vgl. RAINER PAETAU, 1830 als Zäsur in der europäischen und deutschen Geschichte des 19. Jahrhunderts. Zum Wandel einer ideologischen Geschichtslehre, in: HZ 256 (1993), S. 323-52, hier S. 351 sowie HaRTwig BRANDT, Die Julirevolution (1830) und die Rezeption der „principes de 1789“ in Deutschland, in: Roger Dufraisse (Hrsg.), Revolution und Gegenrevolution 1789-1830. Zur geistigen Auseinandersetzung in Frankreich und Deutschland, München 1991, S. 225-35.

34 ERNST LUDWIg BRAUNS, Das liberale System, oder das freie Bürgertum in seiner höchsten Entfaltung; in einem Gemälde des Bundesstaats von Nordamerika praktisch dargestellt. Erster Theil, Potsdam 1831, Zweiter Theil, Potsdam 1833, vgl. vor allem Bd. 1, S. $8 \mathrm{ff}$. und $17 \mathrm{ff}$. 
ervon allen jenen Äußerungen nun, welche ibn in allen wesentlichen Kräften beurkunden, von Verstand, Einsicht, Vernunft, die alle drei in der Natur ibrer Existenz in eine Wesenheit zusammenfallen, dann von Gemüth und Willen, der Zeuge seyn. ${ }^{35}$

Für C. H. Nebbien verkörperte der „radikale christliche Liberalismus“ den höchsten „Freibeitssinn “ und damit den „Zeitgeist" 36 der von einem „schwankenden, faulen und selbstsüchtigen, jesuitisch-täuschenden, und anarchistischumstürzenden Liberalismus" zu unterscheiden war. Als grundlegende Voraussetzung des Liberalismus definierte er wie zahlreiche andere Autoren Bildung. Zusammen markierten beide Begriffe ein bildungsbürgerliches Deutungsmuster, und die Kontur des Liberalismus als politische Bildungsreligion begann sich abzuzeichnen:

Der Liberalismus ist ... die Folge der Bildung. Je größer diese in einem Menschen oder in einem Volke wird, je größer und edler ist der Liberalismus desselben. Ein Staat, der seinen Liberalismus will, muß seine Bildung wollen; denn je größer diese wird, je mächtiger wird jener. Und so geschieht es heute. ${ }^{37}$

Paul Achatius Pfizer verband in seiner Schrift Ziel und Aufgabe des Deutschen Liberalismus geradezu idealtypisch den konstitutionellen und den nationalen Erwartungshorizont um 1830/32 miteinander, wenn er konstatierte: "Auf das Zeitalter der Dynastien ist im liberalen Europa jetzt das der Nationen gefolgt." Bei der Verwirklichung des konstitutionellen Repräsentativsystems und der nationalen Einheit kam für Pfizer den frühkonstitutionalisierten Staaten Südwestdeutschlands eine Vorbildfunktion zu:

Im Sinn und Geiste des Jabrbunderts kann aber dasjenige, was Deutschland organisch vereint und den Bund seiner Fürsten in einen Bund der Völker, das diplomatische Staatenbündnis in einen nationalen Bundesstaat verwandelt, nichts anderes, als eine deutsche $\mathrm{Na}$ tionalvertretung seyn, und hiezu muß die Anregung und der Hauptanstoß durch den Liberalismus gegeben werden. Mit der den Deutschen natürlichen Begeisterung ist seitdem auch diese Idee ergriffen worden. Vom südwestlichen Deutschland, als die Wiege und Heimath, dem Herd und Mittelpunkte des deutschen Liberalismus, soll nun die Wiedergeburt Deutschlands zur Freibeit und zur Einigkeit ausgehen. ${ }^{38}$

Pfizers Forderung lief zunächst auf eine Einlösung des Verfassungsversprechens der Deutschen Bundesakte von 1813 hinaus. Dabei reflektierte er klar-

35 Joseph Gambihler, Philosophie und Politik des Liberalismus. Ein Beitrag zur wissenschaftlichen Begründung der höchsten Interessen der Menschheit und freimüthigen Würdigung der neuesten Zeitereignisse, Nürnberg 1831, S. 9-11, vgl. ebd., S. $37 \mathrm{ff} ., 45 \mathrm{ff} ., 56 \mathrm{ff}$. und $107 \mathrm{ff}$.

36 Vgl. WÜLFING, S. 138.

37 C. H. Nebbien, Radikaler Liberalismus, Volksnoth, und Verwandlung derselben in Volkswohlstand. Oder: Wie kann Stadt- und Landmann von heute an, alljährig wohlhabender werden und es auch bleiben? Ein Fingerzeig für jedermann ... Als Beischrift zum ersten Quartalheft der allgemeinen Gutsherrenzeitung, Königsberg 1831-1832, S. Vf. und 2.

38 Paul Achatius Pfizer, Gedanken über das Ziel und die Aufgabe des Deutschen Liberalismus, Tübingen 1832, neu hrsg. u. bearb. von GEORG KÜNTZEL, Berlin 1911, S. 362 und 344. 
sichtig bereits 1832 das Grundproblem, das sich aus der Diskrepanz zwischen dem vernünftigen Recht und der realen Machtkonstellation für den Liberalismus ergab:

Die Liberalen Deutschlands verlangen im Namen der deutschen Nation die von ibren Fürsten zugesicherte nationale Bundesverfassung, und national kann diese Bundesverfassung niemals werden, wenn sie nicht auf eine zeitgemäße Nationalvertretung des gesammten deutschen Volkes gegründet ist ... Freilich haben die Deutschen das Recht, eine solche [i. e. gemeinschaftliche Volksvertreung] für die ganze Nation zu verlangen ... Allein bei aller Evidenz des Rechts, das ibm zur Seite steht, bei aller Trefflichkeit der Gesinnung, welche für seine Sache kämpft, bei aller Zaubergewalt, welche die Ideen der Freiheit und der Gleichheit über die Gemüther der Menschen ausüben, ist doch gar sehr zu bezweifeln, ob der dentsche Liberalismus sein Ziel vollständig und gleichsam im ersten Anlauf schon erreichen wird, ... weil Recht und Macht verschiedene Dinge sind, und weil auf Erden stets die Macht dem Rechte ... ergänzend sich verbünden muß.

Dies verwies den Liberalismus, wollte er nicht Theorie bleiben, auf die Kooperation mit den einzelstaatlichen Regierungen, wobei Pfizer die „Aufgabe des deutschen Liberalismus " in der Transzendierung des Bundes als Raum lediglich partikularer Territorien von den konstitutionellen Einzelstaaten aus bestimmte. Recht und Vernunft firmierten dabei als Fluchtpunkte der bestehenden Landtage:

Somit bleibt den Freisinnigen in den konstitutionellen deutschen Ländern, wo der Liberalismus seinen Hauptsitz und Brennpunkt hat, vor der Hand nichts übrig, als dabin zu wirken, daß die konstitutionellen Staaten zu einem engern Bund im Bunde sich vereinigen... Denn der Bund allein, und nicht das lächerliche Puissanciren einer bairischen oder badischen Nation ist es, was ibre schwache Kraft stärken ... kann. Daß aber diese vernünftige und rechtliche Politik von den dentschen Kabinetten angenommen werde, dafür sind den deutschen Völkern bauptsächlich ibre Landesversammlungen verantwortlich ... Die Stände sind es, welche den Beruf haben, das Recht gegen die Gewalt, das Gesetz gegen die Willkür, die Freibeit gegen die Unterdrückung zu vertreten ... Dies ist die Aufgabe des deutschen Liberalismus. ${ }^{39}$

Die weitgespannten Erwartungen, die die politische Öffentlichkeit mit Liberalismus verband, schlugen sich auch in einer Flut von programmatischen Artikeln der Tagespresse nieder, die durch die zumindest temporäre Lockerung der Pressegesetze gegenüber den 1820er Jahren einen größeren Spielraum hatte. Hier dominierte bis etwa 1832 eindeutig ein ungebrochener Fortschrittsoptimismus. In Liberalismus schienen die Schlagworte Vaterland und Recht gleichsam verdichtet aufgehoben. Eine ethische Aufladung des Begriffes ging dabei mit dessen mobilisierender Wirkung als Synonym für einen politischen und nationalen Aufbruch einher:

Der Liberalismus, dem die Wabrheit Muth, die Sitte Kraft verleiht, der Vaterland und Recht im Herzen trägt, der allein ist der wabre. Er baut lieber, als er zerstört, aber er schreitet vorwärts, wie ein gewaltiger Strom - er breitet sich aus wie das Licht, schnell und mächtig. Er ist neu aufgewacht bei uns. Er wird siegen, wie auch Befangenheit, Knechtsinn und Eigennutz ibn verdächtigen. Und sollte er untergehen, so ist es besser für ihn, das 
Martyrthum erduldet zu baben, als dabin leben obne Wabrbeit, obne Recht, obne wabre Sitte. ${ }^{40}$

Der Liberalismus sei eine „Überzengung, eine politische und bürgerliche Religion, eine Grundfarbe des Charakters. “Dies grenze ihn von einer reinen „Opposition " und ebenso von der "Revolution“ ab und verweise damit auf die evolutionäre Entfaltung des Rechtszustandes. Als universelles und integratives Deutungsmuster ließ Liberalismus die Revolution nur als äußerstes Instrument des Widerstandes zu:

Fortschreiten im Rechte, in der Wabrheit, in der Freibeit will und muß der ächte Liberalismus... Sein eigentlicher Weg ist, wo er das Gute noch nicht findet, die Reform, die allmähliche Herstellung eines vernünftigen Rechtszustandes, das Herbeifübren des Ersprießlichen im Gesetz, durch das Gesetz. Die Revolution ist ibm eine Nothwehr, ein Zustand, wo kein anderes Mittel übrig bleibt, das Recht der Vernunft und ibre Anforderungen geltend zu machen. 41

Einen deutlicheren Oppositionsgehalt erhielt das Wortfeld im Umkreis der Gruppe um Johann Georg August Wirth in München, der in den Augen der gemäßigten Kräfte zusammen mit Jacob Siebenpfeiffer die „äußersten Endpunkte des Liberalismus" markierte. ${ }^{42}$ Für Wirth schienen die „liberalen Ideen“ dabei "nichts anderes als die wörtliche Bezeichnung der Bedürfnisse der beutigen Staaten ".43 Hier konnte der Begriff instrumentalisiert werden, um die konstitutionelle Reformblockade in bestimmten deutschen Staaten zu brandmarken. So kritisierte die von Wirth herausgegebene Zeitung Das liberale Deutschland das Fehlen „eigentlich liberaler Institutionen “ in Preußen, wo man das „Wesentliche, die Spitze, die Bürgschaft der liberalen Institutionen, eine bei Erlassung der Gesetze und bei Deckung der Staatsbedürfnisse notwendig mit dem Fürsten konkurrierende Volksvertretung und wirksame Verantwortlichkeit der Minister" vergeblich suche. ${ }^{4}$ Auch Pfizer hob vor dem Hintergrund des „Liberalismus im Süden" den „Absolutismus im Norden" und vor allem „das despotische, illiberale " und daher „undeutsche Preußen" hervor. ${ }^{45}$

40 Liberalismus, in: Der Beobachter. Ein Volksblatt (Pforzheim), Nr. 12, 7. April 1832, S. 92; vgl. ferner Aristokraten und Servile, in: ebd., Nr. 7, 21. März 1832.

41 Liberalismus und Opposition, in: ebd., Nr. 29, 6. Juni 1832, S. 225; vgl. ferner Liberalismus und Revolution, in: ebd., Nr. 35, 27. Juni 1832, S. 274.

42 Wilhelm Schulz, Über literarischen und sozialen Republikanismus, zitiert nach HeINE, Schriften, Bd. 4, S. 667.

43 Die liberalen Ideen, in: Deutsche TribÜne. Ein constitutionelles Tagblatt, Nr. 29, 31. Juli 1831; vgl. ferner Die Reaction und die Liberalen, in: ebd., Nr. 132, 11. November 1831.

44 Beleuchtung eines Correspondenzartikels über Preußens Politik [i.e. Berliner Flugschrift mit dem Titel Wo ist man liberal, in Frankreich oder Preußen?], in: DAS LIBERALE DeUTSCHLAND. Eine censurfreie Zeitschrift, hrsg. von JohANN GEORg AugusT WirTh, Nr. 1, 3. August 1831, S. 28; vgl. ferner Liberalismus in Preußen, in: ebd., Nr. 2, 10. August 1832, S. 40 und Nr. 3., 23. August 1832, S. 54.

45 [Paul Achatius Pfizer] Briefwechsel zweier Deutschen, 2. Aufl. Stuttgart 1832, neu hrsg. und bearb. von GEORG KÜNTZEL, Berlin 1911, S. 223, 217 und 273. 


\section{b) Wabrer Liberalismus und Psendoliberalismus:}

Die semantische Polarisierung des Deutungsmusters

Die 1830/32 eingetretene Situation konfrontierte die politische Öffentlichkeit mit der doppelten Herausforderung, die sich bereits in der semantischen Transformation der 1820er Jahre angekündigt hatte, nun aber unter dem Eindruck der Krisen- und Umbruchsphase konkretisiert wurde und von der aus die Bedeutungskohärenz und gesellschaftliche Verbindlichkeit von Liberalismus zunehmend in Frage gestellt wurde: Einerseits ging es um die notwendige Abwehr der Kritik, die von Seiten der regierungsamtlichen und der sich formierenden konservativen Publizistik formuliert wurde, andererseits aber traten in der semantisch faßbaren Auseinandersetzung zwischen wabrem und falschem Liberalismus die Differenzbestimmungen der verschiedenen gesellschaftlichen Interessen und damit auch die inneroppositionellen Gegensätze in ein neues Entwicklungsstadium. Wilhelm Schulz konstatierte 1832 entsprechend: „Ueberall treten hier die Parteien schroffer sich gegenüber, und die eine stößt die andere immer weiter von sich ab. "Ein bedeutendes Zeichen der Gegenwart sei die Polarisierung der Meinungen geworden, die Tatsache "daß unsere Zeit keine Halbheit duldet, daß selbst der Schein der Schwäche und Unentschiedenbeit vor der öffentlichen Meinung als Verbrechen gilt ".46 Eine verbindliche Deutung dessen, wofür liberal und Liberalismus stehen sollten, schien einerseits notwendiger denn je; andererseits relativierte die nun einsetzende Flut der Bestimmungsversuche zugleich jeden Anspruch auf definitorische Eindeutigkeit. Die Dynamisierung des Politikdiskurses zu Beginn der 1830er Jahre spiegelte sich nicht zuletzt in der verbreiteten Klage über die Vieldeutigkeit des Attributs liberal wider. Friedrich von Raumer bekannte 1831:

Müßte ich ... ein politisches Glaubensbekenntnis ablegen, so würde ich rundheraus sagen: ich sey wesentlich liberal gesinnt. Dies Wort ist indessen so vieldentig, daß ich mich mit verschiedener Auslegung desselben immer noch in jede Ansicht und jedes System bineinlügen könnte, darum behaupte ich, belehrt durch Vergangenheit und Gegenwart: das hitzige Fieber politischen Wahnsinns, wie er aus übertriebener und mißverstandener Freibeitslust ensteht, ist ein schneller vorübergehendes, minder verderbliches Übel, als das schleichende Gift, der Knochenfraß und Krebsschaden langer, angewöhnter Sklaverei. ${ }^{47}$

Eine verbindliche Deutung mußte umso schwieriger sein, als die bereits früh erkennbare semantische Breite von Liberalismus als Folge einer je individuellen fortschrittlichen Gesinnung jenseits von Parteizwängen gerade jede Eindeutigkeit politischer Programmatik von vornherein ausschloß. Erst daraus ergab sich die Situation, daß der Begriff von den Rednern des Hambacher Fests genauso für sich reklamiert werden konnte wie von den süddeutschen Kammerabgeordneten, obgleich dahinter unterschiedliche Forderungen und Strategien

46 Wilhelm Schulz, Deutschlands Einheit durch Nationalrepräsentation, Stuttgart 1832, S. $175 \mathrm{f}$

47 Friedrich von Raumer, Briefe aus Paris und Frankreich im Jahre 1830, Erster Theil, Leipzig 1831, S. 116. 
standen, die nunmehr offen zutage traten und die Integrationskraft des Begriffes in Frage stellten. So wandte sich ein Redner auf dem Hambacher Fest vehement gegen ein passives Verständnis von Liberalismus, das mit dem bloßen Pathos des Bekenntnisses keine Antwort auf die drängenden Fragen der Gegenwart bieten könne. Wiederum eröffnete die Unterscheidung zwischen dem Bedeutungsursprung und der vermeintlichen Degeneration eine willkommene Möglichkeit der programmatischen Abgrenzung. Der falsche Liberalismus verkörperte in den Augen vieler Mitglieder der außerparlamentarischen Protestbewegung von 1830/32 einen bloßen Gradualismus konstitutioneller Refomkonzepte und das ängstliche Festhalten der Kammeropposition am erreichten status quo, das die Chance eines politischen Entwicklungssprungs ungenutzt lasse:

solange jener falsche Liberalismus uns blendet, der sich nur kund gibt durch schöne Phrasen und rhetorische Figuren und in Wirklichkeit nur strebt nach nichtigem Glanze und nach Beförderung persönlicher Interessen ... wird Deutschlands Freibeit, Deutschlands Einheit, Deutschlands Wiedergeburt nicht erblüben. ${ }^{48}$

Diese inneroppositionelle Diversifizierung prägte die Semantik, wobei neben den Liberalismus erstmals vermehrt neue Bewegungsbegriffe traten: Johann Bertram Stüve hob die „Nationalität“ als „Kern alles politischen Lebens" gegenüber dem Liberalismus hervor, der ihm nur wie eine „ewige grenzenlose Auflösung alles Lebendigen in schale, unwabre Abstraktion" erschien: „das ist nun und nimmermebr eine Basis" ${ }^{49}$ Kritiker unterstellten den Liberalen, alle bestehenden Institutionen im Namen des Volkes ohne Unterschied anzugreifen. Der Mangel an „innerer Liberalität der Gesinnung“, ein signifikanter Rückgriff auf das fortwirkende Ideal einer individualistischen Privatethik, die jetzt der Abgrenzung gegenüber einer scheinbar ausufernden kollektiven Gewaltideologie bedurfte, kennzeichne die „sogenannten Liberalen“:

Sie greifen alles an, was, sei es notwendig, gut, durch die Rücksicht auf die Erhaltung der öffentlichen Freibeiten bedingt, doch nicht den äußeren Anstrich einer liberalen Maßregel trägt, ... doch sie verdammen die Regierungen a priori und glauben, daß alles, was von dem Volke geschiebt, auch für das Volk und zum Nutzen des Volkes getan sei. ${ }^{50}$

48 Zitiert nach Asmus, S. 203.

49 Brief Stüves an seinen Bruder vom 6. September 1831, in: JOHANN CARL BERTRAM STÜVE, Briefe, Bd. 1: 1817-1848, hrsg. von Walter Vogel, Göttingen 1959, S. 224. Die allzu abstrakt-rationale Orientierung des süddeutschen Liberalismus beklagte Stüve bereits in einem Brief vom 27. Februar 1829, ebd., S. 144 f., wo er insbesondere die Überbewertung der Bildung kritisierte: „Wir Deutsche sind einmal durch die gelebrte Richtung, die wir im Mangel des Politischen genommen haben, sebr dazu geneigt; und der heutige Liberalismus möchte gern alles Heil im Unterricht finden und zieht in dieser Rücksicht die tollsten Folgen."

50 Friedrich BÜlau, Die Liberalen (1831), in: Ders., Zeitfragen aus dem Gebiete der Politik und Volkswirthschaft, Leipzig 1846, S. 304 f.; Ders., Parteinamen und Parteigeist (1831), in: ebd., S. 303 f. sowie Ders., Kritik des Staats-Lexikons, in: [Berliner] JAHRbÜCHER FÜR WISSENSCHAFTLICHE KRITIK (1838), wieder in: DeRs., Zeitfragen, S. 107-29. 
Die realhistorische Erfahrung mit der politischen Aufbruchsituation von 1830/32, von der wesentliche Impulse für die vormärzliche Oppositionslandschaft ausgingen, reichte bei inneroppositionellen Gegnern der außerparlamentarischen Protestbewegung von der abwehrenden Reaktion auf das „alberne Spielen mit Parteinamen von Liberal und Juste Milieu" bis hin zur vehementen Verteidigung des anvisierten maßvollen Reformkurses gegenüber allen revolutionären Implikationen, die die bestehende Ordnung und damit zugleich das erreichte Ausmaß an Konstitutionalisierung zu gefährden drohten. ${ }^{51}$

Aufschlußreich für den historisch-semantischen Niederschlag dieser inneroppositionellen Differenzierung und Polarisierung und die damit verbundene semantische Ambivalenz des Begriffes in der politisch-gesellschaftlichen Situation um 1830 ist die durch die Ereignisse von 1830 bis 1832 veranlaßte Schrift des Leipziger Kantianers Wilhelm Traugott Krug, dessen Geschichtliche Darstellung des Liberalismus bereits 1823 seine Bemühungen um eine verbindliche und umfassende Deutung des Bewegungsbegriffes dokumentiert hatte. ${ }^{52}$ Krugs damalige Befürchtungen hinsichtlich der dem Liberalismus inhärenten Gefährdungen und möglichen Entartungen sah er durch die Gegenwart nunmehr bestätigt. Seine 1832 erschienene Schrift Der Falsche Liberalismus unserer Zeit bietet für eine Analyse des semantischen Wandels von Liberalismus in Deutschland die Möglichkeit, die Veränderung der Erfahrungsräume zwischen 1823 und dem Beginn der 1830er Jahre in ihren Auswirkungen auf die politische Semantik zu rekonstruieren, weil Krugs Schrift explizit eine Bilanz der von ihm in seiner Geschichtlichen Darstellung des Liberalismus alter und newer Zeit von 1823 vorgenommenen Interpretation zog. ${ }^{53}$ Sein Anfang der 1820er Jahre dominierender Optimismus hinsichtlich der politischen Selbstreinigung des Liberalismus von extremen Kräften wich vor dem Hintergrund der Zersplitterung der politischen Meinungen zwischen den Extremen der „Konservativen" und der „Destruktiven“, 54 vor allem aber im Hinblick auf die außerparlamentarische Protestbewegung von 1830/32, einer nunmehr skeptischeren Einschätzung:

ich schrieb eben jene geschichtliche Darstellung in der Absicht zu bewirken, daß der Liberalismus sich seiner Verirrungen und Ausschweifungen entledigen möchte. Allein die Geschichte hat leider vergeblich gesprochen! Viele von denen, welche sich Liberale nennen,

51 Brief Stüves an Pertz vom 8. April 1832, in: STÜVE, Bd. 1, S. 253.

52 Vgl. Kapitel IV.2.d).

53 Wilhelm TraugotT Krug, Der falsche Liberalismus unserer Zeit. Ein Beitrag zur Geschichte des Liberalismus und eine Mahnung für künftige Volksvertreter, Leipzig 1832; zur zeitgenössischen Kritik vgl. FRIEDRICH FunK, Der bodenlose Krug. Nachweisung der Ungereimtheiten in der von Krug herausgegebenen Schrift Der falsche Liberalismus unserer Zeit, Würzburg 1832 sowie Das Glaubensbekenntnis des Professor und Ritter Krug, oder die Männer der gerechten Mitte, Altenburg 1832.

54 Wilhelm TraugotT Krug, Der Kampf zwischen Konservativen und Destruktiven und das europäische Ober=Studien=Direktorium. Auch ein Versuch, das Politisch=Böse unserer Zeit auszurotten (1835), in: [Ders.] Krug's gesammelte Schriften, Bd. 5: Politische und juridische Schriften, Braunschweig 1835, S. 193-230. 
haben sich immer mehr nach dem Extreme bewegt; und es ist daraus ein so falscher Liberalismus hervorgegangen, daß die Besonneneren und Gemäßigteren unter den Liberalen sich dieses Namens fast zu schämen anfangen.

In der Rückkehr zu einem verschärften Repressionskurs durch die Bundesbeschlüsse vom Juni 1832, die als Reaktion auf die um sich greifenden Oppositionsbewegungen und das Hambacher Fest vom Mai 1832 erfolgt waren, erkannte er eine Konsequenz, eine „bittere Frucht jenes falschen Liberalismus“. 55 Unter dem Eindruck des in kurzer Zeit deutlich gewordenen außerparlamentarischen Protestpotentials orientierte sich Krugs Begriffsbestimmung eindeutig an einem gemäßigt-konstitutionellen Reformkurs, der für ihn nach dem zweiten Konstitutionalisierungsschub, so auch in Krugs Heimat Sachsen, am ehesten neue Entwicklungschancen zu versprechen schien. ${ }^{56}$ Dementsprechend stellte der falsche Liberalismus der Gegenwart eine erhebliche Gefährdung für das bereits erreichte Ausmaß an konstitutionellen Zugeständnissen der Regierungen dar, die es gerade zu sichern galt, indem man den antirevolutionären Gehalt des wabren Liberalismus betonte. Entsprechend wollte Krug „diejenigen, die etwa zu künftigen Volksvertretern in und außer Sachsen berufen werden möchten, vor einem so verderblichen Irrsale warnen ". 57

Ob es um Rechtsprechung, Krieg und Frieden, um Fürsten und Völker, Opposition und Pressefreiheit ging - anhand der in der Öffentlichkeit intensiv diskutierten Themen stellte Krug den „falschen“ oder „Pseudo-Liberalismus“ dem „echten Liberalismus" gegenüber, um durch diese semantische Abgrenzung eine „Rückkehr vom falschen zum echten Liberalismus“ zu erreichen und damit konkret auf eine Aufhebung der verschärften Bundesbeschlüsse hinzuwirken. Der bereits zu Beginn der 1820er Jahre auftretende dualistische Topos von falschem und richtigem Liberalismus bot eine Möglichkeit, die eigene Position von den scheinbaren Entartungen des historisch legitimen Fortschrittsbegriffs Liberalismus abzuschirmen. Der Topos verwies noch auf den grundsätzlichen Bedeutungszusammenhang dieser Liberalismen, aber die semantische Untergliederung dokumentierte bereits die Ausweitung des Interpretationsrahmens, innerhalb dessen verschiedene Begriffsbestimmungen um eine verbindliche Definition des zeitgemäßen Fortschritts konkurrieren konnten. Daraus ergab sich das Paradoxon, daß die Bemühungen um eine verbindliche Charakterisierung von Liberalismus ungewollt in eine Inflation von Definitionsangeboten mündeten. In Krugs Begriffsbestimmung schlug sich eine Gegenwartsanalyse nieder, in der die Selbstbindung des legitimen Liberalismus an das staatlich vertretene und vernünftige Recht auf die falsch verstandene rechtlose Freiheit traf, die unter demselben Begriff operierte und ihn damit in den Augen der vernünftigen Öffentlichkeit zu diskreditieren drohte. Während der „echte Liberalis-

55 KRUG, Der falsche Liberalismus, Vorrede, S. IIIf.

56 Vgl. Rudolf MuHs, Zwischen Staatsreform und politischem Protest. Liberalismus in Sachsen zur Zeit des Hambacher Fests, in: W. Schieder (Hrsg.), S. 194-238.

57 KRUG, Der falsche Liberalismus, Vorrede, S. IV. 
mus" vom "Prinzipe des Rechtes" ausgehe, mache der "falsche" gerade „die Willkür zu seinem Prinzipe und verletzt daber das Recht unbedenklich, sobald es seinen Absichten im Wege stebt". 58 Dies entsprach der Einordnung des falschen Liberalismus in die Tradition der durch die radikale Französische Revolution verkörperten anarchischen Despotie, die im Namen eines abstrakten Prinzips zu einer tyrannischen Ordnung degeneriert schien. Wiederum boten die Ereignisse in Frankreich eine Anschauungsfläche für Erfahrungen, die auf die Begriffsbestimmung in Deutschland zurückwirkten: ${ }^{59}$ Denn wie den „Psendo-Liberalen“ Frankreichs, die Krug mit der Zeitung National und den führenden politischen Repräsentanten der Julirevolution, Lafayette und Barrot, identifizierte, so warf er auch ihren deutschen Sympathisanten „reine Willkür" vor: "So haben auch unsre Pseudo-Liberalen zweierlei Maß und Gewicht, ein andres Recht für die, welche sie hassen, und wieder ein andres für die, welche sie lieben. So sind sie bald illiberal, bald ultraliberal nach bloßer Antipathie und Sympathie ".60

Symptomatisch für diese Degeneration der legitimen Ursprungsbedeutung von Liberalismus, der Grundlage des vernünftigen Rechts, erschienen Krug insbesondere die Revolten in zahlreichen deutschen Staaten in der Folge der Pariser Julirevolution als „abermalige Störung der gesetzlichen Ordnung “, wie insbesondere das Hambacher Fest gezeigt habe. ${ }^{61}$ Vor dem Hintergrund dieser neuen Artikulationsformen einer politisierten Öffentlichkeit amalgamierte Krug Liberalismus mit betont antirevolutionären Werten, baue doch der „echte Liberale" auf "Recht und gesetzliche Ordnung und Mäßigung in allen Dingen“.62 Den "Pseudo-Liberalismus" dagegen identifizierte er nunmehr sehr konkret mit einem republikanischen Zielhorizont. Dies reflektierte nicht zuletzt das öffentliche Echo auf bestimmte, im Kontext des Hambacher Fests laut gewordene Forderungen extremer Gruppen. Nicht ohne Genugtuung konstatierte er mit Blick auf die rheinpfälzische Protestbewegung:

So waren denn alle die schönen Hoffnungen vernichtet, welche das berühmte Hambacher Volksfest im deutschen Volke hatte erwecken sollen. Obnehin waren auf demselben die beiden Hauptredner, Wirth und Siebenpfeiffer, die Heroen des deutschen Psendo-Liberalismus, in argen Widerspruch gerathen.

„Was von solchen Helden zu erwarten“ sei, war für den Autor gleichbedeutend mit der gewaltsamen Durchsetzung des republikanischen Prinzips. ${ }^{63}$ Obgleich

58 Ebd., S. 2, Vorrede, S. VI und 3.

59 Vgl. Raumer, Zweiter Theil, S. 6f. und 41 f. sowie Über Liberalismus und Servilismus in den strenge so genannten konstitutionellen Monarchien, in: NEUE MONATSSCHRIFT FÜr DeUTSChland, Historisch-Politischen Inhalts 41 (1833), S. 336-54.

60 KRUG, Der falsche Liberalismus, S. $10 \mathrm{f}$.

61 Ebd., S. 15.

62 DERS., Allgemeines Handwörterbuch der philosophischen Wissenschaften nebst ihrer Literatur und Geschichte. Nach dem heutigen Standpuncte der Wissenschaft bearbeitet, Bd. 2, 2. Aufl. Leipzig 1833, S. 725.

63 DERS., Der falsche Liberalismus, S. $17 \mathrm{f}$. 
der republikanische Zielhorizont nach der Durchsetzung der Julimonarchie selbst in Frankreich zur Oppositionsideologie geworden war und auch bei den außerparlamentarischen Gruppen in Deutschland keinesfalls dominierte, stellte die Republik von nun an eine besonders wirkungsmächtige Negativprojektion im politischen Diskurs dar. Die hier deutlich werdende Diskrepanz zwischen der realen Situation, in der eine republikanische Revolution in Deutschland eine Utopie darstellte, und der subjektiv empfundenen oder stilisierten Bedrohung reflektierte nicht allein die politische Sensibilisierung zu Beginn der 1830er Jahre, sondern vor allem die langfristige und tiefgreifende semantische Wirkungskraft des Schlagworts Republik als gleichsam natürliche Konsequenz jeder revolutionären Umwälzung. Für die Bestimmung von Liberalismus hatte das zeitgenössische Schreckbild der Republik weitreichende Folgen, denn es katalysierte die Ausbildung ideologischer Konfliktlinien zwischen verschiedenen Oppositionsgruppen und -strategien und setzte dem Integrationsanspruch von Liberalismus eine deutliche Grenze.

Hatte Krug den Liberalismus 1823 als primär universalhistorisches Deutungsmuster eines naturgesetzlichen Fortschritts charakterisiert, verwies er $1832 \mathrm{sehr}$ viel deutlicher auf die Alternative zwischen fundamentaler Opposition und einem auf Konsens mit der Regierung ausgerichteten Kurs. Die unversöhnliche Blockadehaltung des "falschen Liberalismus“, der „gegen alles" opponiere, „was seinen egoistischen Absichten widerstreitet“, lehnte Krug ebenso $\mathrm{ab}$ wie einen reinen Dualismus von Regierung und Parlament, in dem die Opposition nur die "Regierung in Verlegenheit setzen, ibre Kraft läbmen" würde. ${ }^{64}$ Für ihn sollten die Volksvertreter vielmehr "mit der Regierung im Namen des Volks verhandeln und, wenn die Regierung etwas Unrechtes gethan hat, der Regierung darüber Vorstellung machen. "Diese Position reduzierte die Rolle des Parlaments auf die eines Verhandlungspartners, dessen konkrete Sanktionsgewalt im unklaren blieb. Die nur angedeutete Kontroll- und Vermittlungsfunktion des Parlaments charakterisierte mithin einen defensiven Konstitutionalismus, dessen Ziel primär in der Übereinkunft mit der Regierung unter Umgehung einer Blockade zwischen opponierendem Parlament und staatlicher Machtsphäre bestand. Die extreme Opposition der „Pseudo-Liberalen“ und ihre Unfähigkeit zur Kooperation kennzeichne die „allerschlechteste Sorte von Liberalismus".65 Dieser Position, die den Konflikt gleichsam

64 Ebd., S. 32 f.; vgl. zur Bestimmung des Begriffes der Oppositionspartei auch WILHELM TRAUgotT KRUg, Ueber Oppositions=Parteien in und außer Deutschland und ihr Verhältniß zu den Regierungen. Nebst einem Nachwort über eine merkwürdige politische Prophezeihung (1835), in: [DERs.] Gesammelte Schriften, Bd. 5, S. 155-92.

65 Ders., Der falsche Liberalismus, S. $36 \mathrm{f}$. und weiter ebd.: „Aber das Davonlaufen, was weder Muth noch Geschicklichkeit verräth und noch überdieß der übernommenen Verbindlichkeit gegen die Kommittenten sowobl als gegen die Regierung widerstreitet, ist, wenn es etwa doch als eine Art von Opposizion gelten sollte, weit mehr einem kindischen Trotze als einem männlichen Widerstande zu vergleichen. Und doch werden diese Deputirten von unsern Pseudo-Liberalen beinabe als Helden gepriesen." 
zum Programm erhob, ordnete Krug auch die „unbedingte“ Pressefreiheit zu, die unweigerlich in "Pressefrechbeit" münde und die notwendige gesetzliche Ordnung offen in Frage stelle. Seine Kritik faßte er in dem Gegensatz zusammen, der zwischen Reform in den Bahnen des Rechts als Erwartungshorizont des echten Liberalismus einerseits und der Revolution und dem Anspruch auf Durchsetzung aller Forderungen als Kennzeichen des falschen Liberalismus andererseits herrsche. Diesen über Deutschland hinausgehenden Bedeutungszusammenhang reflektierte Krug, indem er als Beispiel gelungener politischer Mäßigung und zeitgemäßer Reform die englische Reform Bill von 1832 anführte. ${ }^{66}$ Die Radicals verkörperten dabei für ihn die englische Spielart der „Psendo-Liberalen“, denen wie in Frankreich oder Deutschland die Geduld für eine langfristige Reformstrategie fehle: 67

Aber daran feblt's eben jenen Liberalen. Sie möchten lieber an einem Tage säen und ernten. Wie mit einem Zauberschlage möchten sie gern alle Verbesserungen, die sie im Kopfe haben ... auf einmal durchsetzen. Ein solcher Zauberschlag aber ist keine Reform, bei welcher die gesetzliche Ordnung nicht unterbrochen wird, vielmebr alles sich, dem stetigen Gange der Natur gemäß, allmählich entwickelt, sondern eine Revoluzion, eine plötzliche Umkebrung aller gesellschaftlichen Verbältnisse, wobei es obne Bürgerkrieg, obne Blutgerüste und Plünderungen, schwerlich abgeht.

Dieser europäische Erfahrungshintergrund bestimmte für Krug auch die Deutung des echten Liberalismus: Dieser mußte dem Programm eines evolutionären Reformkurses folgen, um eine Revolution nach französischem Muster in Deutschland zu verhindern. Indem sich der falsche Liberalismus „, auf das Aeußerste“ werfe und zum „Ultraismus" werde, ${ }^{68}$ war für Krug zugleich auch die mit ihm verbundene „Bewegung “ diskreditiert, der die außerparlamentarische politische und soziale Protestformation in den Jahren nach 1830 kennzeichnete. ${ }^{69}$ Krug sah dadurch das „Gewisse, das wir schon besitzen“, also die bisher gewährten Verfassungen und vorhandenen parlamentarischen Institutionen, durch das utopische Ziel einer Republik gefährdet, ein „Ungewisses, das wir erst mit großen Opfern an Gut und Blut erkaufen sollen. "Den wabren Liberalismus koppelte er daher an den politisch-konstitutionellen status quo, das

66 Ebd., S. 38; vgl. ebd., S. 45.

67 Vgl. Wolfgang MenZel, Europa im Jahr 1840, Stuttgart 1839, S. 17, wo Menzel den Begriff Radikalismus auf England anwendet.

68 KRUG, Der falsche Liberalismus, S. 45-8; symptomatisch für diese Auffassung ist auch das von Krug häufig zitierte Wortspiel „Der Servile will sehr viel, der Liberale aber lieber alles", was er allerdings nur auf die "Psendo- oder Ultraliberalen" angewandt wissen wollte, vgl. ebd., S. 2 und DERS., Handwörterbuch, S. 725; zur Verwendung von servil vgl. Ist der ,Freisinnige‘ wirklich ein Serviler, in: DER FrEISINNIGE. Freiburger politische Blätter, Nr. 76, 16. Mai 1832.

69 Vgl. KRUG, Der falsche Liberalismus, S. 49: „Ihr nennt euch Männer der Bewegung. Seltsamer Name, wenn ibr damit andeuten wollt, daß ibr immerfort nach dem Bessern strebt. Denn das thun alle vernünftige Leute. Zum Streben nach dem Bessern gebört aber nicht bloß Bewegung. Denn ibr könntet euch ebensowobl rückwärts als vorwärts bewegen." 
"Bestehende, die monarchische Staatsform" und verpflichtete die künftigen Volksvertreter auf diesen evolutionären Konstitutionalismus. Dies enthielt zugleich eine sozial exklusive Konnotation, da Krug den falschen Liberalismus vor allem mit der Revolutionsneigung der unteren Gesellschaftsschichten identifizierte:

Diese [i.e. die Volksvertreter der landständischen Versammlungen der deutschen Staaten] müssen vor allen Dingen jenem falschen Liberalismus entsagen, der bisher das Werk der Freibeit in Deutschland so gehemmt hat und uns sogar wieder um das schon Erworbne zu bringen drobt. Aber auch ganz und von Herzen müssen sie ibm entsagen, nicht blo $\beta$ mit ibm unterhandeln, sondern unwiderruflich mit ihm brechen, damit er sein Ansehn und seinen Einfluß auf die so leicht und darum auch so leicht irre zu führende Menge verliere.

Diese Position wandte sich gegen jede direkt verstandene Volkssouveränität, die Krug im „Psendo-Liberalismus" verkörpert sah. Eine Bindung des einzelnen Abgeordneten widersprach dem Ideal weitestgehender Unabhängigkeit und Gewissensfreiheit des individuellen Parlamentariers, dem er riet, falls „in den Wablversammlungen pseudo-liberale Wäbler ... den Wäblbaren vorschreiben ..., wie sie stimmen sollten“, besser „auf die Ehre der Wabl [zu] verzichten ... als sich durch Fesselung ibres Gewissens zu Stimm-Maschinen herabwürdigen zu lassen" ${ }^{70}$ Der von seinen Extremen befreite wabre Liberalismus blieb für Krug das Synonym für eine individuelle und damit dem Zwang einer Partei enthobene Gesinnung. Dies rekurrierte auf eine dem gebildeten Staatsbürger eigene Disposition, die über dem politischen Tageskampf stand und die ihn aufgrund seiner vernünftigen Bildung zur Verantwortung für Staat und Gesellschaft prädestinierte, ohne ihn zum bloßen Mandatsträger zu reduzieren. Genau diesem Ideal entsprach auch die semantische Qualität des Adjektivs "freisinnig ", auf das Krug 1833 zur Definition von liberal zurückgriff. ${ }^{71}$ So oft dieses Adjektiv bereits in früheren lexikalischen Definitionen aufgetreten war, so deutlich schälte sich in den 1830er Jahren der veränderte Bedeutungszusammenhang heraus. Es lehnte sich noch deutlich an die vorpolitische Bedeutungsdimension von liberal an, verwies aber unter den veränderten Handlungsbedingungen und Erfahrungen auf den Gegensatz zwischen individueller Gesinnung einerseits und einem Konformitätszwang andererseits, der die negative Bewertung des zeitgenössischen Parteibegriffs dominierte. ${ }^{72}$

Krugs semantische Differenzbestimmung von wabrem und falschem Liberalismus sollte bei aller Kontrastierung jedoch nicht zum Fehlschluß eines vorzeitigen und irreversiblen ideologischen Antagonismus zwischen den Begriffen führen: Indirekt blieb der Zusammenhang zwischen beiden Liberalismen nämlich zunächst noch deutlich faßbar. Die Unterschiede schienen primär die politische Strategie zu betreffen, während der gemeinsame Ursprung im legitimen

70 Ebd., S. 51 und 54f.

71 Vgl. Krug, Handwörterbuch, S. 723; zum Begriff des Freisinnigen vgl. WilHELM SAUERWEIN, ABC=Buch der Freiheit für Landeskinder, Hanau 1832, S. 18-21.

72 Vgl. Theodor Schieder, Die Theorie der Partei im älteren deutschen Liberalismus, in: DeRs., Staat, S. 110-32. 
Anspruch auf eine Synchronisierung von zivilisatorischer Fortschrittsidee und konkreter politisch-gesellschaftlicher Wirklichkeit lag. Während der wabre Liberalismus eine systemimmanente Reform anstrebte, transzendierte der Gehalt des falschen die Bahnen des von Krug intendierten evolutionären Konstitutionalismus. Signifikant für diese Differenzierung, die noch keine endgültige ideologisch-inneroppositionelle Trennung markierte, war wiederum die semantische Bezeichnung selbst: Noch war es nämlich möglich, die Unterschiede auf der Basis von wabrem und falschem Liberalismus zu konturieren oder die Bestandteile des Wortfeldes mit dem Präfix Ultra zu versehen. Die negative Bestimmung einer konkurrierenden Nomenklatur etwa im Begriff des Radicalismus, der den falschen Liberalismus als entgegengesetzte Ideologie ausgegrenzt hätte, suchte man bei Krug vergebens. Darin manifestierte sich noch immer die Erwartung einer gesamtgesellschaftlichen Integration aller vernünftigen Interessen in Liberalismus.

\section{c) Gesinnungsattribut oder Parteibegriff?}

Die bisher vorgestellten semantischen Bestimmungsmuster unterstreichen den Schwellencharakter der Jahre 1830-1832: Hier begann sich vor dem spannungsreichen Hintergrund von politischer Aufbruchstimmung und repressiver Blockade jene Entwicklung abzuzeichnen, die schließlich zur semantischen Spaltung der Oppositionsbewegung in einen demokratischen Radicalismus und einen konstitutionell-gemäßigten Liberalismus führen sollte. Hinter diesen distinkten Ismen standen immer deutlicher inneroppositionelle Interessengegensätze. Die begriffsgeschichtliche Analyse zeigt, wie früh die vielfältigen Bemühungen um Definition eines noch gerechtfertigten und damit verbindlichen Liberalismus einsetzten. Sie erfolgte seit 1830 immer stärker durch die defensive Abgrenzung der Entartungen der „Ultraliberalen“ gegenüber den gemäBigten und vernünftigen Prinzipien der Aufklärung. ${ }^{73}$ Hinter der Diskussion um wabren und falschen Liberalismus stand insofern nichts weniger als die Vorwegnahme einer fundamentalen Richtungsentscheidung innerhalb der vormärzlichen Oppositionslandschaft: Bereits um 1832 antizipierte die semantische Differenzierung die realhistorische Entkopplung verschiedener Proteststrategien und gleichzeitig die Kategorisierung ihrer Träger in unterschiedliche ideologische Lager mit distinkten Eitketten, so etwa durch die Verwendung des Präfix Ultra.

Es zählt indes zu den spezifischen Kennzeichen des Deutungsmusters Liberalismus in Deutschland, daß über der konfliktreichen Auseinandersetzung um

73 Vgl. Brief Stüves an Frommann vom 3.-5. April 1832, in: STÜVE, Bd. 1, S. 252: „Unsere Ultraliberalen schimpfen jetzt auf Goethe, ärgern sich, daß man auf den Aristokraten noch etwas gibt, und nennen ibn einen Philister. Es ist bald eine Ebre, von dem Pack angefeindet zu werden. "; vgl. [JOSEPH FrHR. vON HORMAYER ZU HORTENBURG] Anemonen aus dem Tagebuch eines alten Pilgersmannes, Bd. 1, Jena 1845, S. 53. 
Strategien und Ziele einer politischen Bewegung, die sich nun nicht mehr nur von ihren ideologischen Gegnern, sondern auch von den inneroppositionellen Konkurrenten zur dauernden Selbstbestimmung herausgefordert sah, das Vertrauen in die Integrationskraft des echten Liberalismus als einer gemeinwohlorientierten Gesinnungsethik ungebrochen blieb. Die diesem zugrundeliegenden vernünftigen Prinzipien würden, so die Erwartung, früher oder später von allen, auch den Anhängern des extremen Liberalismus, erkannt und müßten sich daher naturgesetzlich durchsetzen. In dieser Integrationserwartung lag die Zukunftsverheißung des Begriffes begründet. Das ungebrochene Festhalten am Gesinnungsbegriff Liberalismus, das dem Individuum in der Freiheit von Partei- und Fraktionszwängen die Unabhängigkeit der eigenen Meinung beließ, den Bildungsbürger an die Ideale der Aufklärung band und den Staatsbürger auf systemimmanent-antirevolutionären Reformismus verwies, reflektierte das Bedürfnis nach einem harmonisierenden Ideal, das die auseinanderdriftenden Interessen einer in Bewegung geratenen Gesellschaft wie ein Zauberwort wieder zusammenführen sollte. Andererseits entstand aus diesem Nebeneinander von Bedeutungsdimensionen eine semantische Spannung, die auf die Frage hinauslief, ob Liberalismus ein Gesinnungsattribut in der Tradition der Aufklärung oder ein politisches Parteienetikett darstellte. Beide Deutungspole lassen sich auf unterschiedlichen Diskursebenen nachweisen.

\section{Realisierung der Rechtsidee und moralische Bildung des Volkes: Die Persistenz aufgeklärter Gesinnungsethik}

In primär gesinnungsethischer Deutung näherten sich die enzyklopädischen Artikel dem Begriff nach 1830.74 Der Brockhaus von 1833 skizzierte das Ideal einer umfassenden Emanzipation, indem er den Liberalismus bewußt nicht auf die politische Sphäre reduzierte. „Grundton des Liberalismus “ seien

Freibeit, Unabbängigkeit, Selbständigkeit ..., aber nicht die bürgerliche und politische Freibeit allein, sondern die Befreiung von jeder naturwidrigen Schranke, welche dem menschlichen Geiste entweder von außen her gesetzt werden soll, oder in welcher er durch eigne Untätigkeit gefangen gehalten wird. ${ }^{75}$

Hinter dieser Charakterisierung stand gerade die für die lexikalische Definition verpflichtende Tradition der Aufklärung: Liberalismus wurde hier zum Synonym für einen bildungsbürgerlich intendierten Emanzipationsbegriff, sei es in zivilisatorischer, individueller oder politischer Perspektive. ${ }^{76}$ Diese Verbindung stattete den Bewegungsbegriff gleichsam mit einer ethischen Legitimation und universellen Gültigkeit aus, die ihn von jeder bloß politischen Bewegung unterschied. Diesem Bekenntnis zur Aufklärung entsprach die Betonung des

74 Vgl. Vierhaus, Liberalismus, S. 765.

75 [F. A. Brockhaus] Conversations-Lexicon der neusten Zeit und Literatur, Bd. 2, Leipzig 1833, S. 877.

76 Vgl. Neuestes Conversationslexikon für alle Stände. Von einer Gesellschaft deutscher Gelehrten bearbeitet, Bd. 4, Leipzig 1835, S. $420 \mathrm{f}$. 
selbständigen Individuums im „Ringen nach den höhern Gütern der Menschheit, nach einer Freiheit, die ibre Quelle wie ihren Kampfplatz vorzüglich im eignen Herzen und Geiste hat, nach einer Selbständigkeit, welche über jeden Zwang von außen erbaben ist. "In politischer Hinsicht sei der Liberalismus an keine Staatsform gebunden und müsse „keine Partei, sondern eine Gesinnung “ sein. Dies knüpfte an die ursprünglich vorpolitische Bedeutung der Liberalität der Denkungsart an, und es unterstrich vor dem Hintergrund der Differenzierung des politischen Spektrums die integrative Funktion, den überparteilichen Charakter des wahren Liberalismus. Jedes ,gewaltsame, ungesetzliche Eingreifen in die bestehenden Verbältnisse" widerspräche seinem Charakter. Seine Anhänger seien gerade keine Revolutionäre, sondern akzeptierten, „daß sie dem Bestehenden Trene schuldig sind, daß aber diese Trene hauptsächlich darin besteht, die naturgemäße Fortbildung zu größerer Vollkommenheit fördern zu helfen." Diese allmähliche Verbesserung schien naturgesetzlich prädestiniert; sie durch vorsichtige Reformen zu unterstützen, war die berechtigte Aufgabe der Liberalen, sie hingegen gewaltsam zu erzwingen, ohne die bestehenden Institutionen zu achten, mußte den Begriff in der politischen Öffentlichkeit zwangsläufig diskreditieren. Die genuin politischen Forderungen des Liberalismus, der seit einem halben Jahrhundert „seine Richtung vorzugsweise auf das Staatsleben genommen" habe, faßte der Autor als "Realisierung der Rechtsidee" zusammen: „Öffentlichkeit der Staatsverwaltung, Preßfreiheit, Verantwortlichkeit der Beamten für alle Regierungshandlungen, Land- und Reichsstände mit ibren Attributen, Gleichheit vor dem Gesetz, vorzüglich in Ansebung der gleichen Fähigkeit zu Staatsämtern". 77

Die Bedeutung, die der Autor der Gefährdung des Liberalismus beimaß, stellte eine deutliche Reaktion auf die zeitgenössische Diskussion von 1830/32 dar. Sie dokumentierte die veränderte semantische Richtung von Liberalismus, die wachsende politisch-gesellschaftliche Polarisierung nach 1830 und das weite Spektrum an Strategien zur Reform von Staat und Gesellschaft. Gerade die Trennung eines „echten“, „eigentlichen“, „ursprünglichen“ oder wabren Liberalismus von scheinbaren Verirrungen, die überwiegend „links“, also im Lager vermeintlich republikanisch gesinnter Umstürzler und Revolutionäre nach französischem Muster angesiedelt schienen, verwies auf die konnotative Flexibilität eines politischen Begriffs, den um 1830 noch immer verschiedene Gruppierungen als identifikatorisches Etikett für sich in Anspruch nehmen konnten. Vor dem Hintergrund einer dynamischen Politisierung reagierten die Autoren auf die damit verbundene definitorische Unübersichtlichkeit, in der liberal zum vermeintlich bedeutungslosen, lediglich tagespolitischen Schlagwort zu degenerieren drohte, mit einem programmatischen Rückgriff auf die vorpolitische Bedeutungsdimension. Diese gesinnungsethische Aufladung von Liberalismus sollte den Revolutionsvorwurf entkräften und entsprach zugleich dem Individuum als semantischem Fluchtpunkt für jeden vernünftigen Fortschritt: 
Liberalismus als aufgeklärte Gesinnung blieb mit der Idee von Partei als einer von außen aufgezwungenen Institution unvereinbar. Wo der Begriff „liberale Parte $i$ “ in der Publizistik auftrat, verkörperte er keinesfalls eine feste Organisation, sondern eine allgemeine politische Orientierung. ${ }^{78}$ Die deutlich negative Konnotation von Partei resultierte aus der Vorstellung einer ungerechtfertigten Beschleunigung des natürlichen Fortschritts:

So viel aber ist gewiß, daß es eine Verwirrung des Liberalismus ist, wenn er seine eigentümliche Bahn des individuellen redlichen Wirkens für Wabrheit und Recht verläßt, um durch Verbindung zu einer Partei... dasjenige von außen her zu erreichen, was nur von innen heraus durch Lebre und Beispiel gefördert werden kann. ${ }^{79}$

Warnend wandte sich der Brockhaus von 1835 gegen ein zu enges Verständnis von Liberalismus, das sich lediglich an äußeren politischen Erfolgen orientierte - eine kritische Reaktion auf die Forderungskataloge oppositioneller Parlamentarier und des politischen Vereinswesens. Demgegenüber müsse sich jede Verbesserung organisch aus der inneren, „moralischen Bildung des Volkes“ ergeben und dürfe nicht „von außen herein aufgedrungen werden“:

Man ist ... noch nicht wahrhaft liberal, wenn man als Kämpfer für Preßfreibeit, öffentliche Rechtspflege, Geschworene, landständische Verfassung auftritt ... Der echte Liberalismus ist nichts als die Liebe der Wabrheit und der Gerechtigkeit, welche in sich selbst ibre Stärke findet und von äußern Umständen unabhängig ist; der falsche hingegen sucht eine äußere Macht; er erbebt das Banner einer Partei, und daber gibt es bei ibm so viele Abtrünnige. ${ }^{80}$

Diese weit über die politisch-konstitutionelle Sphäre hinausweisende Deutung ließ einen Interessenantagonismus, sei es zwischen Staat und Gesellschaft oder zwischen sozialen Gruppen, nicht zu. Sie suchte Liberalismus durch eine gesinnungsethisch-universelle Projektion gleichsam jeder politischen Konfliktkonstellation zu entheben.

\section{Die Genese der tripolaren Kontur von Liberalismus zwischen radicaler Kritik und conservativer Absetzung}

Die Erfahrung der frühen 1830er Jahre bewirkte neben der allgemeinen Dynamisierung des politischen Diskurses und der publizistischen Verbreitung von liberal/Liberalismus auch eine zunehmend kritische Reflexion über den Bedeutungsgehalt des Begriffs. Darin spiegelte sich eine Ausdifferenzierung von unterschiedlichen Interessen innerhalb der Oppositionsbewegung. So wandte sich David Hansemann gegen die allzu idealistisch-weltfremde Tendenz der deutschen gegenüber den französischen Liberalen mit deren dezidiert politi-

78 Vgl. [ReInhard] Ueber jetzige Zeit und Deutschlands zeitgemäße Politik. Vom Staatsrath Reinhard in Karlsruhe, Karlsruhe 1831, S. 9 sowie Friedrich GenTZ, Betrachtungen über die politische Lage Europas (1831), in: DeRs., Staatsschriften, Bd. 2, S. 101-10, hier S. 103.

79 BROCKHAUS, 1833, S. 881.

80 [F. A. BROCKHAUS] Allgemeine deutsche Real-Encyclopädie für die gebildeten Stände. Conversations-Lexicon, Bd. 6, 8. Aufl. Leipzig 1835, S. 631 f. 
scher Programmatik, wenn er den Liberalen in Deutschland bescheinigte, sie seien „, häufig mehr philanthropisch als national der Freibeit ergeben. “ Kritisch schätzte er im Gegensatz zu Pfizer auch die „Konstitutions-Sucht ... bei manchen Liberalen in den kleinen deutschen Staaten" ein. ${ }^{81}$ Gegenüber solcher Kritik, in denen implizit die Bedenken des erstarkenden rheinischen Wirtschaftsbürgertums deutlich wurden, das die Vertretung seiner spezifischen Interessen einforderte, betonte Heinrich von Gagern, es sei gerade „die Partei der Bewegung, die liberale Meinung "gewesen, die nach der belgischen Revolution die Unverletzlichkeit der deutschen Territorien verteidigt, also politisch stabilisierend für Deutschland als Ganzes gehandelt habe. ${ }^{82}$

Eine Richtungsänderung in der semantischen Bestimmung ließ sich aber auch bei tendenziellen Anhängern ausmachen. Varnhagen von Ense, der die gemäßigte Bewegung des Jahres 1830 durchaus noch begrüßt hatte, konstatierte mit Blick auf Frankreich, daß mit dem Saint-Simonismus „der Liberalismus seine heilsamste Umwandlung " erfahre. Die „Liberalen" forderten "für die Massen metaphysische Rechte, allgemeines Stimmrecht und dergleichen", wo in Wirklichkeit "moralische, intellektuelle und physische Verbesserungen" notwendig seien. 83 Theodor Mundt kritisierte die mit der Selbstbezeichnung liberal verbundenen überspannten Erwartungen: Es sei offenkundig,

daß jene Liberalen, die, von der Aufregung der letzten Weltereignisse ergriffen, in dem Wabn einer maßlosen Perfectibilität der Völkerzustände umberschwärmen, daß jene Liberalen in Deutschland es sind, die an der Verwirrung und Überreizung der Zeit fast planmäßig arbeiten, indem sie sich gewisse politische Abstractionen ausgedacht haben, die sie unter der beliebten Fabne des Zeitgemäßen und Zeitbedürfnisses ausflattern lassen. ${ }^{84}$

Als Folge der Ereignisse zu Beginn der 1830er Jahre geriet Liberalismus verstärkt in die Schußlinie konservativer Autoren, die wie Joseph Maria von Radowitz in ihm eine gefährliche "politische Irrlehre" erkannten. ${ }^{85}$ Die restaurative Kritik der 1820er Jahre gewann jetzt deutlichere Konturen, nicht zuletzt

81 [David Hansemann] Preußen und Frankreich. Staatswirthschaftlich und politisch unter vorzüglicher Berücksichtigung der Rheinprovinz. Von einem Rheinpreußen, Leipzig 1833, S. 309 und 208.

82 Heinrich von Gagern, Rede vom 9. Mai 1834, in: Ders., S. 137.

83 Karl August Varnhagen von Ense, Politische Stimmen in Frankreich, in: Augsburger Allgemeine Zeitung, Nr. 145, 17. April 1832; vgl. Werner Greiling, Varnhagen von Ense. Lebensweg eines Liberalen. Politisches Wirken zwichen Diplomatie und Revolution, Köln 1993, S. 88.

84 Theodor Mundt, Die Einheit Deutschlands in politischer und ideeller Entwickelung, Leipzig 1832, S. 9; vgl. ferner Die liberal gewordenen Jahres Zeiten. Von einem Beobachter der Zeitsymptome des 18ten und 19ten Jahrhunderts, Rottenburg 1834 sowie Christian Schwarz, Der Liberalismus unserer Tage. Rede zu der Feier des Geburtsfestes Sr. Majestät des Königs Wilhelm am 27. September vorgetragen im K. Gymnasium zu Ulm, Ulm 1839.

85 [JOSEPH Maria VON Radowitz] Die Varietäten des Liberalismus, in: BerLINER POLITISCHES WoCHENBLATT 31 (1832), S. 200; vgl. Radowitz' Anmerkungen zu Radikalismus in Ders., Gesammelte Schriften, Bd. 4: Fragmente. Erster Theil, Berlin 1853, S. 23 f., 60 f. und 190. 
durch die Formierung eines eigenen politischen und publizistischen Forums, wie es vor allem das Berliner Politische Wochenblatt und der Zirkel um Radowitz und Carl Ernst Jarcke verkörperten.86 Mit der Wendung gegen das neue politische Deutungsmuster Liberalismus ging eine genauere Bestimmung der eigenen Richtungsposition einher. Radowitz identifizierte die Liberalen mit „den mittleren Classen der Gesellschaft, in deren Hände die Umwälzungen der letzten 40 Jabre einen unverhältnismäßigen Einfluß gelegt" hätten. ${ }^{87}$ Das Berliner Politische Wochenblatt sah die eigentliche Gefahr des „doktrinären Liberalismus", der eine "Mitte ... zwischen Despotismus und Revolution" darstelle, in der Verschleierung einer im Grundsatz revolutionären Ideologie:

[Der] doktrinäre Liberalismus ist seinen Prinzipien nach nichts weniger als eine Ausschließung jener beiden Kalamitäten, er ist eine Mischung aus beiden, und Revolution und Despotismus haben sich freundbrïderlich in ibn geteilt, dergestalt, daß die liberale Doktrin der Monarchie gegenüber, also nach oben hin, nichts weiter als eine, vielleicht nur hinter milden gemäßigten Reden versteckte, durch scheinbare Gelebrsamkeit und eine gewisse Bildung verschleierte, aber eben deshalb viel gefährlichere Revolutionstheorie [ist]. ${ }^{88}$

Für Jarcke sollte der dem „Jacobinismus “ähnliche, aber „in seinen Formen aber viel gefälligere, und deshalb tausendmal gefährlichere, doctrinelle Liberalismus" durch das Berliner Politische Wochenblattes bekämpft werden. Der „moderne, liberale Constitutionalismus" sei von der „absoluten Beamtenherrschaft" zu unterscheiden, indem jener keine „Repräsentation des Volks oder aller Individuen“ fordere, „sondern die Vertretung der herrschenden Zeitmeinungen und Ansichten". 89 Dies führe notwendig zu einer Vernichtung des Rechtsbegriffes, indem der

liberale Constitutionalismus ... wenn man in die Grundtiefe seiner Metaphysik eingeht, den herrschenden Zeitmeinungen und Ansichten, so wie deren (ideellen) Interessen, oder mit einem Worte dem Zeitgeiste ausschließlich das Recht beilegt, zu bestimmen, was Recht sey und unbeschränkt über alle Privatfreibeit und jedes Privatrecht zu gebieten. 90

86 Vgl. Wolfgang Scheel, Das Berliner Politische Wochenblatt und die politische und soziale Revolution in Frankreich und England. Ein Beitrag zur konservativen Zeitkritik in Deutschland, Göttingen 1964, S. 89 ff.; vgl. die entsprechenden wichtigen Artikel des Berliner Politischen Wochenblatts: Die politischen Partheien, in: ebd., Nr. 35 (1832); Zeitgeschichte. Frankreich bei Eröffnung der Session von 1833. Der konstitutionelle Liberalismus, in: ebd., Nr. 8 (1833); Die Kraft und die Schwäche des Liberalismus, in: ebd., Nr. 42 (1833); Geständnisse des reuigen Liberalismus, in: ebd., Nr. 1 (1836); Endziel des constitutionellen Liberalismus, in: ebd., Nr. 2 (1836); Der Liberalismus als Glaube, in: ebd., Nr. 2 (1837) sowie Constitutionelles, in: ebd., Nr. 9 (1839).

87 RADOwITZ, Varietäten, S. 200.

88 [Ders.] Der doctrinaire Liberalismus, in: Berliner Politisches WochenblatT 12 (1832), S. 77-80, hier S. 77-9.

89 Carl ERnSt Jarcke, Die öffentliche Meinung (November 1831), in: Ders., Vermischte Schriften, Bd. 1, München 1839, S. 31-46, hier S. 40 sowie Ders., Stiftung, Zweck und Tendenz des Berliner Politischen Wochenblattes (Oktober 1831), in: ebd., Bd. 1, S. 1-30, hier S. 27.

90 Ders., Der Absolutismus (Sommer 1832), in: DERs., Schriften, Bd. 1, S. 132-65, hier 
Noch deutlicher äußerte sich 1834 die Frankfurter Ober-Post-Amts-Zeitung, wenn sie den Liberalismus der Gegenwart mit dem demokratischen „Radikalismus" identifizierte und darin eine Degeneration seiner ursprünglichen Bedeutung erkannte. Der Liberalismus der Gegenwart wurde hier im Gegensatz zu Krugs Interpretation mit der Gefährdung jeder stabilen politischen Ordnung gleichgesetzt:

Wie hat dies ursprünglich Reines und Edles bezeichnende Wort seinen Sinn verloren! Es ist nicht mehr, was es war. Die Faction des Umsturzes hat seinen Gehalt umgegossen, und doch den alten Namen darauf geprägt. Deshalb wird man es auch keinem Freunde der Ordnung verargen, wenn er - die sich in Gesinnungen und Handlungen beurkundende ächte Liberalität hoch ehrend - doch den Namen eines Liberalen endlich von sich stößt. Der Liberalismus ist zum Radikalismus geworden. ${ }^{91}$

Hinter dieser Äußerung wird der begriffsgeschichtliche Mechanismus deutlich, der das Verhältnis des Liberalismus zu seinen Kritikern in den 1830er Jahren bestimmte: Das breite Spektrum von oppositionellen Gruppen, die den Begriff für sich in Anspruch nahmen und die damit verbundene semantische Erweiterung hatten zu einer konnotativen Umprägung des ursprünglichen Bedeutungsgehalts geführt. Von diesem konnten sich konservative Autoren distanzierten, indem sie den Verfall der ursprünglichen Bedeutung betonten, während radikal-demokratische Kritiker gerade das Beharren der Liberalen auf scheinbar anachronistischen Prinzipien angriffen. Hier zeichnete sich ein langfristig folgenreicher Gegensatz zwischen der dem Begriff zugesprochenen Integration aller vernünftigen Zeitkräfte auf der einen und der sich faktisch entfaltenden Tripolarität des politischen Kräftespektrums auf der anderen Seite ab, in dem der Liberalismus zwischen radicaler und conservativer Kritik stand. Entsprechend trennte der Autor der Ober-Post-Amts-Zeitung eine vorpolitische Gesinnung, die „ächte Liberalität", von einem neuen politisierten Liberalismus, den man mit den umstürzlerischen Umtrieben politischer Radikaler identifizierte. Darin spiegelte sich die politische Konfliktphase der beginnenden 1830er Jahre, die, wie im Frankfurter Wachensturm und in den oberhessischen Oppositionszirkeln um Georg Büchner und Friedrich Ludwig Weidig, auch Versuche revolutionärer Aufstände einschloß. Dem derart erneuerten Revolutionsverdacht wuchs bei der Diskreditierung der Liberalen eine zentrale argumentative Funktion zu:

Furcht vor der Revolution erweckte Abschen vor allem, was etwas anderes wollte und dachte, als was bestand, weil die Revolutionäre sich für Männer des Fortschrittes ausgege-

S. 162; vgl. zur kritischen Wendung gegen den Begriff Ders., Revolution und Absolutismus (Februar 1833), in: ebd., S. 166-203, hier S. 183; DerS., Absolutismus, Gerechtigkeit und Gemeinwohl (September 1834), in: ebd., S. 63-81, hier S. 72; Ders., Ueber die Wirksamkeit der loyalen Presse (Dezember 1835), in: ebd., S. 52-62, hier S. 62; DERS., Ist die Theorie der Volkssouveränität in unsern modernen Staaten praktisch realisierbar? (Dezember 1837), in: ebd., S. 204-7, hier S. 204.

91 Aus dem Großherzogthum Hessen, in: Frankfurter Ober-Post-Amts-Zeitung, Nr. 144, 5. Juni 1834. 
ben hatten, so wurden die Männer des Fortschrittes nun für Revolutionäre gehalten. Wenn man früher stolz auf die Bezeichnung liberal gewesen war, so wurde dieses Epitheton jetzt zum Schimpfwort und zur Anklage, und hieß soviel als unrubig, intrigant, subversiv, gefäbrlich. ${ }^{92}$

Auch Friedrich Julius Stahl grenzte, von einem christlich-organischen Staatsverständnis ausgehend, den Liberalismus als naturrechtliche Ableitung und revolutionäre Ideologie aus: „Ist diese Darstellung von dem Wesen des Staates richtig, so folgt daraus von selbst die Nichtigkeit jener Lebre, welche den Staat als eine Gesellschaft der Menschen zum gegenseitigen Schutz ibrer Freibeit betrachtet: der Lebre des Naturrechts, des Liberalismus, der Revolution". ${ }^{93}$ Stahls Prämisse gründete auf der Zurückweisung des Rationalismus, der die ethischen und rechtlichen Beziehungen aus naturrechtlich verankerten Vernunftprinzipien bestimmte. Der politische Liberalismus verkörperte für ihn genau diese abstrakte Ableitung, die in der Revolution ihre Fortsetzung fand. Von daher unterschieden sich für ihn Revolution und Liberalismus lediglich wie Praxis und Theorie:

Der Liberalismus oder die Revolution in diesem Sinne ist die Wirkung eben der Prinzipien, auf welchen das ,Naturrecht' berubt. Sie erscheinen hier in ibrer letzten folgerichtigen Durchbildung wie dort in ibrer untersten Grundlegung, hier von ibrer praktischen wie dort von ibrer theoretischen Seite. Das Naturrecht sucht apriorische Erklärung und Rechtfertigung des Staates, die Revolution dagegen apriorische Errichtung und Gestaltung des Staates. Das heißt: jenes macht den Versuch, den Staat in Gedanken abzutun und rein aus der Vernunft zu deduzieren, diese macht den Versuch, ibn in der Wirklichkeit abzutun und rein aus der Vernunft einen neuen zu gründen. Nach beiden aber wird der Vernunftstaat bloß auf dem Gedanken der Freibeit oder des Willens des Menschen aufgefübrt. ${ }^{94}$

Die Identifizierung des Liberalismus mit dem modernen „Repräsentatifsystem“ forderte die neoständische Kritik heraus, wenn auf die notwendige Verteidigung „des germanisch-bistorischen concret-natürlichen Stände-Systems mit, neben und unter dem Schutze einer freien bistorischen Autorität" verwiesen wurde. ${ }^{95}$ Den Optimismus, mit dem Wilhelm Traugott Krug die geschichtliche

92 Ueber das Ständewesen in Preußen, in: Deutsche Vierteljahrsschrift Heft 3 (1842), S. $208 \mathrm{f}$.

93 Friedrich Julius Stahl, Die Philosophie des Rechts nach geschichtlicher Ansicht, Bd. 2/2: Christliche Rechts- und Staatslehre, Heidelberg 1837, S. 17; vgl. ebd., S. 18: „Der Staat ist nicht ein Zusammentritt, eine Gesellschaft von Menschen, sondern eine Anstalt, ein organisches Ganzes über ibnen, dem sie als dienende Glieder angehören, ein jegliches zu seiner bestimmten Stelle und Verrichtung. Und zwar ist er die Anstalt Gottes. Von Gott hat er seine Vollmacht und sein Anseben. Deshalb ist er Träger der Majestät, die nicht von Menschen, sondern allein von Gott ausgehen kann."

94 Ebd., Bd. 1: Geschichte der Rechtsphilosophie, zitiert nach HANS-JOACHIM LIEBER (Hrsg.), Politische Theorien von der Antike bis zur Gegenwart, Bonn 1991, S. 347.

95 KarL Vollgraf, Die Täuschungen des Repräsentativsystems, oder Beweis, dass dieses System nicht das geeignete, rechte und zeitgemäße Mittel ist, den Bedürfnissen unserer Zeit zu begegnen; mit Andeutung der geeigneten, rechten und zeitgemäßen Reformen, Marburg 1832, S. 94; vgl. ferner [LUDwIG FÜRST ZU SOlms-LICH UND HoHENSOLMS] Deutschland und die Repräsentativverfassungen, Gießen 1838, S. 54 f. 
Entfaltung des Liberalismus noch 1823 nachgezeichnet und im Begriff des Perfectibilismus projektiert hatte, kehrte L. Peters $1831 \mathrm{um}$, indem er die „irregeleitete Religion" als Stütze des Liberalismus und das „strenge Recht" als seinen „natürlichen Feind" identifizierte. ${ }^{96}$ Hier kündigte sich die katholische Kritik des Deutungsmusters an.

Auf der anderen Seite wurde das politische Reformkonzept von Liberalen und Liberalismus gerade nach 1830 auch von den radikaler orientierten Oppositionellen kritisiert, ein Vorgang, der sich gerade im politischen Diskurs niederschlug. Der Differenzierungsprozeß innerhalb der Oppositionsbewegung wurde vor allem in den Attacken der Intellektuellen innerhalb der literarischen Bewegung des Jungen Deutschland gegen den überkommenen "nüchternen und hausbackenen Liberalismus" greifbar, "der sich zwischen der Monarchie und Republik seine gemütliche konstitutionelle Pfeife stopft" sowie gegen „alle bloß Konstitutionellen ... alle mit den Sätzen des Contrat social oder mit den Resultaten des kantischen Kritizismus sich obne weiteres begnügenden Politiker". 97 In den Auseinandersetzungen mit den literarischen Vertretern des Jungen Deutschland spielte der Rekurs auf liberal und Liberalismus immer wieder eine zentrale Rolle. ${ }^{98}$ Noch die Auseinandersetzungen zwischen Heinrich

96 L. Peters, Der Liberalismus in seiner weltgeschichtlichen Entwickelung, Leipzig 1831, S. 55; vgl. dagegen den positiven Rekurs auf liberal in der Wendung gegen den Papst bei Ludwig SNell, Die Bedeutung des Kampfes der liberalen katholischen Schweiz mit der römischen Kurie, betrachtet aus einer Gesammt-Uebersicht der Tendenzen des restaurirten Papstthums, Solothurn 1839.

97 Karl GutZKow, Erklärung gegen Dr. Menzel in Stuttgart, in: Augsburger AllgemeIne Zeitung, Nr.262, 19. Oktober 1835, Außerordentliche Beilage 374/375, S. 1497-9, zitiert nach Alfred EstermnN (Hrsg.), Politische Avantgarde 1830-1840. Eine Dokumentation zum Jungen Deutschland, Bd. 1, Frankfurt a.M. 1972, S. 67-70, hier S. 68 sowie [GUSTAv SCHLESIER] Spekulativer Radikalismus, in: Blicke auf deutsche Geisteswelt, in: Augsburger Allgemeine Zeitung, 11./12. November 1835, Außerordentliche Beilage 454/455/456, S. $1813 \mathrm{f}$. und $1821 \mathrm{f}$., zitiert nach ESTERMANN (Hrsg.), Bd. 2, S. 368-73; vgl. ferner WERnER Funk, Die Verfassungsfrage im Spiegel der Augsburger Allgemeinen Zeitung von 1818 - 1848, Berlin 1977, S. 97.

98 Vgl. als wichtigste Beiträge Victor Aimé Huber, Das junge Teutschland und das alte Mecklenburg, in: MECKLENBURGISCHE BläTTER, Nr. 2-3 (1834), S. 1-32, zitiert nach EstermanN (Hrsg.), Bd. 1, S. 23-41, hier S. 39; KARL GuTZKow, Appellation an den gesunden Menschenverstand. Letztes Wort in einer literarischen Streitfrage, Frankfurt a. M. 1835, zitiert nach ebd., Bd. 1, S. 93-101, hier S. 99; [ERNST WILHELM HENGSTENBERG] Über die Rehabilitation des Fleisches, in: EvANGELISCHE KIRCHENZEITUNG (1835), zitiert nach ebd. (Hrsg.), Bd. 1, S. 195-235, hier S. 210; Wolfgang MenZeL, Unmoralische Literatur, in: LITERATUR-BLATT (zum MORGENBLATT FÜR GEBILDETE STÄNDE) 109, 23. Oktober 1835, S. 435 f., ebd. 110, 26. Oktober 1835, S. 437-40, zitiert nach EstermanN (Hrsg.), Bd. 1, S. 56-64, hier S. 63; [SAmuel GotTlieb LiesCHING] Die Jeune Allemagne in Deutschland, Stuttgart 1836, zitiert nach ebd., Bd. 1, S. 159-64, hier S. 160; [GuSTAV PFIZER] Votum über das Junge Deutschland, Stuttgart 1836, zitiert nach ebd., Bd. 1, S. 149-59, hier S. 155; BerThOld Auerbach, Das Judenthum und die neueste Literatur. Ein kritischer Versuch, Stuttgart 1836, zitiert nach ebd., Bd. 1, S. 305-29, hier S. 313 ff.; KARL BiedermanN, Die junge Literatur und ihr Princip in der Reform des Geschlechtsverhältnisses, in: HALLISCHE JAHRBÜCHER FÜR 
Heine und Ludwig Börne zeugten hiervon. ${ }^{99}$ Während Börne in Heine allenfalls ironisch den „Regimentstambour des Liberalismus“ zu erkennen glaubte, polemisierte Eduard Beurmann, der „Liberalismus“ sei Heine „nur ein Relief für sein Talent, er kokettierte mit ihm wie mit Napoleon". 100

Die hier thematisierte Polarisierung zwischen konstitutionell-gemäßigtem und radikal-demokratischem Lager ließ in Umrissen bereits die doppelte Frontstellung von liberal zwischen den Polen der altständisch-conservativen Kritik und der demokratischen Absetzung des Radicalismus erkennen. Für den letzteren betonte Theodor Schuster Mitte der 1830er Jahre den fundamentalen Zusammenhang zwischen sozialer und politischer Reform, den gerade jene Liberalen übersähen, die die gesellschaftlichen Interessen der Unterschichten nicht berücksichtigten:

Was jetzt noch den Einwand jener Liberalen betrifft, welche eine politische Reform für den allein erlaubten Zweck einer Umwälzung halten, so könnte man ibnen nur mit ibren eigenen Gründen antworten. Auch sie wollen Reform, und zwar politische Reform: ist nun aber wobl einzusehen, inwiefern eine politische Reform mebr erlaubt sein kann als eine soziale?

Schuster war sich des ideologischen Unterschieds zwischen Liberalismus und Radikalismus bewußt und gelangte in der Auseinandersetzung mit den sich nur in konstitutionellen Bahnen bewegenden Liberalen zur Selbstbestimmung der eigenen sozial-emanzipatorischen Position:

Der Liberalismus jener will den Mißbrauch beschränken, unser Radikalismus will ibn vernichten, und nur darin besteht der Unterschied zwischen jenen und uns, daß jene mit ibrer Reform auf der Oberfläche des Erdkreises bleiben, während wir in dessen Tiefe graben,... daß bei jenen der Streit sich zwischen Personen verhandelt, bei uns aber, obne persönliche Rücksicht, zwischen Einrichtungen und Sachen ... es ist nicht unsere Absicht, uns mit einer jener jämmerlichen Theaterpossen von Regierungs- und Verfassungswechseln zu begnügen, welche, auf Unkosten des Volkes, in der neueren Geschichte so oft ibr Glück gemacht haben: unser Zweck geht weiter... Er heißt: radikale soziale und politische Emanzipation der arbeitenden Klassen. 101

Deutsche Literatur und Kunst 176-178, und 181 f., Juli 1838, zitiert nach ebd., Bd. 1, S. 282-94, hier S. 285; sowie [Eduard BeurmanN] Mundt, Gutzkow, Wienbarg, in: DeRs., Vertraute Briefe über Preußens Hauptstadt. Theil 2, Stuttgart 1838, zitiert nach EsTERMANN (Hrsg.), Bd. 2, S. 505-18, hier S. 505 f. und 514.

99 [Ludwig Börne und HeinRich HeIne] Ludwig Börne und Heinrich Heine. Ein deutsches Zerwürfnis, bearb. von Hans MAGNUS ENZENSBERGER, Leipzig 1991, S. 35, 38, 49, 67, 74, 92, 107, 309 und 329; vgl. Ludwig BöRNE, Menzel der Franzosenfresser (1836), hrsg. von RudOLF WOLFF, Berlin 1987, S. 11, 17, 18 f., 118 und 122 sowie LudWIG BÖRNE, Briefe aus Paris (1832-1834), Wiesbaden 1986, S. 18, 70, 206 und $588 \mathrm{f}$.

100 Ders., Über Deutschland von Heinrich Heine (Mai 1835), zitiert nach BÖRNE und HeIne, S. 67 sowie EduARd Beurmann, Spitzelbericht an die österreichische Regierung (1836), zitiert nach BÖRNE und HEINE, S. 92.

101 [TheOdOR Schuster] Freiheit, in: DeR GEÄCHTETE. Zeitschrift in Verbindung mit mehreren deutschen Volksfreunden, hrsg. von JacoB Venedey, Bd. 2, Paris 1835, S. 220 f.; vgl. ferner Deutschland und Frankreich. An den Herausgeber des Geächteten. Von S., in: Der GeÄchtete, Bd. 1, Paris 1834, S. 61-8. 
Eine überaus kritische Bilanz nach den Erfahrungen von Aufbruch und Enttäuschung zog auch Johann Bertram Stüve am Ende der 1830er Jahre. In skeptischem Pragmatismus resümierte er für den Liberalismus der süddeutschen Kammern, den er nach den vergeblichen Anläufen von 1830 bis 1832 jetzt überall im Rückzug begriffen sah, daß die Liberalen sich dort für „unentbebrlich“ hielten, „worin sie sich häßlich täuschen können. “ Man könne glauben, „es sei ihnen nur um den Zank und zwar um jeden Preis zu tun. "Sich wie zu Beginn der 1830er Jahre „nur durch Hoffnung zum Handeln bewegen zu lassen und, sobald sich diese Hoffnung oder besser unbestimmte Aufregung sich verliert, das Schlachtfeld [zu] räumen mit allerlei Grimassen, die doch nur die Mutlosigkeit bemänteln", sei als "Schwäche vor allem dem neumodischen Liberalismus eigen, und je grimmiger dieser 1831 den Anlauf nahm, desto jämmerlicher zieht er jetzt überall zurück". 1021839 setzte sich Stüve kritisch mit Niebuhrs Haltung gegenüber dem Liberalismus auseinander. Bei diesem sei der „Liberalismus bald die Unredlichkeit der Mittel, deren sich jeweilige Häupter bedienen, bald ist es die Gleichmacherei, im allgemeinen möchte ich sagen, das schrankenlos Auflösende. "Obwohl er ihm in diesem Punkt zustimmte, wandte er sich gegen die bloße „Opposition gegen das Liberale", da „der Opponent nicht sagt, was er will!“ 103 Für die Zeit nach 1832 beklagte er, daß „, bei vielen Lenten von wabrer Einsicht das Schimpfen auf diese Ideen, auf den Liberalismus, Mode geworden" sei. Niebuhr selbst predige einen innovationslosen „Stabilism oder leidenden Gehorsam. " Die zahlreichen "Invektiven auf die Liberalen" könnten noch keine eigenen "philosophisch historischen Systeme" ersetzen.104 Stüve selbst identifizierte sich mit einem maßvollen Reformkurs auf der Basis historischer Ideen, wie er sie etwa in der norddeutschen Tradition kommunaler Korporationen erkannte. Hierbei unterschied er sehr deutlich zwischen organischnorddeutschen und rational-süddeutschen „Freibeitsideen": 105

Mir ist der Liberalismus auch ekelhaft, insofern er eben die stumpfe Gleichmacherei und mouvement ist. Aber wer will es lengnen, daß mit Maß behandelt die liberalen Ideen und Maßregeln allein Heil versprechen? Es kommt darauf an, ob man sie bildend machen kann, der Stabilismus kann das nicht sein. Die historischen Ideen allerdings, aber in Wabrbeit nur in dieser Richtung. ${ }^{106}$

102 Brief Stüves vom 28./30. November 1838, in: STÜVE, Bd. 1, S. 466 f.

103 Brief Stüves vom 15./17./24./25. November 1839, in: ebd., S. 490.

104 Brief Stüves vom 4./7./8./14. Dezember 1839, in: ebd., S. 490 f.

105 So schrieb Stüve in seinem Brief vom 15./17./24./25. November 1839, ebd., S. 490 : „Das ist wobl schon ganz Deutschland klar geworden, daß in den Städten die vis politica steckt und daß man das Korporationswesen vor allem in Ebren balten und nicht verwässern soll. Diese große Lebre wäre allerdings schon ein ziemliches Lehrgeld wert, und an ibr könnten sich sie süddeutschen und norddeutschen Freibeitsideen einmal scheiden."

106 Brief Stüves vom 4./7./8./14. Dezember 1839, in: ebd., S. 491. 
Parlamentarischer und außerparlamentarischer Diskurs:

Polemische Funktion und soziale Bestimmung des Deutungsmusters

Die neue semantische Richtungsqualität der frühen 1830er Jahre wird insbesondere an der Ausdifferenzierung politischer Gruppenbezeichnungen erkennbar. Es ist kein Zufall, daß sich dies am deutlichsten in den konstitutionalisierten Bundesstaaten mit repräsentativen Körperschaften zeigte. Das parlamentarische Sprachhandeln stellte dabei ein wichtiges Indiz für den semantischen Wandel dar, zumal sich hier gegenüber den lexikalischen und syntagmatischen Bestimmungsmustern der spezifische Charakter des parlamentarischen Diskurses nachweisen läßt: Während auf der lexikalischen Bestimmungsebene die individuelle Gesinnungsqualität von liberal und Liberalismus betont wurde, ließen sich in den Landtagen aufgrund unterschiedlicher Positionen und Strategien bereits distinkte Handlungsgruppen unterscheiden. In Kurhessen differenzierte man vor dem Hintergrund der konfliktreichen Kammerdebatten verschiedene Gruppen, die für oder gegen den kurfürstlichen Hof eingestellt waren. ${ }^{107}$ Zumeist überwog bei diesen Nomenklaturen ein bipolares Bestimmungsmuster zwischen der liberalen „Partei der Bewegung “ und der „Widerstands-oder Stillstandspartei“. 108 Das orientierte sich zwar an der französischen Parteienlandschaft während der Julimonarchie, übertrug diese Etiketten nun aber auf die deutschen Verhältnisse. ${ }^{109}$ Zum Teil gelangte man zu noch differenzierteren Bestimmungen, etwa nach unterschiedlichen Fraktionen. Der kurhessische Generalstabschef von Cochenhausen identifizierte insgesamt fünf politische Gruppierungen:

1. die Ultraliberalen an deren Spitze Jordan, beabsichtigte Reformen für ganz Teutschland, schreckte aber durch ibr schreckliches Geschrei, welches sie bei jeder Gelegenheit, bäufig ganz obne Ursache, erhob, alle Vernünftigen ab, sich mit ibr zu vereinigen, 2. die Parthei der Reformatoren, welche besonders aus den angestellten Civilisten, meist Juristen bestand und hauptsächlich Reformen für Hessen bezweckte ... 3. die gemäßigte Constit[utionelle] Parthei... 4. die Adelspartei mit den Landgrafen ... 5. die Hofparthei.

Ein anonymer Artikel zum kurhessischen Landtag von 1833 unterschied sieben Richtungen, wobei das Etikett liberal die Linke kennzeichnete: „entschieden li-

107 Vgl. Ewald Grothe, Verfassungsgebung und Verfassungskonflikt. Das Kurfürstentum Hessen in der ersten Ära Hassenpflug 1830-1837, Berlin 1996, S. 397 ff., von dem auch die folgenden Zitate übernommen worden sind. Dem Verfasser danke ich darüber hinaus für den Hinweis auf weitere Quellenbelege.

108 Wer sind die Feinde der bestehenden gesetzlichen Regierungen und der gesetzlichen Ordnung im Staate?, in: Schaumburger VolksblatT, Nr. 4, 3. April 1832, S. $13 \mathrm{ff}$.; Bewegungs-Partei und Widerstands- oder Stillstands-Partei, in: DER BEOBACHTER, Nr. 120, 14. Oktober 1836, S. 477 ff.; ebd., Nr. 121, 16. Oktober 1836, S. 481 ff., zitiert nach GroTHE, S. 399, Anmerkung, dort auch weitere Quellenbelege; vgl. ferner WÜLFING, S $204 \mathrm{f}$. und 214.

109 Vgl. CARL VON ROTTECK, Bewegungs-Parthei und Widerstands- oder Stillstands-Partei, in: Ders. und Welcker (Hrsg.), Bd. 2, 1835, S. 558-65 sowie Carl Theodor Welcker, Centrum der Deputirten-Kammern, insbesondere der französischen, in: ebd., Bd. 3, 1836, S. 389-92. 
beral“, „gemäßigt liberal“, „Juste-Milieu“, „volkstbümlich gesinnt“, „zuverlässig auf der Seite der Regierung ", "für die Standesherrn. "Der Rekurs auf solche kategorisierenden Bezeichnungen diente den politischen Akteuren vor allem der Diskreditierung des politischen Gegners und bewirkte von daher eine nicht zu unterschätzende Polarisierung durch ideologisch aufgeladene Etiketten. So sprach Sylvester Jordan von einer „Parthei ..., welche auf den Umsturz der gesetzlichen Ordnung hinarbeite [und] ... das Mittelalter wieder heraufbeschwören möchte. "Auch die polemische Qualität in Bezeichnungen wie „jesuitischmystische Parthei", „Servile“, „Ministerielle " und „reactionäre Parthei" wiesen in diese Richtung. ${ }^{110}$ Gegenüber der lexikalischen und der syntagmatischen Deutungsebene zeigte sich im parlamentarischen Diskurs eine spezifische Affektfunktion der Begriffe. Sie dienten hier weniger der Projektion universalhistorischer Erwartungen oder der Bestimmung letztlich philosophischer Prämissen, sondern der sprachlichen Konfliktaustragung, hinter der distinkte politisch-soziale Interessen standen, die sich semantisch nicht mehr durch einen Begriff integrieren ließen.

Im Hinblick auf die sozialhistorische Einordnung des Deutungsmusters liberal/Liberalismus, seiner gesellschaftlichen Relevanz, bietet der zu Beginn der 1830er Jahre enstandene oberhessische Oppositionszirkel um Georg Büchner und Friedrich Ludwig Weidig einen besonders aussagefähigen Ansatzpunkt. Denn über lexikalische, syntagmatische und parlamentarische Bestimmungsmuster hinaus lassen sich hier aus den noch immer weitestgehend nicht edierten, offiziellen Verhörprotokollen semantische Trennlinien rekonstruieren, die sich nicht in den bildungsbürgerlich grundierten Interpretationen der zeitgenössischen Wörterbücher und Monographien ableiten lassen. ${ }^{111}$ Georg Büchner markierte seine sozialrevolutionäre Position und die damit verbundene Distanz gegenüber den konstitutionellen Liberalen bereits 1833. In einem Brief an August Stöber bekannte er im Dezember 1833: „Die politischen Verbältnisse könnten mich rasend machen. Das arme Volk schleppt geduldig den Karren, worauf die Fürsten und Liberalen ibre Affenkomödie spielen. Ich bete jeden Abend zum Hanf und zu den Laternen".112 Gegenüber dem tradierten Antagonismus zwischen Liberalismus und Absolutismus hob er eine neue ge-

110 Zitiert nach GROTHE, S. 400-2; vgl. [THEODOR SCHACHT] Der Liberalismus auf dem merkwürdigen Landtage zu Darmstadt 1833. Freimüthig geschildert für Alle, denen es um Wahrheit und Kenntniß des jetzigen deutschen Ständewesens zu thun ist, Gießen 1834, S. 23-68.

111 Die im folgenden zitierten archivalischen Quellen wurden mir in der Form privater Exzerpte von Ewald Grothe freundlicherweise zur Verfügung gestellt. Sie stammen aus den umfangreichen Quellensammlungen, die von der Marburger Georg BüchnerForschungsstelle unter der Leitung von Burghard Dedner zusammengetragenen worden sind. Bei der Zitation wurde auf die Angaben von Ewald Grothe zurückgegriffen, dem ich an dieser Stelle ausdrücklich danke.

112 Brief Büchners an August Stöber vom 9. Dezember 1833, in: GeORG BÜCHNER, Werke und Briefe. Nach der historisch-kritischen Ausgabe von R. LeHmann, 3. Aufl. Darmstadt 1984, S. 253. 
sellschaftliche Trennlinie zwischen arm und reich hervor: „Die ganze Revolution“ habe sich „in Liberale und Absolutisten geteilt" und müsse „von der ungebildeten und armen Klasse aufgefressen werden; das Verbältnis zwischen Armen und Reichen ist das einzige revolutionäre Element in der Welt".113 In dieselbe Richtung wies die Ansicht Weidigs, die sozialrevolutionäre Agitation des Hessischen Landboten gebe Anlaß, „daß die konstitutionellen Revolutionärs sich von uns trennen würden, wenn sie die heftigen Invektiven gegen die Reichen läsen". 114

Diese inneroppositionelle Differenzierung dominierte auch die Rekurse auf liberal und Liberale in den zeitgenössischen Verhörprotokollen, die zumindest partiell auch die Sichtweise der klein- und unterbürgerlichen Mitglieder der oberhessischen Oppositionszirkel widerspiegelten, zumal deren Deutung außerhalb solcher Quellen sonst kaum rekonstruierbar ist. Die Gießener Burschenschaft habe, so die Aussageprotokolle, keine "practisch revolutionäre Tendenz" gehabt, sondern eine „volksthümliche, liberale, politische Ausbildung und Vorbereitung der Mitglieder für's politische Lebens durch Lectüre, Reden und Debatten in den Versammlungen " angestrebt. ${ }^{115}$ Demgegenüber verfolgte die von Büchner und Weidig vertretene Gruppe eine offensive Strategie gegen die "liberale Parthei“, ja man vertrat sogar die Ansicht, es sei „rühmlicher, in den gegenwärtigen Verbältnissen fortzuleben, als eine Partbei zu unterstützen, die bei ibren liberalen Bemübungen nur ibre eignen egoistischen Zwecke im Auge habe und dazu nicht einmal Verstand genug, sie durchzusetzen". 116 Die sozialkritische Abgrenzung gegenüber liberal wurde auch bei Gustav Klemm deutlich, der die „Klubbs solcher jungen Bürgersleute, die den s.g. Liberalismus repräsentirten, deren Theilnehmer sich Liberale nannten", charakterisierte und die „liberale Parthei“ mit den „Leuten aus der gebildeten Klasse “ assoziierte.117 Dagegen sei Büchner „bei weitem nicht so betrübt, daß dieser oder jener Liberale seine Gedanken nicht drucken lassen dürfe, als daß viele tausend Familien nicht im Stand wären, ibre Kartoffeln zu schmelzen ".118 Noch im Nekrolog auf Büchner betonte Wilhelm Schulz, dieser habe den „thatenlosen Liberalismus“

113 Brief Büchners an Gutzkow vom Sommer 1835 (undatiert), in: ebd., S. 269.

114 Zitiert nach ebd., S. 445; vgl. ferner FrIEDRICH NoEllner, Die Kritik des gerichtlichen Verfahrens gegen Pfarrer Weidig. Ein Beitrag zur Charakteristik der politischen Parteien und der Rechtszustände Deutschlands nebst actenmäßigen Belegen, Braunschweig 1845, S. 60, Anmerkung.

115 Verhörprotokoll Gustav Klemm, Friedberg, 2. Juni 1835, in: StA Frankfurt a.M., Acta Criminalia 1834, Nr. 119, Prozeß 7, 174.

116 Martin Schäffer, Untersuchungsbericht, 1839. Die Überlieferung folgt FRIEDRICH NOELLNER, Actenmäßige Darlegung des wegen Hochverraths eingeleiteten gerichtlichen Verfahrens gegen Pfarrer D. Friedrich Weidig, Darmstadt 1844, S. 98-100.

117 Verhörprotokolle Gustav Klemm, Darmstadt, 21. Januar 1836 und 9. Oktober 1835, in: StA Ludwigsburg, E 319, Bü. 46 sowie StA Marburg 270 e, Obergericht Marburg, Acc. 1871/35, Nr. 20, Bd. 5, fol. 11-14.

118 Verhörprotokoll August Becker, 1. September 1837, Überlieferung nach NoELLNER, Darlegung, S. 420-3. 
gehaßt, „der sich mit seinem Gewissen und seinem Volke durch leere Phrasen abzufinden siebt" 119

Die Protokolle markierten damit jenen Bereich, in dem die gesellschaftliche Wirkungsgrenze der neuen politischen Begriffe verlief. August Becker hob hervor, daß gerade die Bauern „gleichgültig “ gegenüber „Ehre und Freiheit ibrer Nation" seien und „keinen Begriff von den Rechten des Menschen" hätten, "und in dieser Gleichgültigkeit allein berubt ibre angebliche Trene gegen die Fürsten und ibre Theilnahmslosigkeit an dem liberalen Treiben der Zeit".120 Die in den zeitgenössischen Lexika dominierende bildungsbürgerliche Konnotation erreichte diese Schichten nicht oder nur abgeschwächt. Zugleich dokumentieren die zuletzt vorgestellten Quellen die Abgrenzung einer sozialen Protestgruppierung gegenüber einem primär politisch-konstitutionellen Deutungsmuster und seinen bürgerlichen Trägern.

\section{Italien}

a) Der Antagonismus von liberalismo antisociale und liberalismo sociale in der Aufstandsbewegung von 1830/31

In Italien unterstrichen die Reaktionen auf die französische Julirevolution das Fortwirken der von den einzelstaatlichen Regierungen und der katholischen Kirche überwunden geglaubten Oppositionsbewegungen. Hier wurden der Kirchenstaat sowie die Herzogtümer Modena und Parma von Aufständen erschüttert, während andere Staaten wie Neapel im Gegensatz zu 1820/21 zumeist nicht berührt wurden. Wie in Bologna konstituierten sich in zahlreichen mittelitalienischen Städten neue Regierungen, wobei der nationalen Zielsetzung der Bewegungen ein besonderes Gewicht zukam. Die österreichische Intervention, scheinbar legitimiert durch ein Hilfsersuchen des neuen Papstes Gregor XVI. an Metternich, beendete die Aufstandswelle und leitete in eine erneute Repressionsphase über, die in Modena von zahlreichen Todesurteilen begleitet wurde. Im Kirchenstaat zeichnete sich unter dem Eindruck der Ereignisse eine "Tendenz zur autoritären Defensive“ ab, die in der ersten großen Enzyklika Mirari Vos des neuen Papstes und der Blockade weitergehender Reformen ihren Niederschlag fand. In seiner Enzyklika verurteilte Gregor XVI. Rationalismus und religiösen Indifferentismus, aber auch explizit die Forderungen der Aufstandsbewegung, wie vor allem die Gewissens- und Meinungsfreiheit sowie die Auflehnung gegen jede Autorität. ${ }^{121}$

119 Wilhelm Schulz, Nekrolog, Zürich, 28. Februar 1837, in: SCHWEIZERISCHER REPUBLIKANER, Nr. 17, 28. Februar 1837, S. $71 \mathrm{f}$. sowie in: LITERARISCHE UND KRITISCHE BLÄTTER DER BÖRSENHALLE, Nr. 160, Mai 1837, S. 493 f.

120 Verhörprotokoll August Becker, 1. September 1837.

121 Rudolf Lill, Geschichte Italiens in der Neuzeit, 4. Aufl. Darmstadt 1988, S. 110. 
Auf diesen Kontext ist insofern hinzuweisen, als er für das Verständnis der spezifischen Polarisierung von liberali/liberalismo in Italien nach 1830 grundlegend wurde. Die Teilnehmer an den primär bürgerlich geprägten Bewegungen von 1830/31 bekannten sich als liberali und "generosi spiriti“ zum Widerstand gegen die päpstliche Herrschaft, in der man das Symbol für Rückschrittlichkeit und ein entscheidendes Hindernis für nationalpolitische Fortschritte sah. Das Vorwort der 1831 veröffentlichten Collezione completa degli opuscoli liberali pubblicati nelle legazioni pontificie wandte sich an die „liberali ... a voi magnanimi che versaste con serena fronte il sangue vostro sotto la scure Sacerdotale fra le esecrande mura dell'avara Babilonia per la santissima causa della libertà “. 122 Mit dem angestrebten Ende der weltlichen Herrschaft des Papstes im Kirchenstaat verbanden die liberali zugleich einen nationalpolitischen Fortschritt für ganz Italien, einen "momento sospirato della rigenerazione Italiana“. 123 Insofern gingen die mit den „istituzioni giuste, e liberali" verbundenen konstitutionellen Forderungen, die man zunächst in den Stadtregierungen umzusetzen suchte, mit nationalpolitischen Zielen eine enge Verbindung ein. ${ }^{124}$ Der Widerstand der römischen Kurie, „l'odio implacabile che la Romana Corte ha giurato ad ogni idea liberale", resultierte insofern aus einem grundsätzlichen weltanschaulichen Antagonismus und aus dem weltlichen Herrschaftsanspruch des Papsttums, der der staatlichen Einigung der Nation zuwiderlief.125 Dieser Zusammenhang wurde für die Bestimmung von liberalismo im italienischen Risorgimento grundlegend. Die „riforma con basi liberali“ verkörperte den Anspruch auf politische Partizipation, die die Kurie niemals gewähren

122 Dedica del raccogliatore ai liberali, in: Collezione completa degli opuscoli liberali pubblicati nelle legazioni pontificie dall'epoca dell'invasione austriaca accaduta nel marzo 1831, 3 Bde., Genf 1831, hier Bd. 1, S. I-III, hier S. I.

123 Ai Romani appello dei Romagnuoli a Macon (1831), in: ebd., Bd. 1, S. 37-47, hier S. 46.

124 Alcune verità al signor conte Camillo Grassi, Prolegato di Bologna, riferibili anche ai prolegati delle Romagne (1831), in: ebd., Bd. 1, S. 73-98, hier S. 85; vgl. zur Abgrenzung gegenüber den liberali in den in der Collezione completa zusammengetragenen Texten ferner Alcune parole di un Ferrarese (1831), in: ebd., Bd. 2, S. 3-12, hier S. 6; Lettera estratta da un Foglio Francese al redattore (1831), in: ebd., Bd. 2, S. 126-8, hier S. $127 \mathrm{f}$.; [G. SERCOGNANI und C. BorgIA] Memorie sulle ultime commozioni politiche dell'Italia centrale de' signori G. Sercognani, e C. Borgia al signor Presidente del Consiglio de' Ministri (1831), in: ebd., Bd.2, S. 151-72, hier S. 160 f.; [GIUSEPPE GHERARDI] Note storico-politiche generali, e più in particolare intorno alla rivoluzione di alcune provincie centrali d'Italia, accaduta al mese di febbraio del 1831, in: ebd., Bd. 2, S. 173-204, hier S. 189; Memoriale indirizzato a Sua Santità Papa Gregorio XVI. da Mons. Asquini pro-legato di Ferrara, dall'ex direttore di polizia Arzé, dal cavaliere Baratelli, dal colonnello Bentivoglio, e da altri credibili devoti della lodata Sua Santità (1831), in: ebd., Bd. 3, S. 32-8, hier S. 33 ff. sowie Alle incivilite nazioni europee gl'infelici sudditi del Ducato di Modena (1831), in: ebd., Bd.3, S. 106-28, hier S. 128 .

125 Pro-Memoria dichiarante le giuste querele delle provincie insorte contro il governo papale. I loro voti e le loro domande umiliate ai ministri delle cinque grandi potenze (1831), in: ebd., Bd. 1, S. 117-46, hier S. 139. 
würde: „La natura della Corte di Roma, e la volontà generale del popolo sono due principii eterogenei, e diametrale opposti".126

Die Bestimmung des liberale folgte der Vorstellung eines selbstverantwortlichen Bürgers einer politischen Gemeinschaft, dem Ideal einer aufgeklärten, interessenlosen Grundhaltung und der Bindung des einzelnen an die Nation. Hier verknüpften sich vorpolitische Nuancen der liberalità mit neuen politischen Gehalten. Die dem liberale zugewiesenen Wertbegriffe reflektierten aber auch die gerade in Italien besonders starke kommunale Perspektive politischer Freiheit und Autonomie, die in der historischen Tradition der Stadtrepubliken wurzelte:

La prima virtù cittadina che distingue il vero liberale si è quella, che rende l'uomo non ambizioso di onori... ma che lo rende contento della propria coscienza, e dell'onore del bene operato. Essa sublima l'uomo fino a soffrire le ingiustizie dei proprii concittadini senza cessare di amare la patria. Gli nomini che vengono destinati agli uffizi civili debbono avere molta sapienza, molta prudenza, e soprattutto onestà e disinteresse. ${ }^{127}$

Wie nach 1815 und um 1820/21 bildete die „costituzione saggiamente liberale“ den konkreten Zielhorizont für die Sicherung politischer Partizipation auf der Basis repräsentativer Volksvertretungen. ${ }^{128}$ Der Blick auf England oder Frankreich schien dieser Erwartung um 1830/31 besonderen Auftrieb zu verleihen. Die costituzione liberale bot den italienischen Fürsten danach die Möglichkeit, das Vertrauen des Volkes zu erlangen und damit die eigene Herrschaft auf eine stabilere Grundlage zu stellen: „Noi facciamo fervidi voti, affinchè $i$ Principi d'Italia rendino felici e contenti i loro sudditi: al che non potranno riescire senza una Costituzione saggia e liberale; dalla quale unicamente otterranno l'amore de' cuori del popolo, e renderanno ferma e stabile la loro ormai vacillante Sovranità". 129

Die politische Relevanz von liberale trat unter dem Eindruck der Aufstandsbewegungen zu Beginn der 1830er Jahre deutlicher hervor. Dazu zählte die optimistische Hoffnung auf Durchsetzung der „liberali istituzioni“ gegenüber "tutte le tirannidi“ sowie die ideologische Temporalisierung der eigenen Gegenwart zwischen dem „sistema progressivo" und dem „sistema retrogrado“, das man im Kirchenstaat verkörpert sah. ${ }^{130}$ Wie in Deutschland ließen sich Fortschritt und Zukunft semantisch durch liberale besetzen, was die ideologische Abgrenzung gegenüber Rückschritt und Vergangenheit ermöglichte. Ge-

126 Pronostico per l'anno bisestile 1832. Tratto dal lunario, intitolato Il Ciabattino astronomo e politico (1831), in: ebd., Bd. 1, S. 231-9, hier S. 233; vgl. auch S. 237 und 233.

127 Ebd., S. 238.

128 [Domenico Bentivoglio] Indirizzo del colonnello Domenico Bentivoglio ai popoli ed ai principi d'Italia (1831), in: ebd., Bd. 3, S. 129-49, hier S. 137 f.; vgl. die Stigmatisierung der „idee costituzionali“ in Lettera sul vantaggio della Monarchia assoluta sopra qualunque altro governo a procurare la felicità dei popoli, Modena 1832, S. 32.

129 Bentivoglio, S. 149.

130 La Sentinella della Libertà, Nr. 1, 24. Februar 1831, S. 8; vgl. ebd., Nr. 2, 3. März 1831. 
genüber den 1820er Jahren veränderte sich aber vor allem der semantische Differenzierungsgrad der Begriffe. So unterschied die in Bologna erscheinende Pallade Italiana im Februar 1831 den "liberal volgare" vom "liberale d'un ordine più elevato. “Den „liberal volgare“ charakterisierte man als Gegner jeder gesellschaftlichen Bindung, was sich mit sozialer Anarchie identifizieren ließ, die zumal bei fehlender Bildung des liberal volgare drohte:

Il liberal volgare è un nomo che sente molestia pei vincoli di società, che ne soffre impazientemente $i$ legami, che di mal animo sacrifica alcune sue convenienze particolari a convenienze più generali, e che aspira con ogni suo voto all'indipendenza assoluta della sua volontà. Di costui non ne facciamo ancora un Selvaggio; la sua ragione può ancora insegnargli di credere alla necessità; può essere un onest'nomo; ma non ostante per non dir di più, lo chiamiamo Liberal volgare. Con minor coltura, con un educazione più difettosa può egli diventare all'occasione un artigiano d'Anarchia; giacchè per lui la società non è che un mal necessario.

Der positiv konnotierte "liberale d'un ordine più elevato" dagegen verband libertà und ordine miteinander. Dies schloß jede gewaltsame Strategie und revolutionäre Spannung zwischen Gesellschaft und Staat aus und zielte auf eine universelle politisch-gesellschaftliche Harmonie:

Il liberale d'un ordine più elevato è un nomo a cui la libertà apparisce come lo scopo, come l'ordine, come lo stato normale dell'umanità, e come eminentemente sociale egli vuole la libertà nell'interesse medesimo della società. Egli è appunto per nobilitare la società che accorda la maggiore possibile parte all'individualità. Egli è per l'interesse della società che ributta l'intervento d'ogni inutile violenza, vessatoria, o sacrilega, che corromperebbe l'associazione togliendole la sua bellezza. Esso vuole la società, l'unione, l'armonia, e per ciò solamente vuole la libertà. In una parola la libertà si mostra come una legge eterna della natura umana, come un mezzo potente di perfezionamento.

Entsprechend diesen Kategorien unterschied der Autor einen „liberalismo antisociale“ von einem „liberalismo sociale per eccellenza“, der aber in der eigenen Gegenwart eher die Ausnahme darstelle. Seine Entfaltung hänge von der Verbreitung der moralischen und religiösen Grundlagen ab: „a nostro avviso quest'ultimo liberalismo è ancor raro purtroppo. Egli non sarà comune, e generale, che allorquando la coltura, non già intellettuale soltanto ma soprattutto morale, e religiosa sarà essa stessa divenuta comune, e generale ".131 Wie in Deutschland die Unterscheidung von wabrem und falschem Liberalismus eine inneroppositionelle Differenzierung abbildete oder mindestens antizipierte, so reflektierten liberalismo sociale und liberalismo antisociale auch in Italien eine neue Stufe der ideologischen Differenzierung.

Die neuen Herausforderungen für die liberali spiegelten sich auch in den Schriften des Historikers und Nationalökonomen Sismondi wider, der sich zu Beginn der 1830er Jahre mit den politischen Perspektiven seiner Gegenwart auseinandersetzte. Sismondi ging vom allgemeinen "progresso nelle istituzioni“ der Gegenwart aus und reflektierte die erneute Infragestellung der tradierten monarchischen Herrschaftslegitimation um 1830. In diesem Zusammenhang

131 La Libertà, in: Supplemento alla Pallade Italiana, Nr. 2, 20. Februar 1831, S. 9. 
standen die liberali, für deren Positionsbestimmung um 1830/32 die Unterscheidung zwischen der allgemeinen Programmatik der liberali und den Versuchen, die Prinzipien der Volkssouveränität gewaltsam durchzusetzen, entscheidend war:

La preponderanza un tempo apparteneva alla volontà regia, ora è passata alla popolare; le limitazioni che i liberali si erano forzati di opporre all'autorità, intendevano a frenare i capricci dei rei, ed oggigiorno mirano a comprimere quelli deli popolo; e desse sono sempre utili; ma i loro istitutori, e custodi non devrebbero più essere gli uomini medesimi, ed i tentativi che due anni sono si continuavano in favore della sovranità popolare, ora produrrebbero un effetto a lei dannoso. ${ }^{132}$

Sismondi griff zur Kennzeichnung der oppositionellen Zirkel in Italien auch auf andere Etiketten zurück, so vor allem auf patriotti, um den nationalpolitischen Horizont der Bewegung von 1830/31 hervorzuheben, wobei eine republikanische Konnotation wie in Frankreich fehlte. Die in diesem Kontext ebenfalls auftretende Gruppenbezeichnung moderati wies bereits darauf hin, daß sich innerhalb der liberali verschiedene Richtungen abzuzeichnen begannen, von denen die moderati eine gewaltsame Duchsetzung des konstitutionellen Programms ablehnten und eher die Kooperation mit den Regierungen suchten. ${ }^{133}$ Die Existenz einer solchen konkurrierenden Bezeichnung dokumentierte auch, daß man eine deutliche Trennlinie gegenüber den negativen Implikationen eines liberalismo antisociale zu ziehen bemüht war. Vor allem im Kirchenstaat prägten die moderati die neoguelfische Bewegung der 1840er Jahre, die alle Hoffnungen auf den zum Reformpapst stilisierten Pius IX. setzte.

\section{b) Der negativ bestimmte dizionario liberale:}

Die Persistenz der katholisch-restaurativen Bestimmungsmuster

Auf der Gegenseite intensivierte die katholisch-restaurative Publizistik unter dem Eindruck der Aufstände im Kirchenstaat ihre Polemik gegen die liberali. ${ }^{134}$ Dieser semantische Antagonismus bildete für die Phase des gesamten italienischen Risorgimento auch über die Jahrhundertmitte hinaus eine dominante Kontinuitätslinie. In deutlicher Parallele zu Frankreich, wenngleich in charakteristischer Phasenverschiebung, setzte sich der Bewegungsbegriff liberalismo zunächst in der polemischen Kritik durch, da er hier die Möglichkeit bot, alle negativen Konnotationen schlagwortartig zu verdichten. Damit setzte sich eine Entwicklung fort, die sich bereits während der 1820er Jahre abgezeichnet hatte. Im Anschluß an die relative Zurückhaltung der Regierungen nach 1815 hatte nach 1821 die restaurativ-katholische Auseinandersetzung mit den idee liberali umso intensiver eingesetzt. ${ }^{135}$ Eine besondere Rolle spielten

132 J. C. L. De Sismondi, Le Speranze e le realtà, Genf 1831, S. $6 f$.

133 Ders., Delle speranze e dei bisogni dell'Italia, Lugano 1832, S. 9; vgl. ebd., S. 12 f.

134 Vgl. Un'Oretta di conversazione tra sei illustri matrone della buona antichità, o.O. 1832, S. $32 \mathrm{f}$.

135 Vgl. LiLl, S. 104 f. 
dabei wie gezeigt auch immer wieder Übersetzungen ausländischer Autoren, so in Carl Ludwig von Hallers Schrift über die denominazioni di partiti. ${ }^{136}$ Die auch für Italien nachweisbare relative Dynamisierung des politischen Diskurses äußerte sich in der verstärkten publizistischen Präsenz des Wortfeldes bis etwa 1835 (vgl. Abbildung 7) und vor allem in der Verschärfung der bereits angelegten bipolaren Semantik von liberale und cattolico. Der Zusammenhang von positiver Identifikation und negativer Abgrenzung blieb auch hier virulent: Der Berufung auf liberali und liberalismo folgten Stigmatisierung und Diffamierung der Begriffe in einer unabsehbaren Flut von Traktaten der katholisch-restaurativen Publizistik.

Eine herausragende Stellung in der Ausprägung dieses semantischen Antagonismus nahm Antonio Capece Minutolo di Canosa ein. Als herausragender Repräsentant der Gegenrevolution und Restauration profilierte er sich bereits um 1815, als er die konstitutionellen Konzessionen der Bourbonen scharf verurteilte. In Neapel amtierte er 1816 kurze Zeit als Polizeiminister und wurde zum Sprachrohr reaktionärer Adelskreise. Sein Übereifer veranlaßte schließlich selbst die Österreicher, auf seine Abberufung zu drängen. Wichtig wurde vor allem seine Förderung der katholisch-restaurativen Publizistik in Neapel.137 Insbesondere das Schlagwort der costituzione liberale symbolisierte für Canosa und seine reaktionären Gesinnungsgenossen Graf Monaldo Leopardi und Cosimo Andrea Sanminiatelli bereits eine gefährliche Konzession gegenüber den Prinzipien der Revolution, die es für Italien unter allen Umständen zu verhindern gelte. Sie formulierten das Ideal einer statischen Gesellschaft, die in hierarchischen Ständen organisiert und auf den Souverän hingeordnet sein sollte. Canosa wandte sich vor allem gegen eine unvollkommene Restauration, die die gefährliche Wurzel der Französischen Revolution nicht gänzlich beseitige und polemisierte gegen das abstrakte Ideal der neuen politischen libertà in der Tradition von 1789.138 Den Erfahrungsraum dieser restaurativen Theorien bildete die überschaubare norditalienische Stadtkommune. So kritisierte vor allem Monaldo Leopardi die staatliche Zentralisierung nach napoleonischem Vorbild, die einem despotischen Herrscher besonders entgegenkomme, weil die lokale Autonomie durch sie untergraben werde. Leopardi verwies damit auf die in Ober- und Mittelitalien besonders ausgeprägte Tradition kommunaler Unabhängigkeit. Aus dieser Perspektive bot der kommunale Partikularismus eine Garantie gegen despotische Willkür. ${ }^{139}$

136 Vgl. Kapitel IV.3.b).

137 Vgl. Walter Maturi, Il principe di Canosa, Florenz 1944 sowie Sabbatucci und VIDOTTO (Hrsg.), Bd. 1, S. 266 ff.

138 Vgl. [AnTonio Capece Minutolo di Canosa] I piffari de montagna. Ossia cenno estemporaneo di un cittadino imparziale sulla congiura del principe di Canosa e sopra i carbonari, Dublin 1820, zitiert nach N. Del CORNO, Gli scritti sani. Dottrina e propaganda della reazione italiana dalla Restaurazione all’Unità, Mailand 1992, S. 64.

139 Vgl. Monaldo Leopardi, Sulle riforme del Papa. Una parola ai sudditi del Papa, o.O. 1832, o.S., zitiert nach Del Corno, S. 163. 
Der Rückgriff auf Canosa, Leopardi und Sanminiatelli erscheint gerechtfertigt, weil sie mit ihren Polemiken nach 1830 einen der profiliertesten Gegenpole zu liberali und liberalismo bildeten. Darüber hinaus standen sie hinter den beiden Organen, die in zahllosen Artikeln zu Beginn der 1830er Jahre die Auseinandersetzung mit liberalismo in der politischen Presse prägten. Die Voce della Ragione und die Voce della Verità trugen auf diesem Weg maßgeblich zur Diffusion des neuen Bewegungsbegriffes bei. Ihre Artikel folgten dabei einem durchgängigen Bestimmungsmuster: ${ }^{140}$ Programmatisch setzte man den gottlosen und revolutionären Liberali die Gesuiti als Verkörperung des wahren Katholizismus entgegen. ${ }^{141}$ Interessant erscheint die Bestimmung des Ursprungs von liberali. Für den italienischen Autor ersetzte liberale das Attribut giacobino, ${ }^{142}$ ohne daß die semantischen Ursprünge der französischen idées libérales dabei berücksichtigt wurden. Die Revolutionäre der Gegenwart schienen ihre Intentionen mit einem neuen Etikett lediglich zu tarnen:

Liberali. Il nome. Questo nome non è punto francese, perchè nel dizionario dell'Academia non ha il nuovo significato che si vuole attribuirgli, è questo un barbarismo non intelligibile, che è stato sostituito al terribile nome di giacobino, il quale non verrebbe più tanto bene applicato, ora che $i$ rivolutionarii sono divenuti persone di buona compagnia dopo essere stati purificati affatto gratuitamente dalla nuova liberalità di cui avevano tanto bisogno.

Diesem Bedeutungszusammenhang folgte auch die Charakterisierung der operazioni der liberali. Der Zusammenhang von katholischer Religion, Kirche, Obrigkeit und Monarchie firmierte als Legitimationsrahmen für den Erhalt des politischen und gesellschaftlichen status quo:

Ho detto che al vocabolo giacobino si è sostituito quello di liberale; ed è questa, io credo, la miglior maniera di definire la parola liberale attesa l'oscurità del barbarismo. Dalle operazioni dei liberali non si può fare a meno di non conoscere l'identità, perchè che cosa fanno essi? Tutto quello che hanno fatto i giacobini ... I liberali mentiscono, calunniano, fanno degl'intrighi, ingannano, provocano petizioni scandalose, con i loro giornali ed i loro libriccini nei quali la religione è continuamente attaccata, i sacerdoti vilipesi, le autorità disprezzate, ed i re insultati. ${ }^{143}$

140 Vgl. die Sammlung von Briefen und Dokumenten in La Gazzetta La Voce della Verità condannata a morte ignominiosa senza appello con sentenza proferita a Parigi nell'aprile 1835 da Ser Cotale Niccolò Tommaseo e compagni per strage commessa dell'Antologia e per attentati contro la liberalesca settaria sovrana canaglia, Filadelfia 1835, S. 17, 38 f., 62 f., 105 und 170; vgl. Monitore Bolognese, Nr. 10, 12. März 1831 sowie ebd., Nr. 12, 18. März 1831.

141 Gesuiti - Liberali, in: La Voce Della Ragione 1 (1832), S. 178-87.

$142 \mathrm{Vgl}$. Cenni al popolo intorno alla religione ed umanità del liberalismo nelle nostre provincie. Catechismo e dialogo fra padre e figlio, o.O. 1833, S. $19 \mathrm{ff}$.

143 Gesuiti - Liberali, S. 179 und 181; vgl. ferner Dissertazione medico-filosofica sul liberalismo, in: LA VOCE DELLA RAGIONE 1 (1832), S. 105-11; La credulità de' Liberali, in: ebd. 1 (1832), S. 244-51; I Liberali. Traduzione dall'originale francese, in: ebd. 1 (1832), S. 287-94; I Liberali. Sonetto, in: ebd. 1 (1832), S. 346; Sulla libertà dei filosofi, in: ebd. 4 (1833), S. 14-7; Dove condurrebbero l'Italia i progetti dei liberali?, in: ebd. 5 (1833), S. 3-11; Esame della filosofia del liberalismo, in: ebd. 8 (1834), S. 302-11; Le 
Durch die Aufnahme der negativen Begriffe eguaglianza und repubblicanismo ließen sich die liberali jederzeit als rivoluzionarii in der Tradition der Französischen Revolution diskreditieren. ${ }^{144}$ Auch die im französischen Politikdiskurs so häufig anzutreffende Kritik an der Wandlungsfähigkeit der Bezeichnungen ließ sich in der italienischen Publizistik nachweisen: „Passerà agevolmente il liberale da costituzionale a repubblicano, da questo ad anarchico ec., ma realista, sinceramente realista, non diventerà giammai". 145

Die Voce della Verità widmete dem neuen Deutungsmuster sogar eine eigene Rubrik mit der Überschrift „dizionario liberale“, in der wichtige Schlagworte der liberali mit programmatischen Gegendefinitionen versehen werden sollten: „abbiamo deliberato di stendere qui mano a mano un Saggio di Dizionario, onde quelli che non sono bene al fatto delle idee correnti possano imparare il vero significato dei termini del senso liberale; e con ciò crederemo di aver fatta opera di somma utilità. " $\mathrm{Zu}$ den behandelten Schlagworten zählten u. a. gesuiti, tolleranza, secolo illuminato, tiranno, patriotta sowie filantropia ed umanità. 146 Diese Strategie wies eine deutliche Parallele zu Carl Ludwig von Hallers Versuch einer systematischen Entlarvung des jargon libéral auf, der seinerseits dem Vorbild des französischen Dictionnaire libéral von 1823 gefolgt war. ${ }^{147}$ Mit der Gegendefinition sollte auch im italienischen Kontext die diskursive Deutungsmacht der liberali gebrochen werden: ${ }^{148}$ Dies reflektierte die auch für Italien

Idee Liberali, in: ebd. 10 (1834), S. 317; Il liberalismo vaneggia, in: ebd. 11 (1834), S. 53-5 sowie Una speranza fallita per i dilettanti del liberalismo. Circolare del Regio governo di Napoli, in: ebd. 11 (1824), S. 190-2.

144 [Mario Felice Peraldi] Pensieri sulla disuguaglianza sociale di Monsignor Mario Felice Peraldi, 2. Aufl. Rom 1836, S. 25, 28 und 35 sowie Catechismo sulle rivoluzioni, o.O. 1832, S. 28.

145 Lettera da Faenza a Perugia per conoscere i liberali della Romagna, o.O. 1831, S. 39; vgl. Lettera da Lugo per conoscere i liberali della Romagna, o.O. 1831, S. 8f.; Lettera da Castelfranco per conoscere i liberali della Romagna, o.O. 1831, S. 2 sowie Lettera da Ravenna e da Perugia per conoscere i liberali della Romagna, o.O. 1831, S. 2 und 9.

146 Saggio di un dizionario liberale, in: LA Voce Della Veritâ, Nr. 2, 8. Juli 1831 sowie Nr. 4, 15. Juli 1831; Supplemento alla Gazzetta La Voce della Verità, Nr. 9 , 2. August 1831; Nr. 10, 5. August 1831; Nr. 13, 16. August 1831; Nr. 21, 13. September 1831; Nr. 22, 16. September 1831 sowie Nr. 40, 8. November 1831.

147 Vgl. Kapitel IV.1.c).

148 Vgl. Sogni Pseudo-Profetici del Liberalismo, in: Voce Della Verità, Nr. 17, 30. August 1831; Ai Panegiristi delle virtù liberali, in: Supplemento, Nr. 19, 6. September 1831; Confessioni del Liberalismo, in: ebd., Nr. 47, 24. November 1831; Del Liberalismo e della Libertà civile, in: ebd., Nr. 68, 12. Januar 1832; Catechismo liberale del giusto-mezzo, in: Supplemento, Nr. 85, 21. Februar 1832; Dell'indole del moderno barbarismo volgarmente Liberalismo, in: ebd., Nr. 90, 3. März 1832; Il Liberalismo al tribunale dell'esperienza, in: ebd., Nr. 120, 12. Mai 1832; L'impostura del liberalismo smascherata, in: ebd., Nr. 141, 30. Juni 1832; Due parole ai Liberali Toscani, in: ebd., Nr. 143, 5. Juli 1832; Delle metamorfosi liberalesche, in: ebd., Nr. 170, 6. September 1832; Del patriottismo Liberale, in: ebd., Nr. 227, 17. Januar 1833; Liberalismo dei bonapartisti, in: ebd., Nr. 233, 30. Januar 1833; Umile proposizione ai principi sulla estirpazione dei liberali, in: ebd., Nr. 258, 30. März 1833 sowie Ai Liberali Italiani, in: ebd., Nr. 270, 27. April 1833. 
grundsätzlich veränderte Relevanz des Wortfeldes; allerdings setzte jene spezifische Form der Auseinandersetzung mit einer charakteristischen Verzögerung von rund zehn Jahren gegenüber der begriffsgeschichtlichen Entwicklung in Frankreich ein. Dabei erscheint es signifikant für den relativ schwächer entwikkelten italienischen Politikdiskurs, daß auch weiterhin zahlreiche Artikel aus dem Französischen wörtlich ins Italienische übersetzt wurden, ohne daß es zu neuen eigenständigen semantischen Bestimmungen kam. ${ }^{149}$

Für Canosa verkörperten die Schlagworte „bugiardo liberalismo “, „settarioliberali“ und „canaglia liberale“ die Fortsetzung der gottlosen Französischen Revolution, 150 die er in eine negative Kontinuitätslinie zur Englischen Revolution und zur Abwendung Heinrichs VIII. von Rom stellte:

E siccome le rivoluzioni settario-democratiche sono sempre le stesse, e la filantropia liberale ha sempre prodotti i medesimi spaventevoli risultamenti, cosi quanto avvenne nell'anarchica rivoluzione di Francia non era che una copia di quello che era successo in Inghilterra, in seguito dell'apostasia di Enrico VIII.

Auch hier zeigte sich, daß hinsichtlich der italienischen Begriffsbestimmung stärker als in den übrigen Vergleichsländern die historische Stellung zu Katholizismus und Papsttum richtungweisend war. Für die negative Konnotation von liberale übernahmen cattolicismo und papa die Funktion historisch verankerter und weltanschaulich legitimierter Deutungsmuster, an die jederzeit angeknüpft werden konnte, so wie im englischen Politikdiskurs unter ganz anderen Vorzeichen an die Begriffe liberty und constitution. Canosa reflektierte in Anlehnung an den in der Voce della Verità zusammengestellten dizionario liberale die Verschiebung von Begriffsinhalten seit der Französischen Revolution, ja die regelrechte Umkehrung von Bedeutungsgehalten als besonders subversives Mittel der politischen Auseinandersetzung. Dies erkannte er zumal in der verbreiteten Wertschätzung der filosofi der Aufklärung als spiriti forti:

Quelli che gli stolti del secolo chiamano filosofi; gli Atei in particolare, i materialisti, e coloro tutti che dopo questa momentanea vita terrena, altra non ne ammettono eterna, sono quelli precisamente assai più attaccati dalla Paura morale; abbenchè con impudente jattanza vengono nominati Spiriti Forti da quel Dizionario liberale, che per sistema adatta ai vocaboli un'idea tutta opposta a quella che loro regolarmente competerebbe per convenzione avutane tra tutti gli abitatori dell'universo, fin dalla prima creazione del Mondo. ${ }^{151}$

149 Vgl. Confutazione del principio che la sovranità risiede nel popolo e delle conseguenze che se ne ritraggono. Prima traduzione italiana dal francese di Emmanuele Marini Romano, Rom 1835, S. $7 f$.

150 [Antonio CAPECE Minutolo di CAnOsa] I miracoli della paura. Ragionamento di Antonio Capece Minutolo principe di Canosa, dedicato ai suoi amici, Modena 1831, S. 5f., 9 und 11; vgl. DeRs., Epistola ad un Carciere [Rom 1834], S. 2, 10 f., 13 und 15.

151 Ders., Miracoli, S. 36 und 39; vgl. [Ders.] Sulla Corruzione del secolo circa la mutazione dei vocaboli e delle idee. Lettera ad un amico, Italia [o.O.] 1833, S. 9: „Nulla di più facile per i nostri rivoluzionarj. Essi avendo accoppiato le stranissime idee della ribellione col diritto (il quale non può collegarsi che colla sola legittimità), e le qualità contradittorie della superbia colla debolezza, si sono fortificati colla mutazione degli antichi vocaboli, e coll'altri inventarne tutti nuovi di conio. Col cangiamento de' voca- 
Den konstitutionellen Erwartungshorizont des liberalismo in der costituzione liberale deutete Canosa als Einfallstor für die über die Anarchie noch hinausgehende neue Despotie im Namen eines abstrakten Freiheitsideals. Es sei unübersehbar, „che il liberalismo moderno, sotto l'ipocrita moderata richiesta della costituzione, vuole la licenza; che non contento della Democrazia anela l'Anarchia, per cui unico rimedio è quello di un giusto ma ferreo dispotismo. "Dieser Prämisse entsprach auch seine konsequente Ablehnung auch des geringsten konstitutionellen Zugeständnisses nach 1815. ${ }^{152}$ Die aus Canosas Perspektive entscheidende semantische Trennlinie markierte die Haltung der liberali zu Religion und Kirche. Dieses Kriterium erlaubte es ihm wie den meisten Vertretern der katholisch-restaurativen Publizistik, liberali und liberalismo ohne weitergehende Differenzierung dem feindlichen Lager von Freimaurern, Kirchenkritikern, Protestanten und oppositionellen Untergrundzirkeln zuzuordnen. Zwischen diesen gänzlich heterogenen konfessionellen und politischen Gruppen, zu denen der Autor insbesondere auch die Giovine Italia Giuseppe Mazzinis zählte, machte Canosa keine Unterschiede: „i Massoni, i Liberali, $i$ Carbonari con tutta la settaria canaglia odiano $i$ Gesuiti, tutti gli zelanti Sacerdoti regolari, ed odiano specialmente le Missioni". 153

Dem gleichen Bestimmungsmuster folgten zu Beginn der 1830er Jahre auch Monaldo Leopardi und Andrea Sanminiatelli in zahlreichen Schriften. ${ }^{154}$ Sanminiatelli erkannte in liberalismo und radicalismo ein Gefahrenpotential in ganz Europa, sei es in der französischen Julimonarchie, der englischen Reform Bill oder den „riforme liberali“ in Spanien. ${ }^{155}$ Insbesondere die Zurückweisung

boli intanto, presso la sempre stolta moltitudine, sono essi arrivati ad alterare il principio e le massime fondamentali della pubblica credenza, della Morale, non che i principj di Politica, d'Etica, e Giustizia universale."

152 CAnOsA, Miracoli, S. 48; vgl. die paradigmatische Formulierung einer echten Restauration in ebd., Anmerkung: „, Se noi non salveremo il Re, ritarderemo almeno la perdita del suo Trono, dando a' liberali la Costituzione che ardentemente desiderano, e che alla scoperta chiedono. ' Cosi nell'anno 1817 mi dicea un soggetto, che il volgo diplomatico caratterizzava come un Uomo di Stato, ,Precisamente l'opposto, io replicava. Un sistema giusto, fermo, severo, vigilante contro le Società segrete; un'aristocrazia potente ed influente; impiegati di non dubbia fede; istruzione vera, educazione perfetta, missioni continue, Gesuiti e tutto il rimanente detestato dal liberalismo fisserà il vero ristabilmento della Monarchia e farà svaporare lo spirito rivoluzionario. Data la Costituzione sia qualunque, il Re va inevitabilmente perduto. “"

153 Antonio Capace Minutolo Di Canosa, Introduzione, in: Discorso sull'albero della libertà francese. Tradotto dal tedesco da L.P., o.O. [1833/34?], S. 1-9, hier S. 3 und 8.

154 Vgl. [Monaldo LeOpardi] Dialoghetti sulle materie correnti nell'anno 1831, o.O. 1831, S. 7, 24, 54, 60 und 71; Ders., Prediche recitate al popolo liberale da Don Muso Duro curato nel paese della verità e nella contrada della póca pazienza, o.O. 1832, S. 19, 21, 28, 37 und 47; DERS., Sulle riforme del governo. Una parola ai sudditi del Papa, o.O. 1832, S. 8 f., 56 und 71 f. sowie Ders., La città della filosofia [Pesaro 1833], S. $10 \mathrm{f} ., 14,23$ und $26 \mathrm{f}$.

155 [COSIMO ANDREA SANMINIATELLI] Brevi considerazioni sulla politica europea al prin- 
der aufklärerischen "filosofia liberale" als atheistisch-freimaurerische Verschwörung wurde zu einem Topos in der polemischen Auseinandersetzung. Der von den "filosofi liberali" vertretene Grundsatz der gesellschaftlichen uguaglianza schien das aus restaurativ-katholischer Sicht besonders betonte ständisch-hierarchische Gesellschaftsideal in Frage zu stellen „per adulare e suscitare le passioni del popolo ".156 Besonders aufschlußreich für die Begriffsbestimmung zu Beginn der 1830er Jahre ist eine 1833 von Leopardi verfaßte Schrift, in der er die Forderungen der „liberali illusi“ zunächst charakterisierte, um sie dann systematisch zu widerlegen. Die ,rigenerazione o restaurazione filosofica" entsprach dabei den Idealen der Aufklärung. Ihnen ließen sich sowohl die Forderung nach "libertà della stampa" als auch nach "libertà del culto" sowie der „patto sociale“ zuordnen. $\mathrm{Zu}$ diesen Aspekten traten im italienischen Kontext vor allem die „indipendenza italiana" und die „rivoluzione negli Stati pontificii“ als Fluchtpunkte der liberali hinzu. ${ }^{157}$ Dieser nationale Anspruch, für dessen Realisierung den liberali aber, so Leopardi, alle Machtmittel fehlten, bedrohte die weltliche Herrschaft des Papstes. Bei der Zurückweisung der Forderungen rekurrierte Leopardi auf das tradierte Argumentationsmuster, das von der göttlichen Einsetzung jeder legitimen Herrschaft ausging und mit dem sich der geistliche und weltliche Herrschaftsanspruch des römischen Papsttums verteidigen ließ:

Un governo nuovo se vuole stabilirsi sodamente, bisogna che abbia forza, tempo, e bravi governanti... ora tutte e tre queste cose importanti e necessarie mi pare che manchino totalmente ai liberali per questa italiana indipendenza. Manca la forza, e tanto la fisica, quanto la morale. É vero che nella massa dei liberali vi sono delle ricche borse, ma ci vnol altro per mettere in piedi un esercito da poter far fronte ai nemici interni ed esterni... Gl'italiani sono tutti cristiani cattolici... la massa totale è cattolica, e riconosce, e professa il Vangelo. Ora il cattolico sa ... che il potere legittimo vien da Dio, e non dal popolo ribellato, e molto meno dai liberali... Per provare che i liberali non sono cristiani cattolici basterebbe questo solo sillogismo: chi prediga una dottrina contraria a quella della chiesa cattolica, non è cristiano cattolico; ma i liberali predicando lecita la rivoluzione; e come di diritto dell'uomo, predicano una dottrina condannata dalle antiche scritture, dal Vangelo, dai PP. della Chiesa ..., dunque essi non sono cristiani catolici; dunque non devono essere ascoltati. 158

Das hier formulierte negative Bestimmungsmuster entwickelte eine im Vergleich zu Frankreich, Deutschland und England einzigartige Persistenz. In der Zurückweisung der politischen und nationalen Ansprüche der liberali wurde der päpstliche Anspruch auf das geistliche und weltliche Deutungsmonopol verteidigt. Hinter diesem Konflikt verbargen sich letztlich zwei antagonistische

cipio dell'anno 1833, o.O. [1833], S. 14 ff.; vgl. Ders., La Costituzione e la politica nel secolo dei lumi e del progresso, o.O. 1835, S. 7, $10 \mathrm{f}$. und 17.

156 [MONALDo LEOPARDI] Catechismo filosofico per uso delle scuole inferiori proposto dai redattori della Voce della Ragione, Pesaro 1832, S. 23; vgl. ebd., S. 7 ff.

157 Vgl. Ders., Otto Giorni dedicati ai liberali illusi, o.O. 1833, S. 45 ff., S. 7 ff., 15 ff., 55, $35 \mathrm{f} ., 67$ und $80 \mathrm{ff}$.

158 Ebd., S. 35 f. und 67. 
Legitimationskategorien politischer Gewalt: Die säkulare Staatsidee der liberali stand der päpstlichen Interpretation des Gottesgnadentums gegenüber, und die Existenz des Kirchenstaates machte diesen Konflikt für den italienischen Bedeutungszusammenhang unausweichlich. ${ }^{159}$ Der Bewegungsbegriff liberalismo wurde nicht zufällig besonders häufig in die semantische Kontinuität der Aufklärungsbegriffe „spiriti forti“ und den „illuminati del secolo “ gestellt, denn die Französische Revolution war in katholisch-restaurativer Sicht primär das Ergebnis der atheistischen Gedankenwelt der Aufklärer gewesen. Die italienische Semantik blieb bis zur Jahrhundertmitte und darüber hinaus von diesem Antagonismus zwischen cattolici, preti und Chiesa auf der einen und liberali sowie liberalismo auf der anderen Seite bestimmt. Ihn charakterisierte P. da Pancaldo 1832 pointiert:

Componete ora insieme questo impasto di contraddizioni. Il Curato è un mestiere che muove le risa del liberale, anzi l'astio: il Sacerdote desta nel liberale l'idea più barbara e più antisociale: l'abito del clerico genera acrimonia e suscita le imprecazioni: l'aver amicizia co' preti è pei liberali un marchio di fanatismo, di stolidità, d'ipocrisia, di congiurato ... I Cattolici che serbano ancor buon seme della pietà di Dio giudicheranno di quest'arbore dai frutti che noi loro abbiamo raccolti, e riconosceranno quandunque e dovunque che son liberali i nemici de' Cattolici, liberali i calunniatori dei Preti, liberali $i$ violatori dei diritti della Chiesa, liberali finalmente ove commettesi una profanazione, ove proferiscesi una bestemmia. Non si perda dunque tempo e pazienza ad aspettare dal liberalismo Francese e da ogni altro che ne è figlio o fratello la prosperità delle genti, la dolce libertà pel Vangelo. $\grave{E}$ impossibile che i governi senza Religione, senza Dio, sieno tolleranti della Religione Cattolica, la quale è cosi fatta che bisogna odiarla qual madre tiranna d'errore, quando non si ama siccome prima verità Sovrana. 160

159 Vgl. [Domenico Alpi] Risposta di un amico ad un altro con quali diritti tenghi il Papa gli stati temporali coll'aggiunta di un dialoghetto. Dedicata al Sig. tenente colonello Stanislao Freddi, Pesaro 1832, S. 86; Ricorrendo in Bologna le solenni funzioni del Corpus Domini l'anno MDCCCXXXIII. Commento di un sonetto liberalesco sortito in simile occasione l'anno precedente, o.O. 1833, S. 7-15 und 30 sowie LuigI Ugolini, Lettera pastorale di Monsignor Luigi Ugolini, vescovo di Fossombrone contro il preteso diritto pubblico filosofico ovvero sistema rivoluzionario moderno, Pesaro 1833, S. 7, 10, 13, 16 und 29.

160 P. Da Pancaldo, Delle discordanze del liberalismo overo dell' esclusione de' clerici dal potere civile, Modena 1832, S. $42 \mathrm{f}$. und $128 \mathrm{f}$. 


\section{England}

a) Die semantische Bestimmung von whig und liberal in den Reformdebatten von $1830 / 32$

Die in den 1820er Jahren vollzogene Adaption von liberal als Etikett der reformorientierten progressive whigs, wie sie von den Edinburgh Reviewers um Henry Brougham und Francis Jeffrey verkörpert wurden, führte auch zu Beginn der 1830er Jahre noch nicht zur Verdrängung der tradierten Etiketten whig und tory. ${ }^{161}$ Das englische Parteiensystem und die Persistenz seiner Bezeichnungen begründete im Vergleich mit der fragmentierten politischen Parteienlandschaft Frankreichs gerade nach 1830 ein spezifisches Sonderbewußtsein englischer Autoren. ${ }^{162}$ Andererseits stellte sich der langfristige Übergang von der whig party zur liberal party und von tory zu conservative bis zur Jahrhundertmitte als außerordentlich komplexer semantischer Prozeß dar, in dessen Verlauf alte und neue Begriffe nebeneinander standen oder eine Amalgamierung erfuhren, während bestimmte Bedeutungsaspekte von whig zunehmend als unzeitgemäß gedeutet und ausgesondert wurden. Die Ambivalenz der Phase bis 1850 besteht mithin aus einer Überlagerung tradierter oder neukonnotierter Begriffe, in der sich aber genau jener semantische Wandel widerspiegelte, der das Ende der langfristigen Sattelzeit des englischen Politikdiskurses seit dem 17. Jahrhundert in den 1830er Jahren bedeutete.

Auch während der 1830er Jahre blieb das überlieferte Spektrum der Gruppenbezeichnungen von tories, whigs und radicals virulent. ${ }^{163}$ Vor dem Hintergrund der parlamentarischen und außerparlamentarischen Reformdiskussionen seit Ende der 1820er Jahre verstärkte sich zudem die publizistische Auseinandersetzung um den Begriff reformer, der von radicals und whigs mit verschiedenen Konnotationen für sich reklamiert wurde: Die "Whig-Reformers“ verfolgten eine begrenzte Ausweitung politischer Partizipation unter der Prämisse, daß diese Reform die überkommene Stellung der aristokratischen

161 Vgl. zur zeitgenössischen Bestimmung von toryism im Gegensatz zu liberal und liberalism [WILliam MAGINN] The state and prospectus of toryism, in: FRASER's MAGAZINE FOR TOWN AND COUNTRY 9 (1834), S. 1-25; [DERs.] The state and prospectus of toryism, in: ebd. 11 (1835), S. 610-6, hier S. 610 und 613; vgl. ferner die Bestimmung von whiggism und radical in [DERs.] The state and prospectus of whiggism, in: ebd. 14 (1836), S. 515-30; The Radicals, the Dissenters, and the Papists, in: ebd. 14 (1836), S. 681-94 sowie Toryism versus English liberty - An Argument from History, in: THE EClectic Review, New Series 9 (1841), S. 578-603.

$162 \mathrm{Vgl}$. State and Prospects of Parties in France, in: British and Foreign Review 3 (1836), S. 167-201, hier S. $167 \mathrm{f}$.

163 Vgl. Peter Nemo, Political Pledges, or Garbage to catch Gudgeons, and a tub to the whale; being a Tug for the Tories! Wipping of the Whigs!! And Rooting out of the Radicals!!! A New Song, written for the occasion at the Conservative Banquet, On 13th June 1834, London 1834. 
Politikeliten nicht in Frage stellte. ${ }^{164}$ Dagegen setzten die außerparlamentarischen radicals den Begriff als Identifikationsattribut gegen die etablierten Parteien ein. So betonte der Reformer's Catechism von 1832:

The Reformers have no confidence in either [i. e. whigs oder tories] as a political party; though in both parties there are many individuals estimable for integrity, intelligence, and private worth. Why have the Reformers no confidence in either of these parties? Because, as between Whigs and Tories, the struggle has been, either to maintain or to acquire place. When in place, to strengthen their own position by the aid of patronage; when out of place, to annoy and weaken their opponents, without much scruple as to the means employed: and either party, when in power, have used their political ascendancy for promoting or preserving exclusive or partial interests. 165

Auffällig blieb im Gegensatz zu der in der politischen Publizistik nachweisbaren Politisierung von liberal die eher stagnierende Begriffsdeutung auf lexikalischer Ebene. Nur vereinzelt traten neben die tradierten Definitionen von whig und tory überhaupt politische Inhalte von liberal. ${ }^{166}$ Dagegen assoziierte man

164 [HENRY Rich] Whig Government, or two years retrospect, 2. Aufl., London 1832, S. 31 .

165 The Reformer's Catechism: Intended for reformers of all classes, and adapted to the plainest capacities, London 1832, S. 5.

166 Vgl. [Webster's Dictionary] A Dictionary of the English Language and a concise Grammar, philosophical and practical, of the English Language. By NOAH WEBSTER, New York 1828, reprinted by E. H. Barker, Norfolk, Bd. 2, London 1832, o.S. sowie Charles Richardson, A New Dictionary of the English Language, Bd 2, London 1837, S. 1211 f.; zur politischen Definition von liberal vgl. Encyclopaedia Americana. A Popular Dictionary of Arts, Sciences, Literature, History, Politics and Biography, brought to the present time; including a copious collection of original articles in American Biography; on the basis of the seventh edition of the German Conversations-Lexicon. Edited by Francis Lieber, assisted by E. Wigglesworth and T. G. BraDFORD, Bd. 23, Philadelphia 1833, S. $151 \mathrm{ff}$. sowie The Penny Cyclopaedia of The Society for the Diffusion of useful knowledge, Bd. 27, London 1843, S. $322 \mathrm{f}$.; vgl. zur dominierenden Sicht auf die kontinentaleuropäischen Staaten Encyclopaedia Americana, Bd. 7, Philadelphia 1831, S. 533; The Popular Encyclopedia; or, „Conversations Lexicon:" Being a General Dictionary of Arts, Sciences, Literature, Biography, History, Ethics, and Political Economy, Bd. 4, Glasgow 1841, S. 457; vgl. W. T. BRANDE (Hrsg.), A Dictionary of Science, Literature, \& Art: Comprising the History, Description, and scientific Principles of every branch of Human Knowledge; with the derivation and definition of all the terms in general use. Edited by W. T. BRANDE. Assisted by Joseph CAuvin, London 1842, S. 659; Encyclopaedia Metropolitana; or, Universal Dictionary of Knowledge, On an Original Plan: Comprising the twofold advantage of a philosophical and an alphabetical arrangement, with appropriate engravings, Bd. 21, London 1845, S. 415. Der Bewegungsbegriff liberalism ist auf lexikalischer Ebene überhaupt erst für die 1840er Jahre nachweisbar; vgl. JOHN BOAG (Hrsg.), A Popular and Complete English Dictionary; exhibiting the pronunciation, etymology, and explanation of every word usually employed in Science, Literature, \& Art, Bd. 2, London 1848, S. 785; [Webster's Dictionary] A Dictionary of the English Language; containing the whole vocabulary of the first edition in two volumes quarto; the entire corrections and improvements of the second edition in two volumes royal octavo. By NoAh Webster. Revised and enlarged by Chauncey A. GoOdrich, London 1848, S. 661 sowie [Webster's Dictionary] A Dictionary of the English Language; exhibiting 
in der politischen Publizistik der frühen 1830er Jahre liberal und liberals nunmehr eindeutig mit den großen Reformprojekten. Der „Liberal supporter of Roman Catholic Emancipation and Parliamentary Reform" nahm im tradierten whig-Diskurs eine immer größere Bedeutung ein. ${ }^{167}$ Dabei konnotierte man liberal nicht mehr wie noch bis $1820 \mathrm{im}$ Blick auf die um 1830 erneut sichtbar werdenden revolutionären Krisen auf dem europäischen Kontinent, sondern unterstrich mit diesem Attribut einen evolutionären Reformprozeß in England "to combine liberal institutions with order, stability, and a necessary strength in the executive". 168 Dies eröffnete auch eine Verbindung zu den liberal tories in der Tradition George Cannings. Dieser hatte im Kontext wachsender sozialer Unruhen Ende der 1820er Jahre betont, daß sich das Land „on the brink of a great struggle between property and population" befinde und daß dieser Kampf nur „by the mildest and most liberal legislation" verhindert werden könne. ${ }^{169} \mathrm{Zu}$ dieser „liberal legislation" zählten vor allem die Emanzipation der Katholiken und Dissenter 1828/29.170 Daneben verband man im Gegensatz zu den restaurativen Maßnahmen Metternichs auch die Außenpolitik Cannings, die die Freiheits- und Unabhängigkeitsbewegungen in Griechenland und Südamerika unterstützt hatte, mit "liberal principles. “ Selbst George IV. mußte sie als „wise and comprehensive principles" anerkennen, „by which the peace and general interest of Europe were bound together. "Henry Brougham lobte im Hinblick auf Canning "those sound, enlightened, liberal, and truly English principles - principles worthy of our best times and of our most distingnished statesman - which now govern this country in her foreign policy ". ${ }^{171}$

Mit der Regierungsübernahme durch Earl Grey 1830 wurde liberal noch deutlicher mit den whigs und ihren Reformzielen identifiziert. Francis Baring setzte whigs und liberals gleich, indem er letztere ganz im Sinne der whig-Topoi des 17. und 18. Jahrhunderts als „a body of men connected with high rank

the Origin, Orthography, Pronunciation, \& Definition of Words. By NOAH Webster. Revised and Enlarged by CHAUnCEY A. GOODRICH, London 1852, S. 594.

167 Vgl. The Liberal, Chatham, Rochester, Strood \& Brompton Repository, Nr. 1, 1. August 1835, S.11f. sowie Letters to a Friend, by a Liberal Supporter of Roman Catholic Emancipation and Parliamentary Reform, on the Irish Reform Bill, [London] 1831.

168 Vgl. zur Rezeption von ultra-liberal [GEORGE MOIR] The German Ultra-Liberal Press. Börne and Heine, in: The Foreign Quaterly Review 10 (1832), S. 150-62 sowie John Walsh, Popular Opinions on Parliamentary Reform, considered by Sir John Walsh, London 1831, S. 92.

169 [George Canning] Some Official Correspondence of George Canning, Bd. 2, hrsg. von E. J. STAPLETON, London 1887, S. 321.

170 Vgl. die Charakterisierung von Canning bei FrIEDRICH LIST, Schriften, Reden, Briefe. Im Auftrag der Friedrich-List-Gesellschaft e.V. mit Unterstützung der Deutschen Akademie und der Notgemeinschaft der deutschen Wissenschaft, hrsg. von ERWIN VON BECKERATH et al., 10 Bde., Berlin 1927-1935, hier Bd. 2, S. 142 ff., Bd. 4, S. 454 f. und 510 sowie Bd. 6, S. 376.

171 Zitiert nach A. G. Stapleton, George Canning and His Times, London 1958, S. 411 und 219. 
and property" definierte, „bound together by hereditary feeling and party ties, as well as higher motives, who in bad times keep alive the sacred flames of freedom, and when the people are roused, stand between the constitution and revolution, and go with the people, but not to extremities". ${ }^{772}$ Die Edinburgh Review wandte liberal seit Ende der 1820er Jahre nicht nur zur Bezeichnung des Reformkurses der moderate Whigs an, sondern kennzeichnete 1830 auch den Tory Robert Peel als liberal, weil er seit seinem Eintreten für die Emanzipation der Katholiken und seinem Einsatz für Aufhebung der corn laws als überzeugter reformer galt:

He has become a distinguished and most valuable votary of liberal principles. He had taken ... to reform the criminal law; he has heartily supported the reformers of our civil jurisprudence. He is the friend of a liberal policy in commercial matters; and, probably, no adherent to the false views of arbitrary power, cherished by the Wellingtons and the Aberdeens in respect to foreign affairs... That such conduct has justly recommended him to the chiefs of the liberal party, is as certain as that it has destroyed his whole personal weight in the country. ${ }^{173}$

Die Tatsache, daß liberal im Sprachgebrauch der Edinburgh Reviewers auch die fortschrittlichen Mitglieder der tories umfaßte, bestätigte eine weitere Äußerung Henry Broughams von 1834. Während die tories nicht leugnen könnten, "that the public voice is with their liberal adversaries", nahm er die "liberal Tories" hiervon ausdrücklich aus: „When we speak of Tories, - we use the name for shortness, and to express the ultra principles of that party... We are far, indeed, from holding that the liberal Tories and their views are in the same disrepute among us". 174 Dies zeigte, daß liberal noch keinesfalls eine eindeutige ideologische Trennlinie zwischen whig und tory markierte, sondern ausdrücklich auch die reformorientierten tories wie Canning oder Peel einschloß. Die Ausbildung des „parteipolitischen“ Antagonismus liberal/conservative verfestigte sich erst in den 1850er und 1860er Jahren.

Spätestens mit der Regierungsübernahme durch Earl Grey und der First Reform Bill 1832 wurde liberal im politischen Sprachgebrauch zu einem fest etablierten Begriff der Whig-Reformer. ${ }^{175}$ Zeitgenossen sprachen nun immer

172 Thomas George, Earl of Northbrook, A Memoir, hrsg. von Bernard Mallet, London 1908, S. $32 \mathrm{f}$.

173 [Henry Brougham] The Ministry, and the State of Parties, in: Edinburgh Review 51 (1830), S. 564-82, hier S. 576.

174 [Henry Brougham] The Last Session of Parliament, in: Edinburgh Review 60 (1834), S. 230-54, hier S. 252.

175 Vgl. [Henry Rich] Tory and Reform Associations, in: Edinburgh Review 62 (1835), S. 167-84, hier S. 171: ,the first Reform Parliament, which met in February 1832, was essentially liberal.", vgl. ebd., S. 180: "It is therefore against the House of Commons, against its liberal cast, that all their efforts [i. e. der Tories] and intrigues, all their speeches and measures, whether in or out of power, are ultimately directed. "Der Autor sprach im Zusammenhang mit der Gründung eigener Reform Associations als Antwort auf die sich organisierenden conservatives vom "Liberal cause“ und den „Liberal voters" als Anhängern der Reform; vgl. ebd., S. 183. 
häufiger von „liberal viewes“, „Liberal Ministry“, „liberal policy“, „liberal principles", "liberal opinions", „liberal colours" und von einer parlamentarischen „Liberal party“, mit der sie das Lager der reformers bezeichneten. ${ }^{176}$ Eine Infragestellung der aristokratischen Dominanz im Parlament und damit des politischen Einflusses der adligen Eliten verband sich mit liberal dagegen nicht. In einem fiktiven Dialog mit einem liberal von 1832 antwortete dieser auf die Frage nach der Stellung der "aristocracy in our constitution" in denkbar whiggistischer Tradition: „I consider it conservative of the just balance of the State. I hope that its just influence may never be weakened. I respect hereditary virtue and talents; cherish the memory of those nobles, who, in former times, have won and secured their country's liberties. "Die positive Selbstbezeichnung liberal wies nun auf eine veränderte Rolle der politischen Öffentlichkeit auf der Grundlage des reformed parliament hin: Der Erwartungshorizont des liberal lag im „change from a government by Influence, to government by Public Opinion... Such a government, supported by a Reformed Parliament, and dependant on the real representatives of the people, would not again plunge us into an expensive and ruinous war, to support the despots of Europe". 177

Die Führer der whig party wurden nach 1830 in durchaus programmatischer Absicht als "liberal talents of the Empire " bezeichnet; eine revolutionäre Implikation schloß diese Charakterisierung aus. Vielmehr wirkte auch hier das soziokulturelle gentleman-Ideal nach, wenn Earl Grey und Lord Althorpe als "names synonymous with every thing noble, liberal and free" bezeichnet wurden. ${ }^{178} \mathrm{Als}$ "merely nominal liberals" oder "pretended liberals" erschienen dagegen die bloßen Mitläufer der Reform Bill im Parlament, die nicht zu den überzeugten reformers gezählt wurden. ${ }^{179}$ Auch auf der politischen Gegenseite setzte sich nach 1830 neben der Polemik gegenüber radicals und radicalism die politische Gruppenbezeichnung liberals für die Anhänger der parliamentary reform durch. ${ }^{180}$ Die Bezeichnungen „liberal government" und „liberal institu-

176 Brougham, Last Session of Parliament, S. 230-2, ebd., S. 248: „Earl Grey ... and the principles of liberal and reforming policy" sowie [DERS.] Last Session of Parliament House of Lords, in: EDinburgh Review 62 (1835), S. 185-204, hier S. 196: „One thing is clear - that men of liberal opinions are as much divided to the full as the Antireformers. ", vgl. ebd., S. 185-7.

177 A Few Questions concerning Oligarchy \& Tithes, proposed to a Liberal, Bristol [1832], S. 7f.

178 Hints to all Parties, by a man of no party, London 1834, S. 90.

179 Peter Jenkins, A Letter to Isaac Tomkins, Gent. author of the Thoughts upon the Aristocracy, 11. Aufl. London 1835, S. 6 und 9; vgl. zur Verwendung von liberals und liberal im Bezug auf Earl Greys Kabinett EDwARD LYTTON Bulwer, The Present Crisis. A Letter to a Late Cabinet Minister, 19. Aufl. London 1834, S. 3 und 15.

180 Vgl. T. W. Dyke, A Poetical Satire, adressed to the British Radicals, and Pretending Reformers. Dedicated to the real, sincere, and substantial Reformers of England, London 1831, S. 27; Subordination the True Safeguard against Despotism. Adressed to Infidels, Radicals, Jesuits and Christians. By a Freeborn Briton, London 1831, S. 11; Thomas Brothers, The United States of North America as they are; not as they are generally described: Being a cure for Radicalism, London 1840, S. III; THE LIVERPOOL 
tions" wurden in positiver Wendung konkret auf das Reformministerium Earl Greys bezogen. ${ }^{181}$ Andererseits blieb eine verbindliche Identifizierung aller whigs als liberals unmöglich, denn unter dem Etikett whig firmierten verschiedene Gruppen, die keinesfalls eine homogene Reformbewegung bildeten. So unterschied man 1835 in einer "classification of the degrees and denominations of Whiggism ... three distinct classes, the doubtful, the aristocratic, and the liberal Whigs. "Vor dem Hintergrund der Wahlrechtsreformen hob man hervor, "that the Whiggism of the present day is, and must necessarily be, of another spirit than the Whiggism of 1688. "Hier kündigte sich die Transzendierung des traditionellen Verständnisses von whig bereits an. Den „modern liberal Whig“, der von den traditionellen „aristocratic Whigs" deutlich unterschieden wurde, kennzeichne seine Bereitschaft, auch zusammen mit den radical reformers die Reformprojekte gegen den Widerstand des politischen Gegners durchzusetzen. In diesem Sinne fungierte reform als semantisches Bindeglied zwischen whigs und liberal party. Die spezifische Anpassung an veränderte Erwartungen der Gegenwart bestätige, so der Autor, erneut die historische Rolle der whigs. Es sei unbestreitbar, "that the Whigs, without the slightest dereliction, but rather in vindication of their principles, might identify themselves with the liberal party, the thorough uncompromising Reformers". 182

Auch in der semantischen Amalgamierung von whig und liberal blieb insofern das historische Bedeutungsmuster von whig, die Aktualisierung einer historisch begründeten Rolle als friends of the people und Verteidiger der constitution, dominant. Auch wenn eine Kooperation mit den radical refomers zumindest temporär notwendig erschien, ergab sich daraus keine Identifizierung von whig und radical. Die besondere Ambivalenz von whig zu Beginn der 1830 er Jahre resultierte auf der einen Seite aus dem Bekenntnis zu reform und der begrenzten Kooperation mit den radicals und auf der anderen Seite aus dem Versuch, die spezifische whig-Identität zu bewahren. Vor diesem Hintergrund wird verständlich, warum sich gerade um 1830/32 auffällig viele Bestimmungen von whig finden, die im Gegensatz zu den Prinzipien der radicals das traditionelle Bekenntnis zu liberty, constitution und zu der auf diese nationalen Wertbegriffe hingeordneten aristokratischen Identität herausstellten. In der Auseinandersetzung um die 1832 von John Walsh verfaßte Schrift On the Present Balance of Parties in the State griff ein Kritiker bewußt auf den Topos der „popular Constitution“ zurück und formulierte ganz im Sinne der im 17. und

EXAminer. A Monthly Magazine, Nr. 1, 2. Dezember 1832, S. 1; Plain Words addressed to the electors of The United Kingdom. By a Reformer, London 1834, S. 8 sowie Who shall be our Leaders? Adressed to the People of England, London 1835, S. 14. 181 [Charles Grey] Four Years of a Liberal Government, London 1834, S. $14 \mathrm{f}$.

182 Capel Lofft, The Whigs, their Prospects and Policy, London 1835, S. 14 und 18-21. 
18. Jahrhundert entwickelten Argumentationsmuster noch einmal ein geradezu idealtypisches Selbstverständnis von whig. Walsh hatte die whigs dahingehend definiert, "that their political principle was a peculiar regard for the popular parts of the English Constitution". 183 Dem entgegegnete Montague Gore:

but this position rests on the assumption which we have already seen to be fallacious, that the Whigs regarded the popular parts of the Constitution, to the exclusion of other parts; and thence Sir John comes to the conclusion, that whenever they appeared to favour the Aristocracy or the Monarchy, they must have been actuated not by principle, but by interest. But the great principles of what Sir John denominates the Whig party, have been, regard not for this, or that particular part of, but for the whole Constitution; for the whole Constitution, because the whole is a popular Constitution; because the whole is designed to answer the ends and purposes of good government. Our Monarchy is a limited Monarchy; our Aristocracy have [sic!] no power as an Aristocracy; but only as a part of the legislature. And if the Whigs have appeared at times to be favourable to the Monarchy and Aristocracy, did it never occur to Sir John Walsh, that their motive might have been, not predilection for Monarchy, or Aristocracy, but regard for the free Constitution of England, of which Monarchy and Aristocracy are component and essential parts. 184

\section{b) A Liberal and a radical are synonymous:}

Die antiaristokratische Projektion der Movement party bei den Westminster Radicals um John Stuart Mill

Die Bestimmung von liberal als Etikett der moderate whigs im Umkreis der Edinburgh Review blieb nicht unumstritten. So wurde es als Ausdruck weitergehender Reformen im Laufe der 1830er Jahre gerade von den Philosophic Radicals um James und John Stuart Mill reklamiert. Diese kleine Gruppe von Abgeordneten, zu denen neben John Stuart und James Mill so bedeutende politische Theoretiker wie John Arthur Roebuck, Joseph Parkes und George Grote gehörten, ließ sich bei aller programmatischen Nähe zu Jeremy Bentham, der zumal James Mill und seinen Sohn tiefgreifend geprägt hatte, nicht auf das Programm eines lediglich theoretischen Utilitarismus reduzieren. ${ }^{185}$ Diese Gruppe, die ihr publizistisches Sprachrohr in der Westminster Review besaß und die Regierung Grey bei der parlamentarischen Durchsetzung der Reform Bill unterstützt hatte, wurde in der zeitgenössischen Terminologie häufig der reform party zugerechnet, obgleich sich allein aus der nichtaristokratischen Herkunft ihrer Mitglieder Spannungen mit den hocharistokratischen Repräsentanten der whig party ergaben. Nach 1832 setzten sich die parliamentary radicals für die konsequente Ausweitung des Wahlrechts zugunsten derjenigen sozialen Schichten ein, die auch nach der Reform Bill noch nicht zu Wahlen zu-

183 John Walsh, On the present Balance of Parties in the State, 2. Aufl. London 1832, S. 36.

184 Montague Gore, Reply to Sir Walsh's Pamphlet, entitled The Present Balance of Parties, London 1832, S. $11 \mathrm{f}$.

185 Vgl. Thomas, S. $95 \mathrm{ff}$. und $147 \mathrm{ff}$. 
gelassen waren. Ihre wachsende Enttäuschung über die erlahmenden Reforminitiativen der Regierung schlug sich in einer Distanzierung gegenüber whig und whiggism nieder. Dabei kam der eigenständigen Bestimmung von liberal und liberalism eine besondere Bedeutung zu: Bei der Abgrenzung der eigenen Position bediente man sich des neuen programmatischen Bewegungsbegriffes, der noch immer außerhalb der tradierten Parteibezeichnungen lag und sich daher als semantische Folie zur Formulierung des eigenen Selbstverständnisses anbot. So stellte John Stuart Mill bereits 1831 toryism und liberalism einander gegenüber. Toryism meine die Überzeugung, "that it is good for man to be ruled; to submit both his body $E$ mind to the guidance of a higher intelligence $E$ virtue. "Demgegenüber stehe hinter liberalism das selbstverantwortliche Individuum mit seinem Anspruch auf Emanzipation und konsequente Selbstbestimmung:

It [i.e. toryism] is therefore the direct antithesis of liberalism, which is for making every man his own guide $\mathcal{E}$ sovereign master, E letting him think for himself $\mathcal{E}$ do exactly as be judges best for himself, giving other men leave to persuade him if they can by evidence, but forbidding him to give way to authority; and still less allowing them to constrain him more than the existence $\mathcal{E}$ tolerable security of every man's person and property renders indispensably necessary. ${ }^{186}$

Gegenüber den eher pragmatischen Deutungen der Edinburgh Reviewers dominierte in Mills Definition von liberalism eine anthropologische Dimension, die in der politischen Semantik von liberal in England bisher nicht thematisiert worden war. Mill sah das eigenverantwortliche Individuum im Gegensatz zu autoritärer Fremdbestimmung als Ursprung des politischen Emanzipationsbegriffes liberalism. In den Mittelpunkt trat bei ihm die Forderung nach dem weitestgehenden Freiraum für den einzelnen, der nur durch die Rechte von jedermann auf Sicherheit und Eigentum begrenzt werden dürfe. Der anthropologisch bestimmte Ansatzpunkt der Philosophic Radicals widersprach damit dem historisch-organischen Verständnis von liberty gemäß der traditionellen WhigInterpretation und ließ sich eher dem vernunftrechtlichen Emanzipationsgedanken der Aufklärungsphilosophie zuordnen. ${ }^{187}$

Sowenig die Bezeichnung whig im Verlauf der 1830er Jahre völlig verdrängt wurde, so sehr änderte sich in dieser Phase doch die semantische Richtungsqualität des Begriffes, der immer häufiger zur Charakterisierung einer zunehmend anachronistischen Haltung herangezogen wurde. Dennoch blieben verbindliche Abgrenzungen zwischen den politischen Gruppen schwierig, und semantische Trennlinien ließen sich auch weiterhin nicht in parteipolitischer Ein-

186 Brief John Stuart Mills an John Sterling vom 20./22. Oktober 1831, in: [JOHN STUART Mill] Collected Works of John Stuart Mill, Bd. 12: The Earlier Letters of John Stuart Mill 1812-1848, hrsg. von FranCis E. MineKa, Toronto 1963, S. 84.

187 Vgl. Winch, S. 109 f. sowie Jack Lively und JoHn ReEs (Hrsg.), Utilitarian Logic and Politics. James Mill's Essay on government, Macaulay's critique and the ensuing debate, Oxford 1984. 
deutigkeit formulieren. ${ }^{188}$ Insofern kam der Kritik der radicals an dem überlieferten whig-Begriff besondere Bedeutung zu, denn sie markierte den Beginn der langfristigen Transformation von whig im veränderten Kontext seit der Reformgesetzgebung von 1831/32. Für Mill erschienen die whigs bereits 1836 längst als „, a coterie, not a party; a set, confined to London and Edinburgh, who commanded a certain number of seats in Parliament, and a certain portion of the press, and were accepted by the Reformers as leaders, because they offered themselves, and because there was nobody else." Aus Mills Sicht stellten die whigs eine prinzipienlose politische Clique dar, deren Strategie darin bestand, die öffentliche Meinung zu instrumentalisieren und aus lediglich historischen Versatzstücken den Anspruch auf treuhänderische Vertretung der liberties und Schutz der ancient constitution abzuleiten, um ihre eigenen aristokratischen Interessen umso wirkungsvoller durchzusetzen. Die vermeintliche Popularität ihrer Politik sei in Wirklichkeit ein lediglich rhetorisches Bekenntnis zu „liberal opinions" in der politischen Öffentlichkeit. Dies reflektierte einerseits den Wert dieses Ausdrucks als Synonym für politische Fortschrittlichkeit, verwies aber zugleich auf dessen Funktion, eine aristokratische Interessenpolitik wirkungsvoll zu verschleiern. Die Durchsetzung von Positionen beruhte mithin auf der positiven Besetzung meinungsfokussierender Grundbegriffe:

By this means they [i.e. the whigs] always kept themselves apparently at the head of all that part of the public who professed liberal opinions. But their leadership was ostensible only. Since the questions arising out of the Hanoverian succession had been set at rest, the term Whig had never been the symbol of any principles.

Hatte Henry Brougham in den 1820er Jahren die neue ideologische Richtungsqualität von liberal antizipiert, als er die überkommenen Antonyme loyalist/jacobin, whig/tory und court/country vom neuen Antagonismus liberal/illiberal transzendiert sah, so unterschied man bei den Westminster Reviewers die Liberals von der bloßen Zweckkoalition zwischen Whigs und Radicals. Jene seien einer "thorough reform " verpflichtet und entschlossen, die Wahlrechtsreform so weit voranzutreiben, wie es das „public good" verlange. Sie allein könnten dem Ideal eines good government folgen, nicht den interests oder prejudices einer privileged class. Insbesondere zeichneten sich die Liberals durch ihre Vorurteilsfreiheit gegenüber weiteren einschneidenden Veränderungen aus, deren Umsetzung von den Whigs nicht mehr zu erwarten waren. Daraus ergab sich als neue Antonymie für Mill der Gegensatz zwischen Liberal/Reformer und Whig:

This position [i. e. der Whigs] the Liberals of the empire have never chosen to participate. They did not repudiate the Whigs; but as little did they repudiate what the Whigs repudiated. They were neither Whigs nor Radicals; they were Reformers. They had not predetermined how far parliamentary reform should go; but they were disposed to carry it as far as, on trial, should be found necessary for obtaining good government. They were not for the

188 Vgl. Halévy, History, Bd. 3, S. 180: „Each group was divided from its neighbour by indefinable shades of opinion." 
ballot, or annual parliaments, because the opinion did not generally prevail among them that nothing less would suffice; but they had no prejudice against either, if an extension of the suffrage, with septennial or triennial parliaments, should fail to give them a government of which the pervading spirit should be a regard to the public good. ${ }^{189}$

Für Mill bot die Gruppenbezeichnung liberals die Möglichkeit für eine Reformprojektion außerhalb der bestehenden politischen Nomenklaturen. Mit liberals identifizierte Mill eine neue Movement Party mit dezidiert antiaristokratischer Ausrichtung unter programmatischer Führung der Westminster Radicals. Dies schloß ein Bekenntnis zu weitergehenden Reforminitiativen im Sinne der utilitaristischen Idee gesellschaftlicher Fortentwicklung ein, die zwangsläufig mit dem organisch-pragmatischen Reformverständnis der moderate whigs kollidieren mußte: "We will not say that we shall stop, for it would be absurd to set limits to improvement. "Die konkreten inhaltlichen Forderungen, die von Mill mit liberal überschrieben wurden, reflektierten die Schwerpunkte in der innenpolitischen Diskussion nach der Verabschiedung der Reform Bill und reichten von einer Reform des Justizwesens, über die Abschaffung der Kornzölle und die staatliche Zurückhaltung in Wirtschaftsfragen bis hin zu einer grundlegenden Änderung der Irland-Politik. ${ }^{190}$ Die Movement Party unterschied sich grundlegend von der traditionellen Whig Party, indem sie im Gegensatz zu einer aristokratischen Interessenvertretung als Repräsentantin der politischen Partizipationswünsche der middle classes auftreten sollte. ${ }^{191}$ Damit antizipierte die semantische Scheidelinie zwischen whig und liberal bei John Stuart Mill zugleich die zweite grundlegende Transformation von liberal im englischen politischen Diskurs der 1830er Jahre, nämlich die Wandlung vom whiggistischen Reformetikett zum politischen middle class-Attribut und damit den komplexen Übergang von der Whig zur Liberal Party. Auch hier wird eine sozialhistorische Indikatorfunktion der historischen Semantik deutlich: Hinter den veränderten Begriffsbestimmungen standen die unterschiedlichen gesellschaftlichen Interessen von politisch-parlamentarischer aristocracy und den erstarkenden middle classes.

Mill griff im Verlauf der 1830er Jahre in seinen politischen Beiträgen immer wieder auf die Selbstbezeichnung liberal zurück, um der von ihm angestrebten Reform Party ein programmatisches Etikett außerhalb der traditionellen Bezeichnungen zu geben. Nach der Adaption von liberal durch die Edinburgh Reviewers in den 1820 er Jahren ging diese zweite politisch-semantische Transformation mit einer Reduzierung des semantischen Potentials und der politisch-sozialen Reichweite von whig einher. Als übergeordnetes Deutungsmuster des politischen Diskurses fungierte whig in den späten 1830er Jahren nicht mehr. Der langfristige Übergang von whig/tory zu liberal/conservative unter-

189 [JOHn StUART Mill] Tories, Whigs, and Radicals, in: Westminster Review 25 (1836), S. 281-300, hier S. 293.

190 Ebd., S. 299.

191 Vgl. ebd., S. 298. 
strich, daß die im 17. und 18. Jahrhundert geprägten Begriffe in den 1830er Jahren ihre bis dahin dominierende Wirkung zugunsten neuer Etiketten einbüßten. Darin deutete sich das Ende der vormodernen Sattelzeit des englischen Politikdiskurses an. Im Umkreis der parliamentary radicals wurde diese neue Entwicklungsstufe besonders deutlich. Hier fand seit der Mitte der 1830er Jahre entsprechend der semantischen Distanzierung gegenüber whig eine Amalgamierung der Bezeichnungen radical und liberal statt. Dieser Vorgang führte zwangsläufig zu einer ideologischen Neuausrichtung von liberal/liberalism und stellte von daher den diskursiven Führungsanspruch der whigs in Frage. Nach den Wahlen von 1837 konstatierte Mill, England sei „moderate-Radical“, und unter den „Liberal members" im Parlament bildeten die „moderate Radicals ... a large proportion" bildeten. ${ }^{192}$ Die eigenen radicals identifizierte er selbstbewußt als „professing liberals. “ Mit dem Rekurs auf Liberal Party, liberalism und "progress of liberal opinions“, die für Mill selbstverständliche Bestimmungskategorien der eigenen Position geworden waren, verfestigte sich eine antiaristokratische Konnotation des Wortfeldes. ${ }^{193}$

Welche Perspektive sich mit dieser neuen Deutung verband, wurde in einem 1839 erschienenen Aufsatz Mills zur Reorganization of the Reform Party sichtbar. Mill erkannte, daß durch die Reform Bill von 1832 eine neue Ausgangssituation entstanden war, in der gegenüber dem traditionellen Netzwerk aus aristokratischen Verbindungen und Loyalitätsverpflichtungen nun verstärkt neue Repräsentanten der middle classes auftraten. Deren Anspruch auf politische Partizipation lasse sich nicht mehr durch die von den whigs bemühten Topoi wie friends of the people oder das Ideal des common good befriedigen. Mill forderte daher die Gründung einer neuen Reform Party, die, basierend auf der bestehenden parlamentarischen Gruppierung der radicals, eine möglichst breite gesellschaftliche Unterstützung anstreben und damit die traditionellen, aristokratisch dominierten Gruppierungen zugunsten einer fest organisierten Partei überwinden sollte. Der Verbindung von liberal und radical entsprach dabei auch eine Distanzierung gegenüber einer zu engen Definition von radical:

the moderate Radicals are in possession of a part of the ground on which it is necessary that the combination should be built... But we well know that the Reform party ... cannot be Radical in any narrow or sectarian sense. There may be many coteries in a country, but there can be only two parties. ${ }^{194}$

192 [John Stuart Mill] Parties and Ministry, in: Westminster Review 28 (1837), S. 1-26, zitiert nach [Ders.] Collected Works of John Stuart Mill, Bd. 6: Essays on England, Ireland, and the Empire, hrsg. von John M. RoBson, Toronto 1982, S. 383-404, hier S. 389.

193 Brief John Stuart Mills an John Robertson vom November 1838, in: MiLl, Collected Works, Bd. 13, S. 391, Brief Mills an Sir William Molesworth vom 14. November 1838, in: ebd., S. 391, Brief Mills an Robert Barclay vom 24. Juli 1841, in: ebd., S. 480 sowie Brief Mills an Macvey Napier vom 30. Juli 1841, in ebd., S. 483.

194 [John StUART Mill] The Reorganization of the Reform Party, in: Westminster ReVIEW 32 (1839), S. 475-508, zitiert nach [Ders.] Collected Works, Bd. 6, S. 467-95, hier S. 467; vgl. zur progressiven gesellschaftlichen Konnotation von radicalism ge- 
Auch Mill sah die politische Struktur Englands begrifflich nicht mehr durch den Gegensatz whig/tory bestimmt, sondern durch die neuen semantischen Gruppenbezeichnungen conservative/liberal, wobei er die liberals nicht als beschränkte politische Gruppierung verstand, sondern als Massenpartei mit breiter sozialer Basis. Genau hier verweist die begriffliche Transformation innerhalb des politischen Diskurses auf strukturelle Veränderungen im englischen Parteiensystem der 1830er Jahre: Weder in den traditionellen Cliquen und Zirkeln, in denen sich whigs und tories bisher zusammengefunden hatten, noch als parlamentarische Splittergruppe ohne breite Basis wie die radicals, sondern nur im Rahmen einer organisierten Massenpartei war nach Mills Ansicht eine konsequente Fortsetzung des Reformkurses möglich. Die Liberal party firmierte dabei als Integrationsbegriff für das heterogene Spektrum der reformers. Der alte Antagonismus whig/tory wurde von der neuen Bipolarität liberal/conservative transzendiert; damit ging eine Neustrukturierung der politischen und gesellschaftlichen Kräfte einher:

What we must have to oppose the great Conservative party is the whole Liberal party, not some mere section of it, - a combination which shall exclude no shade of opinion in which one sober or practicable man can be found, - one man capable of adapting rational means to honest ends; a phalanx, stretching from the Whig-Radicals at one extremity (if we may term those among the persons calling themselves Whigs who are real Liberals) to the Ultra-Radicals and the Working Classes on the other. ${ }^{195}$

Die von Mill angestrebte Integration der politisch-gesellschaftlichen Reformkräfte von den progressiven whigs bis zur entstehenden Industriearbeiterschaft im Begriff der Liberal party muß im Kontext des Tamworth Manifesto von 1834 gesehen werden, mit dem Robert Peel gegenüber dem tradierten tory-Begriff eine politische Neubestimmung unternahm, die mit Conservative Party und conservatism symbolisert werden sollte. ${ }^{196}$ Vor dem Hintergrund der von Peel vorangetriebenen Umwandlung der tories in conservatives wurde die semantische Bestimmung der Liberal party umso drängender. Die Konnotation von Liberal party folgte der grundsätzlichen Polarität zweier politisch und gesellschaftlich distinkter Lager. Die soziale Basis der conservatives erkannte Mill im Landbesitz, beim prohibitiv geschützten Handel sowie in den „professions which partake of aristocracy, - the army, the navy, the bar" sowie in der "benefited clergy of the Church of England. “Demgegenüber sollte die neue „Liberal party" alle diejenigen verbinden, „[who] feel that they do not have justice done

genüber aristokratischen Prinzipien ebd.: „The men of active and aspiring talent in all classes except the highest, are Radicals everywhere, for what is Radicalism, but the claim of pre-eminence for personal qualities above conventional or accidental advantages? And what more certain than that a man of talent, compelled to serve men of no talent ... will be, by a natural tendency, something of a leveller?"

195 Ebd., S. 467.

196 Vgl. Norman Gash, Aristocracy and People. Britain 1815-1865, London 1979, S. $182 \mathrm{f}$. 
to them by existing institutions". 197 Dies umfaßte sozialhistorisch die religiösen Nonkonformisten, Kleinbesitzer und „skilled employments, those which require talent and education but confer no rank, - what may be called the nonaristocratic professions", also die freien akademischen Berufe wie Ärzte, Ingenieure, Lehrer und Journalisten, aber auch "the whole effective political strength of the working classes". ${ }^{198}$ Die Adaption von liberal als sozial-integratives Etikett einer neuen Reform Party war für Mill andererseits nur in deutlicher Abgrenzung gegenüber weitergehenden egalitär-demokratischen Forderungen denkbar, wie er sie etwa bei den Chartisten zu erkennen glaubte. ${ }^{199} \mathrm{Da}-$ mit zeichnete sich auch die semantische Grenze gegenüber potentiell systemsprengenden Kräften ab. Für John Stuart Mill wie für die Gruppe der parliamentary radicals überhaupt verwischten sich in dieser Bestimmung die semantischen Differenzen zwischen radical und liberal. ${ }^{200}$ Im Verständnis Mills hatte sich die ursprüngliche Bedeutung von radical der von liberal so weit angenähert, daß er 1839 für die regionalen Hochburgen der Liberal party konstatierte: "Wherever the electors are in a position to declare their real sentiments we find them Liberals ... a Liberal and a Radical are synonymous".201

\section{Vergleich}

Der Zeitraum von 1830 bis 1835 markierte vor dem Hintergrund der französischen Julirevolution, der von ihr angeregten Revolten und Protestbewegungen in Deutschland und Italien sowie der englischen Reform Bill einen fundamentalen Einschnitt in der Geschichte des 19. Jahrhunderts. In diesen Ereignissen

197 MiLl, Reorganization, S. $474 \mathrm{f}$.

198 Ebd., S. 476-8. Mills Optimismus wird indes durch zeitgenössische Äußerungen relativiert, die die middle classes bei aller Neigung zu liberal principles eher politisch indifferent einschätzten, vgl. Shall we overturn the coach? Or, What ought the Radicals to do? Discussed in a letter to George Grote, Esq., M.P. From a Radical Member of the House of Commons, 2. Aufl. London 1839, S. $31 \mathrm{f.:} \mathrm{„I} \mathrm{have} \mathrm{alluted} \mathrm{to} \mathrm{circumstances}$ other than those immediately connected with the present state of political affairs, which would in a general election be injurious to the prospects of the Liberal party. I had reference to the sentiments of the middle classes. I believe, not only that those important and influential classes would not join the masses in agitating for any large extension of the suffrage, but that their attachment to liberal principles is much less ardent than it was some few years back. I do not mean that they have adopted Tory principles. $I$ believe the instances to be extremely rare, of men of calm and sober judgment having joined the Conservatives; but I believe those classes, speaking of them generally, to have subsided into a state of considerable indifference of political matters, and to feeling nothing like their recent zeal for furthering the progress of Reform."; vgl. zur Kopplung von liberal und nonconformist ferner Liberals and Nonconformists, in: BRITISH QuARTERLY REVIEW 2 (1845), S. 104-29.

199 Vgl. Mill, Reorganization, S. 485-9.

200 Vgl. The Radical Register and Liberal Gazette, Nr. 1, 20. Februar 1835, S. 4.

201 Mill, Reorganization, S. 472. 
schlugen sich Erwartungen nieder, die für jedes der vier Vergleichsländer unterschiedlich charakterisiert waren, deren Blockade durch die Regierungen jedoch in allen Fällen zu tiefgreifenden Krisen geführt hatte.

Die quantitativen Analysen zur publizistischen Präsenz des Wortfeldes zeigen, daß in Frankreich die ermittelten Frequenzwerte in den Jahren 1830/31 extrem hoch lagen, danach aber signifikant abnahmen. Bis in die späten 1850er Jahre ist das Wortfeld in den Titeln der systematisch ausgewerteten Druckschriften kaum mehr nachweisbar (vgl. Abbildungen 3 und 4). Diese Entwicklung tritt im Vergleich mit den anderen Ländern noch deutlicher hervor. Während die publizistische Präsenz des Wortfeldes in Frankreich mit der Julirevolution einen letzten Höhepunkt erlebte, setzte für Deutschland und Italien in dieser Phase überhaupt erst eine deutlich nachweisbare Konjunktur ein. Für diese Länder liegen die Frequenzwerte bis etwa 1834/35 signifikant höher als in der Phase davor oder danach (vgl. Abbildungen 5 und 6 für Deutschland sowie Abbildungen 7 und 8 für Italien). Aus komparativer Perspektive ist aufgrund dieser charakteristischen Konjunkturlinien (vgl. auch Abbildung 2) für Frankreich, Deutschland und Italien von einer Umbruchsphase auszugehen, in der indes hinter der Gleichzeitigkeit der allgemeinen Krise eine tiefgreifende Ungleichzeitigkeit semantischer Entwicklungen stand. Demgegenüber dokumentieren die ermittelten Werte für England eine nur relativ erhöhte publizistische Präsenz des Wortfeldes zwischen 1829 und 1834 (vgl. Abbildung 9).

Vor dem Hintergrund der inhaltlichen Analyse lassen sich die aus der Quantifizierung gewonnenen Hinweise vor allem für Frankreich, Deutschland und Italien bestätigen und differenzieren. Die französische Julirevolution bedeutete für die Zeitgenossen zunächst die Erfüllung der mit dem Bewegungsbegriff $l i$ béralisme assoziierten politisch-konstitutionellen Erwartungen gegenüber den restaurativen Tendenzen des letzten Bourbonenherrschers. Dem entsprach die enthusiastisch-positive Identifizierung mit dem Deutungsmuster. In signifikanter Parallele zu den Bestimmungstopoi der idées libérales nach 1815 sollte libéralisme nach dem Sturz der Bourbonendynastie eine neue Basis für politische Stabilität und gesellschaftliche Versöhnung symbolisieren. Schon bald wurde aber erkennbar, daß mit der neuerlichen politischen Zäsur die inneroppositionellen Interessengegensätze, die sich in den 1820 er Jahren noch durch den Antagonismus zwischen libéralisme und royalisme hatten überdecken lassen, nunmehr offen ausbrachen. Die semantische Integrationskraft des Oppositionsetiketts libéralisme hatte, so zeigte sich nach 1830, im wesentlichen auf der Existenz eines gemeinsamen Gegners beruht, den man der offenen Verletzung der in der Charte garantierten politisch-sozialen Ordnung bezichtigen konnte. Mit der politischen Entmachtung dieses Gegners ging zugleich die integrierende Wirkung des Gegensatzes ultra/libéral verloren. Damit setzte in Frankreich eine langfristige semantische Desintegration des Wortfeldes ein, die den programmatischen Rekurs auf libéral und libéralisme für ganz unterschiedliche politische Kräfte von den légitimistes bis zu den républicains möglich machte, auch wenn die Interessen hinter diesen Rekursen gänzlich unter- 
schiedlich waren. Weil libéralisme nach 1830 keine reine Oppositions-, sondern primär eine Regierungshaltung konnotierte, verschob sich das Bestimmungsmuster grundlegend. Bereits im Verlauf der frühen 1830er Jahre zeichnete sich die konservativ-defensive Richtungsänderung ab, aus der libéral und libéralisme als regierungskonforme Ordnungsbegriffe hervorgingen. In der unter François Guizot in den 1840er Jahren erfolgten programmatischen Amalgamierung von libéral und conservateur in libéralisme conservateur fand diese Entwicklung ihre Fortsetzung. Im Kontext der frühen 1830er Jahre war diese Neubestimmung nur möglich, weil der Begriff mit dem vermeintlichen Sieg der ihm zugeordneten Prinzipien in der Julirevolution ein erhebliches Maß seiner semantischen Innovationskraft eingebüßt hatte. Gemessen an der Valenz des Gegensatzes ultra/libéral wurde libéral/libéralisme damit gewissermaßen dialektisch aufgehoben, was das Deutungsmuster zugleich seiner polarisierenden Wirkung beraubte.

Für den französischen Politikdiskurs ist die Dynamisierungswirkung der aufeinanderfolgenden politisch-konstitutionellen Zäsuren seit 1789 besonders hervorzuheben. Dies verkürzte die Geltungsdauer von Begriffsbestimmungen, indem jede Definition unter dem impliziten Vorbehalt der nächsten Krise stand. Dies hatte 1789 eingesetzt, sich 1815 fortgesetzt und galt in verstärktem Maße auch nach 1830. Die politischen Wechsel gingen mit einem erhöhten Verbrauch an Etiketten und gleichzeitig einer Anhäufung von überkommenen und aktuellen Attributen einher, deren Bedeutungsbereiche sich partiell überlagern konnten. Die Folge war eine bereits von den Zeitgenossen sehr genau reflektierte confusion des idées. Während zum Beispiel ultra nach 1815 einer der am häufigsten benutzten Attribute des Politikdiskurses gewesen war, spielte es nach 1830 eine allenfalls untergeordnete Rolle. Andere Begriffe wie légitimiste bedurften der Anpassung an die veränderten Rahmenbedingungen: Wo die Legitimitätskonzeption auf eine neue Dynastie übergegangen war, änderte sich entsprechend auch das Objekt der légitimistes. Sie konnten Anhänger der alten Bourbonen oder des neuen Bürgerkönigs sein. Ohne entsprechende Kontextuierung verlor der Begriff an direkter Bestimmungskraft.

Im deutschen Politikdiskurs läßt sich um 1830 zunächst eine allgemein verbreitete Aufbruchseuphorie konstatieren, für die das Zauberwort Liberalismus zum sprachlichen Symbol geriet. Der weitgespannte Erwartungshorizont, der sich in einer Flut enthusiastischer Bestimmungen in der Tagespresse, aber auch in zahlreichen ausführlichen Monographien niederschlug, bezog sich dabei sowohl auf politisch-konstitutionelle Reformen, also konkret auf die Konstitutionalisierung derjenigen Einzelstaaten des Deutschen Bundes, die bis 1830 ohne Verfassungen und repräsentative Vertretungsorgane geblieben waren, als auch auf nationalpolitische Fortschritte. Das Programm von 1813/15 verdichtete sich nunmehr in der Berufung auf liberal und Liberalismus. Als Deutungsmuster enthielten sie insofern eine universalhistorische Legitimierung der Forderungen, als sie als Verkörperung eines vernünftigen Fortschritts in gesetzlichen Bahnen verstanden wurden. Wo über eine gemäßigt konstitutionelle Stra- 
tegie, die im wesentlichen auf die Fortentwicklung der einzelstaatlichen Verfassungen und Parlamente setzte, hinausgegangen wurde, so vor allem im Umkreis der außerparlamentarischen Protestbewegungen, die sich zunächst noch weitgehend mit liberal und Liberalismus identifizierten, erkannte man eine scheinbare Degeneration der Liberalismus zugeordneten Gehalte und eine Entfernung vom legitimen Ursprung des Begriffes. Die Wahrnehmung gesellschaftlicher Interessen, die sich nicht mehr allein auf einen Gegensatz zwischen Staat und Gesellschaft zurückführen ließen, sondern die ein komplexes Spannungsfeld vieler gesellschaftlicher und staatlicher Interessen bedingten, bildete sich auch in Deutschland in einer Ausdifferenzierung der politischen Gruppenbezeichnungen ab.

Im signifikanten Gegensatz zu den anderen Vergleichsfällen blieb aber das im weitesten Sinne ethische Bestimmungsmuster von Liberalismus über die faktische Politisierung des Bewegungsbegriffes und selbst noch über die beginnende Ideologisierung hinaus erhalten. Daraus resultierte die charakteristische Bandbreite von semantischen Dimensionen auf unterschiedlichen gesellschaftlichen Diskursebenen. Diese Perspektive verdient besondere Aufmerksamkeit, weil sie zumindest in Ansätzen auch eine sozialhistorische Einschätzung der Begriffsbestimmungen zuläßt. Denn neben der mit stark normativem Anspruch ausgestatteten lexikalischen Ebene, auf der neben den bildungsbürgerlichen Deutungsmustern von Aufklärung, Vernunft und Fortschritt vor allem die Wertbegriffe von individueller Gesinnung und emanzipatorischer Bildung dominierten, entwickelten sich im parlamentarischen und außerparlamentarischen Diskurs distinkte Bedeutungsrichtungen. Während in den lexikalischen Bestimmungen eine universalistische, zuweilen holistische Grundierung anhand philosophischer Prämissen dominierte, die eine Reduzierung von Liberalismus auf einen tagespolitischen Grundbegriff oder gar eine Parteirichtung a priori ausschloß, fungierte das Wortfeld neben anderen Etiketten im parlamentarischen Diskurs längst als polemische Waffe in politischen Auseinandersetzungen. Dem entsprach die ideologische Aufladung von liberal und Liberalismus, die auf der Gegenseite die entsprechende Kritik und Polemik provozierten. Über Grundbegriffe und ihren Einsatz als semantische Orientierungsmarken im zeitgenössischen Spektrum politischer Kräfte etablierten sich mithin auch Mechanismen der politischen Konfliktaustragung. Die Spannung zwischen Gesinnungsetikett und Parteibegriff sollte die Semantik von liberal und Liberalismus in Deutschland auch weiterhin begleiten. Bereits zu Beginn der 1830er Jahre und unter dem Eindruck der aufbrechenden Kluft zwischen konstitutionellen Positionen auf der einen und sozialer Protestbewegung auf der anderen Seite zeichnete sich zudem eine inneroppositionelle Differenzbestimmung ab. Vor diesem Hintergrund begann sich die soziale Kritik an bürgerlichen Liberalen in radical und Radicalismus zu verdichten. Die Projektion einer Interessenhomogenität von Staat und Gesellschaft in Liberalismus wurde von daher mit der faktischen Desintegration der politischen und zumal der sozialen Interessen einer in Bewegung geratenen Gesellschaft konfrontiert. Da- 
mit trat die semantische Entwicklung in das Stadium der Ideologisierung ein, die in Deutschland gegenüber Frankreich spezifisch phasenverschoben einsetzte. Durch die conservative Fundamentalkritik ergab sich eine tripolare Ausrichtung des Spektrums politischer Etiketten mit Liberalismus als Mittelbegriff.

Auch in Italien konzentrierte sich die Euphorie des Jahres 1830 auf liberali und liberalismo, und wie in Deutschland führte die Erfahrung der Aufstandsbewegungen zur Unterscheidung eines scheinbar noch gerechtfertigten liberalismo sociale von einem revolutionären liberalismo antisociale - eine signifikante Parallele zu den bipolaren Bestimmungsmustern wie wahrer Liberalismus und Pseudoliberalismus in Deutschland während der frühen 1820er Jahre. Im Unterschied zu den anderen Vergleichsfällen dominierte aber nach der Niederschlagung der Aufstandsbewegungen, die sich vor allem auf den Kirchenstaat beschränkt hatten, die katholisch-restaurative Fundamentalkritik an liberali und liberalismo. Dieser besonders tiefgehende Antagonismus, in dem die geistliche Stellung und die weltliche Macht des Papstes den konstitutionellen und nationalpolitischen Forderungen des liberalismo gegenüberstanden, absorbierte zumindest zunächst die inneroppositionelle Differenzierung. Sie läßt sich im Vergleich zu Deutschland semantisch phasenverschoben erst in den späten 1830er Jahren nachweisen.

Gegenüber der kontinentaleuropäischen Semantik setzte sich die bereits für die 1820er Jahre deutlich erkennbare Sonderentwicklung des englischen Politikdiskurses auch nach 1830 fort. Sie bestand zum einen in der Verknüpfung von whig und liberal und zum andern in der Identifizierung der politischen Initiativen mit dem Schlagwort reform, sei es in der noch unter Canning durchgesetzten Katholikenemanzipation oder der Reform Bill. Die Politisierung des Wortfeldes fand dabei nun ohne Rekurse auf seinen kontinentaleuropäischen Ursprung statt. Aber im deutlichen Unterschied zu den anderen Vergleichsländern blieb eine eindeutig ideologisch polarisierende Wirkung des Etiketts einstweilen noch aus, so daß liberal ausdrücklich auf alle fortschrittlichen Maßnahmen angewandt werden konnte, was die Initiativen Peels und Cannings ausdrücklich einschloß. Zunächst übernahmen die tradierten Parteinamen whig und tory noch die Funktion der Polarisierung. Die entscheidende zweite semantische Transformation von liberal nach der Übernahme durch die progressive whigs in den 1820 er Jahren bestand während der frühen 1830 er Jahre in der programmatischen Adaption des Attributs durch die Westminster Radicals unter John Stuart Mill. Dabei kam es zu einer Umdeutung der aristokratisch konnotierten Verbindung zwischen whig und liberal aus dezidiert antiaristokratischer Perspektive, indem nun liberal und radical amalgamiert wurden. In der Transformation von liberal vom whig-Etikett zum middle class-Attribut wurde die Überwindung der alten Parteinamen whig/tory durch liberal/conservative gleichsam antizipiert, denn Mill stellte das tradierte whiggistische Selbstverständnis und die ihm zugrundeliegenden historischen Identifikationsmuster grundsätzlich in Frage. Dies reflektierte indirekt auch den langfristigen, 
sozialhistorisch wichtigen Wandel des aristokratischen Partei-Begriffs des 18. Jahrhunderts. Hierbei ist jedoch die Persistenz der alten Etiketten hervorzuheben, die bis weit in die 1830er und 1840er Jahre gebräuchlich blieben. Ihr relatives Zurücktreten gegenüber dem neuen bipolaren Antagonismus liberal/ conservative dokumentierte die abnehmende Relevanz der im 17. und 18. Jahrhundert geprägten Bestimmungsmuster und damit das Auslaufen der vormodernen Sattelzeit des englischen Politikdiskurses. 